\title{
Feasibility of Using Radar for Characterizing and Tracking Plumes
}

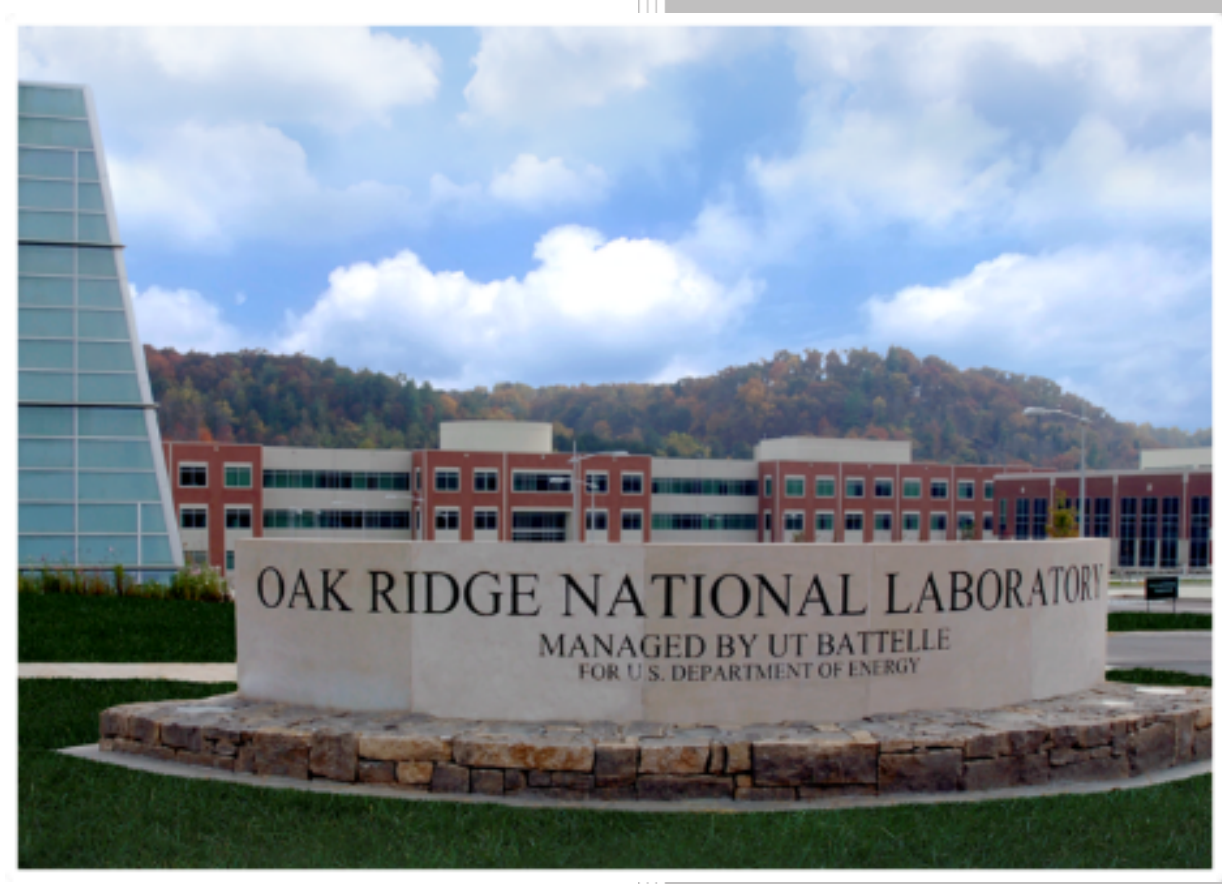

Approved for public release. Distribution is unlimited.
Erik D. Kabela, Ph.D. S. Craig Moss Daniel B. Koch, Ph.D. Barry K. Daniel Vincent J. Jodoin, Ph.D. David A. Hooper, Ph.D. Steven T. Fiorino (AFIT), Ph.D. Jaclyn E. Schmidt (AFIT) Brannon J. Elmore (AFIT) Valery Melnikov, (OU/CIMMS), Ph.D. Dusan Zrnic (NOAA NSSL), Ph.D. Richard J. Doviak, Ph.D. (NOAA NSSL)

May 2018 


\title{
DOCUMENT AVAILABILITY
}

Reports produced after January 1, 1996, are generally available free via US Department of Energy (DOE) SciTech Connect.

\section{Website www.osti.gov}

Reports produced before January 1, 1996, may be purchased by members of the public from the following source:

\author{
National Technical Information Service \\ 5285 Port Royal Road \\ Springfield, VA 22161 \\ Telephone 703-605-6000 (1-800-553-6847) \\ TDD 703-487-4639 \\ Fax 703-605-6900 \\ E-mail info@ntis.gov \\ Website http://classic.ntis.gov/
}

Reports are available to DOE employees, DOE contractors, Energy Technology Data Exchange representatives, and International Nuclear Information System representatives from the following source:

Office of Scientific and Technical Information

PO Box 62

Oak Ridge, TN 37831

Telephone 865-576-8401

Fax 865-576-5728

E-mail reports@osti.gov

Website http://www.osti.gov/contact.html

This report was prepared as an account of work sponsored by an agency of the United States Government. Neither the United States Government nor any agency thereof, nor any of their employees, makes any warranty, express or implied, or assumes any legal liability or responsibility for the accuracy, completeness, or usefulness of any information, apparatus, product, or process disclosed, or represents that its use would not infringe privately owned rights. Reference herein to any specific commercial product, process, or service by trade name, trademark, manufacturer, or otherwise, does not necessarily constitute or imply its endorsement, recommendation, or favoring by the United States Government or any agency thereof. The views and opinions of authors expressed herein do not necessarily state or reflect those of the United States Government or any agency thereof. 
Nuclear Security and Isotope Technology Division

\title{
FEASIBILITY OF USING RADAR FOR CHARACTERIZING AND TRACKING PLUMES
}

\author{
Erik D. Kabela, Ph.D. \\ S. Craig Moss \\ Daniel B. Koch, Ph.D. \\ Barry K. Daniel \\ Vincent J. Jodoin, Ph.D. \\ David A. Hooper, Ph.D. \\ Steven T. Fiorino (AFIT), Ph.D. \\ Jaclyn E. Schmidt (AFIT) \\ Brannon J. Elmore (AFIT) \\ Valery Melnikov (OU/CIMMS), Ph.D. \\ Dusan Zrnic (NOAA/NSSL), Ph.D. \\ P. Zhang (NOAA/NSSL), Ph.D.
}

Date Published: May 2018

Prepared by

OAK RIDGE NATIONAL LABORATORY

Oak Ridge, TN 37831-6283

managed by

UT-BATTELLE, LLC

for the

US DEPARTMENT OF ENERGY

under contract DE-AC05-00OR22725 



\section{CONTENTS}

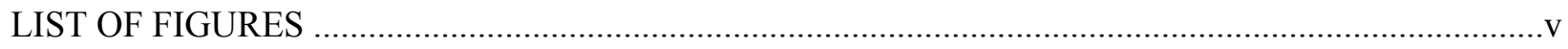

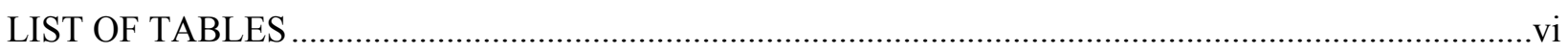

ACRONYMS AND ABBREVIATIONS ......................................................................................... vii

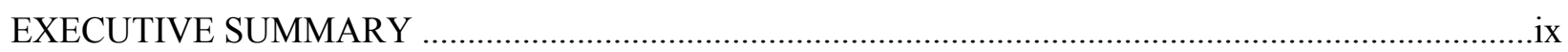

1. RADAR BASICS AND PLUME DETECTABILITY …..........................................................

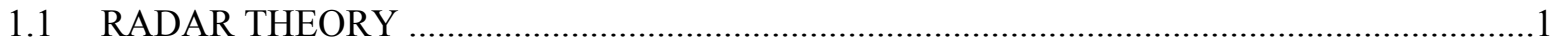

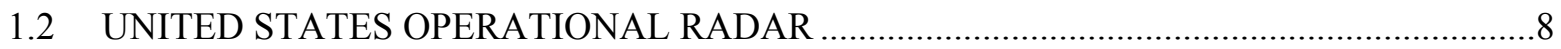

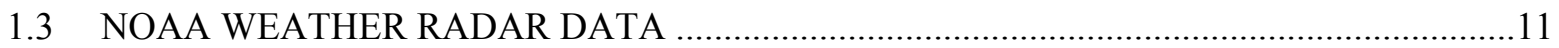

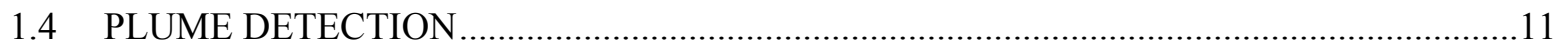

2. RADAR MEASUREMENTS IN FATE AND TRANSPORT MODELS ......................................13

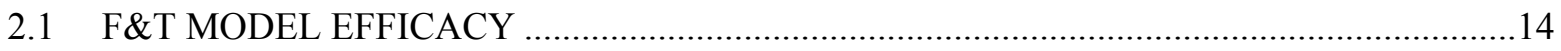

2.2 WEATHER-MODEL-DRIVEN FATE AND TRANSPORT VERSUS RADAR

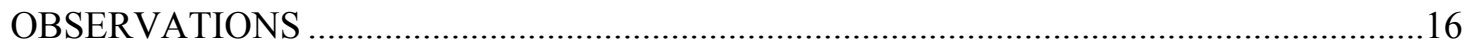

2.3 INGESTION OF RADAR-DERIVED WIND MEASUREMENTS .......................................18

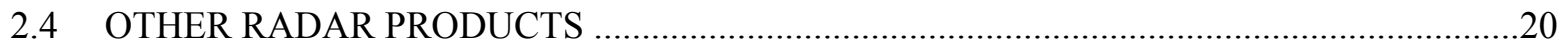

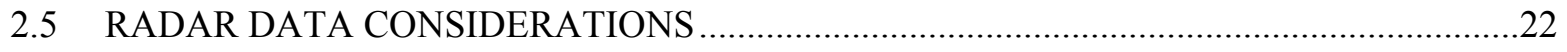

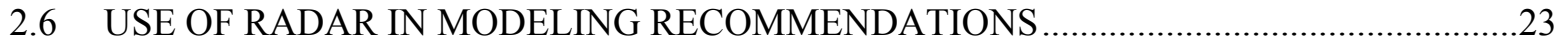

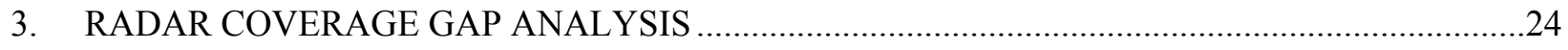

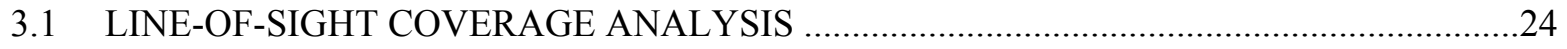

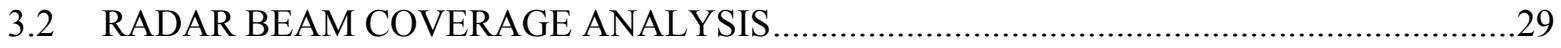

3.3 COMMERCIAL SOLUTIONS TO OPERATIONAL COVERAGE GAP …........................33

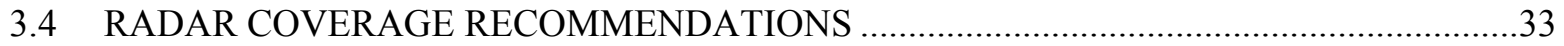

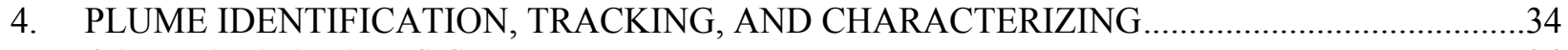

4.1 DATA ANALYSIS ......................................................................................................

4.2 UNSUPERVISED MACHINE LEARNING FOR DETECTION AND TRACKING OF

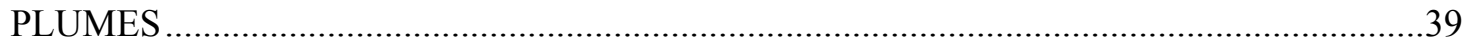

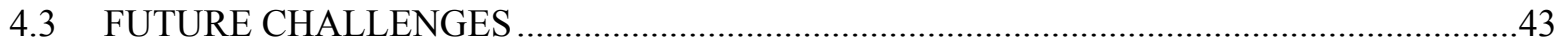

4.3.1 WSR-88D Level II Radar Data Related to Specific Non-meteorological Plume

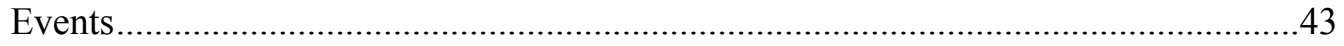

4.3.2 Extraction of Non-meteorological Truth Data Sets .....................................................

4.3.3 Creation of Fuzzy Logic Member Functions ..........................................................4

4.3.4 Testing and Optimization of Fuzzy Logic Member Functions with Modified

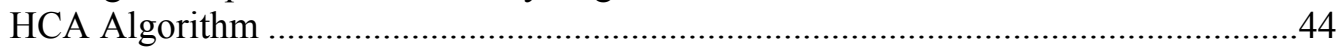

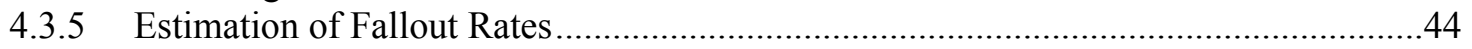

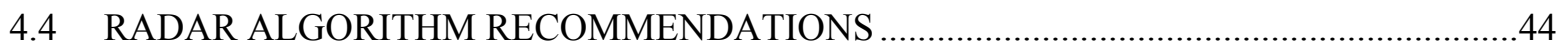

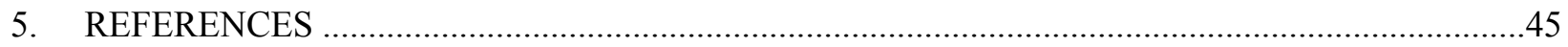





\section{LIST OF FIGURES}

Figure 1. Typical bands of the electromagnetic spectrum................................................................

Figure 2. Flow diagram for the process of a radar to send, receive, and process an

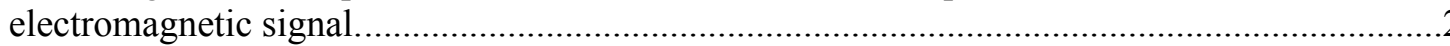

Figure 3. Illustration of the impacts of normal beam refraction (a), subrefraction (b), super-

refraction (c), and ducting (d) on a radar pulse beam.

Figure 4. Radar beam height as a function of distance and beam angle (a) and beam width as a function of distance (b).

Figure 5. Attenuation ( $y$-axis) effects of various phenomena [ambient atmosphere (solid black line); rainfall rates (red, blue, dark green and light green lines); and clouds (pink solid, dashed, and dotted lines)] as a function of wavelength ( $x$-axis).

Figure 6. Example of a three-body scatter spike (or Mie scattering) associated with large hail in a severe thunderstorm.

Figure 7. Radar beam orientation for traditional radar (a) versus dual-pol radar (b) ............................7

Figure 8. Plot of differential radar reflectivity from the Phoenix, AZ WSR-88D radar. ..........................8

Figure 9. US installations of WSR-88D radar, continental United States (a) and outside the continental United States (b).

Figure 10. Typical beam profiles for the "clear air" (a) and "precipitation" (b) scanning strategies for the National Weather Service WSR-88D radars.

Figure 11. US installations of Terminal Doppler Weather Radars (TDWRs).

Figure 12. Atomic cloud echo on an X-band Range Height Indicator (a), and an atomic cloud as shown on the Plan Position Indicator (b).

Figure 13. Radar cross sections of reflectivity factor (a), correlation coefficient (b), radial velocity (c), differential reflectivity (d), differential phase shift (e), and spectrum width (f) from a volcanic ash plume.

Figure 14. Series of images from the SpaceX rocket explosion on September 1, 2016, at Cape Canaveral, FL at approximately 1305 UTC.

Figure 15. Radar image of the plume from the SpaceX rocket explosion from the Melbourne, FL WSR-88D on September 1, 2016, at 1354 UTC.

Figure 16. (a) DELFIC-modeled dose rate based on surface observations from 1258 UTC on September 1, 2016, from Cape Canaveral, FL and (b) a 1 hour composite of maximum radar reflectivity from the Melbourne, FL WSR-88D.

Figure 17. Level II radar reflectivity overlaid on DELFIC-HYSPLIT model results for a) 1312 UTC, b) 1322 UTC, c) 1333 UTC, d) 1338 UTC, e) 1354 UTC, and f) 1405 UTC on September 1, 2016.

Figure 18. Modeled dose rate using two weather data sources.

Figure 19. VAD wind profile for the Melbourne, FL radar from 1312 UTC to 1405 UTC on September 1, 2016.

Figure 20. Cloud rise from DELFIC using only weather model data (left) and substituting VAD wind profile data (right).

Figure 21. Same as Figure 18 but with the inclusion of the modeled dose field using VAD wind profile data.

Figure 22. Enhanced Echo Top Level III radar product shown for (top) 1322 UTC and (bottom) 1343 UTC on September 1, 2016.

Figure 23. Hydrometeor Classification Level III radar product shown for (top) 1322 UTC and (bottom) 1343 UTC on September 1, 2016.

Figure 24. NEXRAD and TDWR radar locations within a $230 \mathrm{~km}$ radius around Washington, DC.

Figure 25. KLWX beam height contours. 


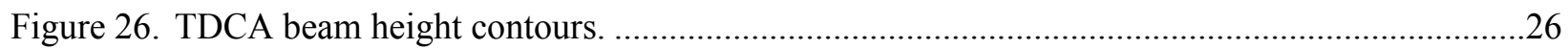

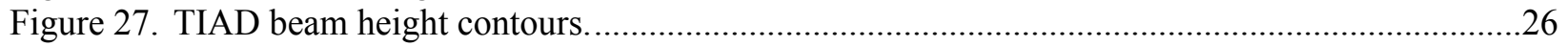

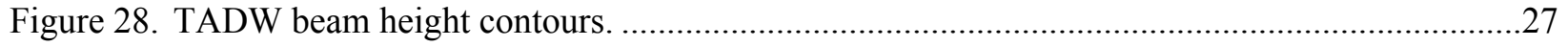

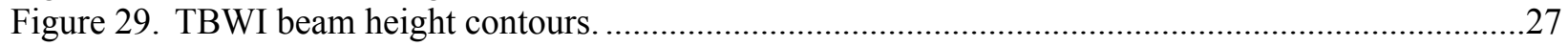

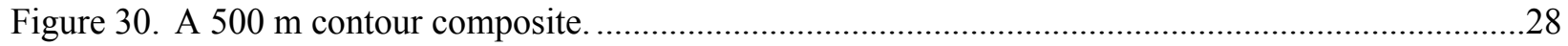

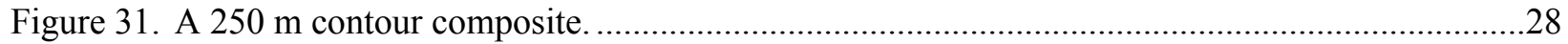

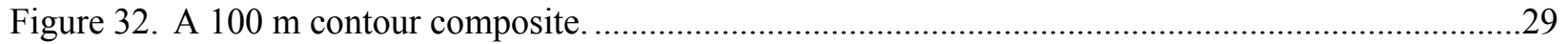

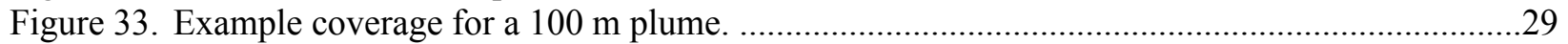

Figure 34. Location of radars during the experiment of July 4, 2017 in Norman, OK...........................30

Figure 35. Reflectivity obtained on July 4, 2017 (July 5 UTC) with the XERES (3 cm

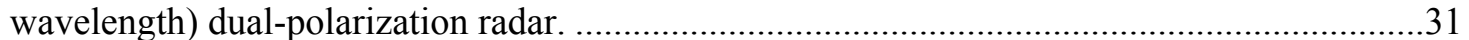

Figure 36. The field of reflectivity factor $(Z)$, differential reflectivity $\left(Z_{\mathrm{DR}}\right)$, and correlation coefficient $\rho_{\mathrm{hv}}$ at the elevation angle of 3.83 degrees and about 2:52:10 UTC, local time 9:52 pm on July 4, 2017...

Figure 37. Reflectivity field obtained from the TDWR radar on July 4, 2017 (July 5, according to

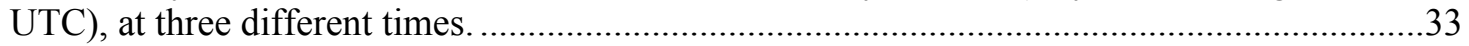

Figure 38. Map of Little Bear fire progression (New Mexico, June 2012)............................................35

Figure 39. Satellite image of the Little Bear fire at three consecutive times on June 8, 2012 ..................35

Figure 40. Fields of reflectivity $Z$, differential reflectivity $Z_{\mathrm{DR}}$, and correlation coefficient $\rho_{\mathrm{hv}}$ obtained with the Holloman Air Force Base radar on June 8, 2012 ........................................36

Figure 41 . Fields of reflectivity $Z$, differential reflectivity $Z_{\mathrm{DR}}$, and correlation coefficient $\rho_{\mathrm{hv}}$ obtained with the Holloman Air Force Base radar on June 8, 2012 ......................................37

Figure 42. Fields of reflectivity $Z$, differential reflectivity $Z_{\mathrm{DR}}$, and correlation coefficient $\rho_{\mathrm{hv}}$ obtained with the Holloman (Air Force Base) radar on June 8, 2012 ....................................38

Figure 43. Polarimetric variables of the smoke plume (encircled with polygons) .....................................39

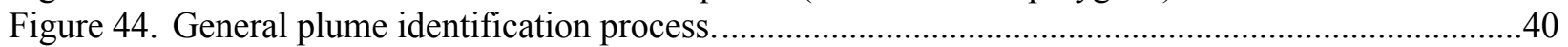

Figure 45. Process for developing fuzzy logic membership functions. ................................................40

Figure 46. Density-based clustering algorithm applied to smoke plume (orange cluster, left).................41

Figure 47. The unwanted clusters (left) are filtered from the wanted smoke cluster (right).....................42

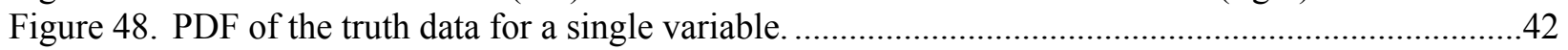

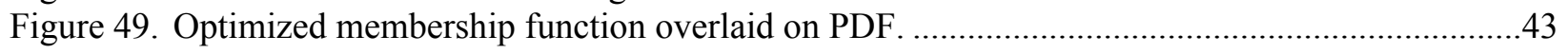

\section{LIST OF TABLES}

Table 1. Microwave frequency bands as designated by the Institute of Electrical and Electronics Engineers (IEEE) and defined in IEEE Standard 521-1984 _..................................5

Table 2. Radar characteristics of the WSR-88D and TDWR ............................................................11

Table 3. Surface weather observations from Cape Canaveral, FL on September 1, 2016....................16 


\section{ACRONYMS AND ABBREVIATIONS}

\begin{tabular}{|c|c|}
\hline AFIT & US Air Force Institute of Technology \\
\hline AGL & above ground level \\
\hline ARSR & Air Route Surveillance Radar \\
\hline ASR & Airport Surveillance Radar \\
\hline CIMMS & Cooperative Institute for Mesoscale Meteorological Studies \\
\hline DBSCAN & Density-Based Spatial Clustering of Applications with Noise \\
\hline DELFIC & Department of Defense Land Fallout Interpretative Code \\
\hline DoD & US Department of Defense \\
\hline DOE & US Department of Energy \\
\hline dual polarization & dual-pol \\
\hline $\mathrm{F} \& \mathrm{~T}$ & fate and transport \\
\hline FAA & Federal Aviation Administration \\
\hline GOES & Geostationary Operational Environmental Satellite \\
\hline $\mathrm{HCA}$ & hydrometeor classification algorithm \\
\hline HYSPLIT & Hybrid Single-Particle Lagrangian Integrated Trajectory \\
\hline IEEE & Institute of Electrical and Electronics Engineers \\
\hline LDM & Local Data Manager \\
\hline LEEDR & Laser Environmental Effects Definition and Reference \\
\hline NAM & North American Mesoscale Forecast System \\
\hline NASA & National Aeronautics and Space Administration \\
\hline NCEI & National Centers for Environmental Information \\
\hline NCEP & National Centers for Environmental Prediction \\
\hline netCDF & Network Common Data Format \\
\hline NEXRAD & Next Generation Radar \\
\hline NOAA & National Oceanic and Atmospheric Administration \\
\hline NSSL & National Severe Storms Laboratory \\
\hline NWS & National Weather Service \\
\hline ORNL & Oak Ridge National Laboratory \\
\hline PDA & plume detection algorithm \\
\hline PDF & probability density functions \\
\hline Py-ART & Python Atmospheric Radiation Measurement Radar Toolkit \\
\hline QA & quality assurance \\
\hline QC & quality control \\
\hline radar & radio detection and ranging \\
\hline RF & radio frequency \\
\hline RPG & radar product generator \\
\hline TDWR & Terminal Doppler Weather Radar \\
\hline US & United States \\
\hline UTC & Coordinated Universal Time \\
\hline VAD & velocity-azimuth display \\
\hline VWP & VAD wind profile \\
\hline WSR-88D & Weather Surveillance Radar, 1988, Doppler \\
\hline XERES & X-band Experimental Radar for Environmental Studies \\
\hline
\end{tabular}





\section{EXECUTIVE SUMMARY}

Since the development of radar systems, applications for radar data have been evolving. As early as the 1940s and 1950s, when radar systems were used to track the plumes from aboveground nuclear tests, it was recognized that radar could be used to track plumes. Based on the technology available at the time, this early application was limited to plumes with high particle concentrations and provided only gross information such as cloud rise rate and cloud boundaries. Today radar technology is vastly improved, has widespread use, and provides an opportunity to leverage its use for applications outside its designed purpose, such as in emergency management.

In the 1990s the National Oceanic and Atmospheric Administration (NOAA) upgraded the nation's weather radar capability to the Next-Generation Radar (NEXRAD), also known as the Weather Surveillance Radar - 1988 Doppler (WSR-88D). NEXRAD is a system of 160 high-resolution Doppler weather radar stations in the contiguous United States, Alaska, Hawaii, US territories, and at military bases. Since 2008 two major upgrades to NEXRAD radars have created opportunities to utilize the radar data for emergency management applications that were not previously available. The first upgrade, called Super Resolution, increased spatial resolution data. Super Resolution improved reflectivity data for 0.5 degree azimuthal by $250 \mathrm{~m}$ range gate resolution to a range of $460 \mathrm{~km}$, and Doppler velocity and spectrum width at 0.5 degree azimuthal by $250 \mathrm{~m}$ range gate resolution to a range of $300 \mathrm{~km}$. The second upgrade, completed in 2013, added dual polarization (dual-pol) capability to all NEXRAD sites. The dual-pol capability adds vertical polarization to more accurately discern the return signal, allowing the radar to better distinguish between types of precipitation and aiding in the removal of non-weather artifacts. ${ }^{1}$

With the enhanced capabilities of NEXRAD radars has come an increased body of research focused on non-weather artifacts in the radar signal. Radar data has been collected and evaluated for a range of plume-generating events. Events such as wildfires, measuring and tracking ash from volcanic eruptions, and tracking plumes from events such as the SpaceX rocket explosion in 2016 have been investigated to determine the useful measurements available in radar data. For decision makers interested in radar use in nuclear forensics or during an emergency response, the usefulness of radar for attempting to provide some answers early in an event is clear. Currently emplaced operational radars provide high spatial and temporal resolution data within minutes of an event. This is not to say radar observations would replace current methods used by decision makers; however, supplementing decision making with radar data can only enhance and better inform the decision process.

This report builds on two previous reports submitted in November 2016 and May 2017. The ultimate questions driving the feasibility study were

1. Is radar use feasible for plume detection, tracking, and characterizing?

2. How could radar inform fate and transport models, early-phase decision making, or forensics?

3. If radar observations of plumes are valuable, how can their measurements be validated and incorporated into current tools or decision cycles?

The feasibility study reviewed 1) the literature, 2) existing US operational radar infrastructure and data analysis techniques, and 3) specific radar use cases.

The literature review consisted of a search through approximately 80 reports from the US aboveground testing archive and approximately 35 peer-reviewed journal articles and books. A significant amount of work has been conducted involving plume detection using radar. As the first report at the end of 2016

\footnotetext{
${ }^{1}$ NOAA Next-Generation Radar (NEXRAD) Products, https://catalog.data.gov/dataset/noaa-next-generation-radar-nexradproducts
} 
outlined, radar was a primary method for tracking a plume after an aboveground nuclear test. In the current era, European countries use radar to track plumes of volcanic ash. All reports lead to the conclusion that plumes can be tracked spatially and temporally with radar, and with enhancements in the radar data, a number of plume characteristics can be measured directly.

The second phase of the feasibility study investigated the radar characteristics that contributed most to plume measurements and the state of current radar infrastructure in the United States. The second phase expanded the look beyond NEXRAD radars and included other radar systems such as Terminal Doppler Weather Radar (TDWR), Airport Surveillance Radar (ASR), and Air Route Surveillance Radar (ARSR). Based on the location and type of radar, it was concluded that if the plume were high enough above ground and contained enough scatterers, the plume could be measured. Additionally, it was demonstrated and reported in the second status report that algorithms and radar parameters could be improved to specifically detect and track plumes. Specifically, by using open-source Python modules, the WSR-88D Hydrometeor Classification Algorithm (HCA) can be improved to include a "plume" class, whereas the current algorithm classifies a plume as a "biological" return. More on this work is presented in this final report.

The final phase of the feasibility study centered around the use of radar in specific cases. This included using radar measurements of echo return height and wind information to enhance fate and transport (F\&T) model projections. The Department of Defense Land Fallout Interpretive Code (DELFIC) model was used to illustrate the improved fallout projections when the WSR-88D's velocity-azimuth display (VAD) algorithm-generated wind profile was ingested. Lastly, an analysis to determine the vertical and horizontal radar coverage over the Washington, DC metro was performed with WSR-88D radar (located at Dulles International Airport) and with four TDWRs (located at Reagan National Airport, Dulles International Airport, Andrews Air Force Base, and Baltimore-Washington International Airport). Analysis indicates relatively good coverage over the metro down to $500 \mathrm{~m}$ above ground level with incomplete coverage below $250 \mathrm{~m}$.

This feasibility study demonstrates that radar can be used to improve decision making in the early phases of a plume-generating event by decreasing uncertainty as well as improving source-term inputs in F\&T models. Radar coverage exists today in capabilities such as NOAA's NEXRAD weather surveillance radars and Terminal Doppler Weather Radars. Improvement could be realized quickly by (1) improving awareness of existing radar products and incorporating them into decision making and modeling efforts, (2) evaluating and improving radar coverage around key urban areas and critical infrastructure, and (3) improving radar algorithms to optimize for non-meteorological events such as plumes. 


\section{RADAR BASICS AND PLUME DETECTABILITY}

Recent improvements in the NOAA NEXRAD system have highlighted real potential for the use of radar in decision making around plumegenerating events.

Key Observations:

- Radar is a viable tool for tracking and measuring plumes.

- X-, C-, and S-band radars are most optimal for tracking particulates in plumes for emergency management applications.

- Wavelengths below X-band radar provide greater resolution of particulate plumes but are limited operationally due to atmospheric beam attenuation.

- Radar algorithms focused on weather applications can track and measure plumes, but work to improve their effectiveness for non-meteorological events should be performed.
Radar has been used to detect objects since the early 20th century. Several studies in the early 19 th century focused on the connection between electricity and magnetism. The founding fathers of this theory and the research they conducted bore names still recognized in the 21 st century, such as Ampere, Faraday, and Oersted. The concept of electromagnetic waves was first proved by James Clerk Maxwell in the early and mid-1860s (Johnson 2002). Maxwell was the first to suggest that light, an electric field, and a magnetic field could all be explained in a single electromagnetic theory. This theory, with some approximations, constituted the basis for the invention of radar. Radars typically operate in the microwave band of the electromagnetic spectrum (Figure 1).

\section{Electromagnetic Spectrum}

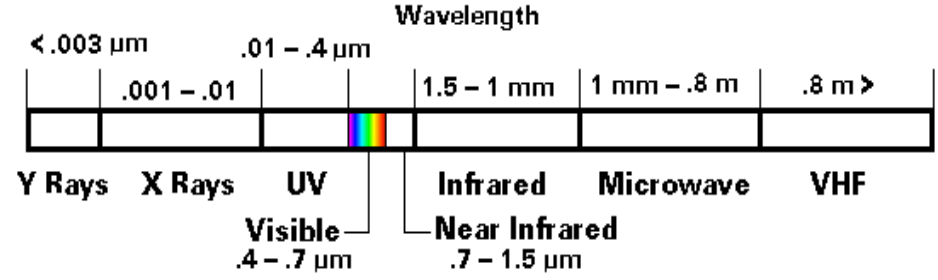

Figure 1. Typical bands of the electromagnetic spectrum. Figure courtesy of the University of Delaware Introduction to Remote Sensing course. https://www1.udel.edu/johnmack/apec480/ 4801ec_image_processingl.html.

\subsection{RADAR THEORY}

A radar (or radio detection and ranging) device is an electrical system that transmits radio-frequency (RF) electromagnetic waves toward a region of interest and receives and detects these electromagnetic waves when reflected from objects in that region (Richards et al. 2010). Figure 2 provides a simplified view of the process the radar follows to send, received, and process the electromagnetic signal. Following Heinrich Hertz's work on verifying Maxwell's theory of electromagnetic waves and, importantly, his discovery that radio waves can be reflected (Hertz 1893), early forms of radar were invented in the early twentieth century by several nations as a means to find directional information for objects. By 1934, Robert Page, working at the United States Naval Research Laboratory, developed the first pulsed radar system (Page 1962), which is the current method of delivering electromagnetic waves from the radar transmitter into the atmosphere. Pulsed radar allows not only for the determination of the range to a target using pulse-timing techniques, but also uses the Doppler effect of the returned signal to determine the target object's velocity. Modern radar became widely used by the Allied Forces in World War II following the invention of the magnetron (high-powered vacuum tube), which allowed for smaller systems operating in the microwave spectrum. 


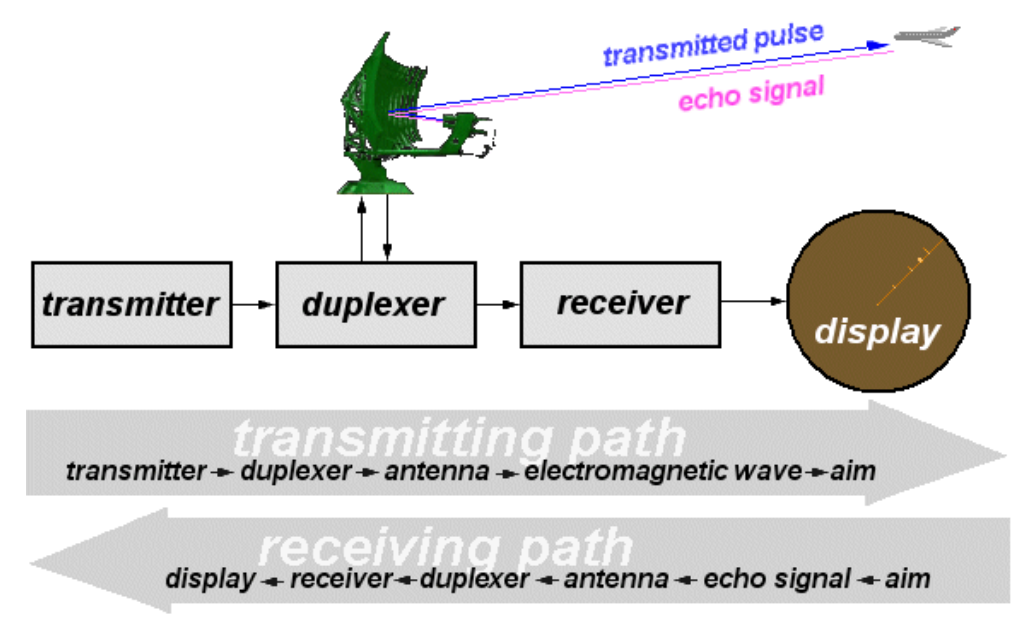

Figure 2. Flow diagram for the process of a radar to send, receive, and process an electromagnetic signal. Figure courtesy of the radar tutorial (http://www.radartutorial.eu/01.basics/Radar\%20Principle.en.html).

The power retuned to the radar from a target composed of randomly distributed particles is a function of multiple variables as shown in Equation (1) from Probert-Jones (1962):

$$
P_{r}=\frac{\pi^{3} \quad P_{o} h_{G}^{2} \theta \phi}{16 \ln 2 \lambda^{2} \quad R^{2}}\left|\frac{\epsilon-1}{\epsilon+2}\right|^{2} \sum r^{6}
$$

where, $P_{r}$ is the received power, $P_{o}$ is the peak transmitted power, $h$ is the radar pulse length in space (distance), $G$ is the actual gain of the antenna, $\theta$ is the horizontal beam width to the $-3 \mathrm{~dB}$ level for oneway transmission, $\phi$ is the vertical beam width to the $-3 \mathrm{~dB}$ level for one-way transmission, $\epsilon$ is the dielectric constant of spherical particles, $\lambda$ is the wavelength of the radar, $R$ is the range, and $r$ is the radius of spherical particles. The actual gain of the antenna, $G$, is related to the beam widths as shown in Equation (2):

$$
G=\frac{\pi^{2} k^{2}}{\theta \phi}
$$

where $k$ is a factor that corrects for the nonuniformity of illumination of the antenna (Probert-Jones, 1962). As noted in Harris et al. (1981), the terms $P_{o}, h, \lambda, G, \theta$, and $\phi$ are always the same for specific radar systems. The authors note that for a particular radar system, the unknown variables are $\sum r^{6}, 1 / R^{2}, \epsilon$, and Pr. If three of these variables are known, a solution to the equation can be found.

Skolnik (1970) writes the radar equation slightly different from Probert-Jones (1962) and is probably the best-known form of the radar equation:

$$
P_{r}=\frac{P_{t} G_{t}}{4 \pi R^{2}} \times \frac{\sigma}{4 \pi R^{2}} \times A_{e}
$$

where $G_{t}$ is the gain from the transmit antenna, $A_{e}$ is the effective area of the antenna, and $\sigma$ is the target cross section. Assuming $G_{t}$ and $A_{e}$ are related by the equation $G_{t}=4 \pi A_{e} / \lambda^{2}$, a form of the radar equation relating maximum range to target to the minimum detectable signal of the radar is written as 


$$
R_{\text {max }}=\sqrt[4]{\frac{P_{t} G_{t}^{2} \lambda^{2} \sigma}{(4 \pi)^{3} S_{\text {min }}}}
$$

where $S_{\min }$ is the receiver minimum detectable signal.

Reflectivity values returned to the radar from the target comprise the primary way in which information about the target is revealed. Reflectivity of a target, according to Atlas (1964) and discussed in Harris et al. (1981), is described as a function of the amount of particles and their scattering cross sections within the target. According to Atlas (1964), the reflectivity is the summation of the backscatter cross sections of the particles per unit volume averaged. For solid spherical particles which obey Rayleigh scattering (discussed more below), the reflectivity is shown in Equation (3):

$$
\eta=\frac{2^{6} \pi^{5}}{\lambda^{4}}\left|\frac{\epsilon-1}{\epsilon+2}\right|^{2} \sum r^{6}
$$

Interestingly, the equation for reflectivity (Equation (5)) looks very similar to Equation 1 (power returned to the radar) due to the dependence upon the particle size distribution, number density, dielectric constant of the particles, and the wavelength of the radar. The dielectric constant of the particles, defined as the quantity measuring the ability of a substance to store electrical energy in an electric field), is highly dependent on the type of particles. For instance, air at standard atmosphere $\left(1 \mathrm{~atm}\right.$ pressure and $20^{\circ} \mathrm{C}$ temperature) is approximately 1.0 (1.00059). When inserted into Equation (1) or Equation (3), one can see why a radar beam transmitted into open air without hitting a target would yield an answer close to zero. Other values of dielectric constants are 3.82 for a silicate glass (high content in ash clouds), 15 for sulfur dioxide, and 2.1 for petroleum oil.

Radar pulses, or beams, do not travel in a straight line but are bent as a function of atmospheric density (by temperature, moisture, and pressure). The amount of bending by the atmosphere is described as the index of refraction, which is defined as the deviation of light or electromagnetic waves from a straight line as it passes through the atmosphere due to the variation in air density. Large gradients in the index of refraction occur near coastlines but can also be present in other locations such as near cold fronts. Figure 3 provides a graphic of the three types of phenomena a radar beam can experience as it travels through the atmosphere: subrefraction, super-refraction, and ducting. Subrefraction occurs when the atmospheric density is less than normal and the beam overshoots the location it would normally hit. Super-refraction occurs when the atmospheric density is more than normal, causing the radar beam to bend closer to the Earth's surface. Ducting occurs when the atmospheric density is so great that it bends the beam equal to or more than the Earth's curvature. 

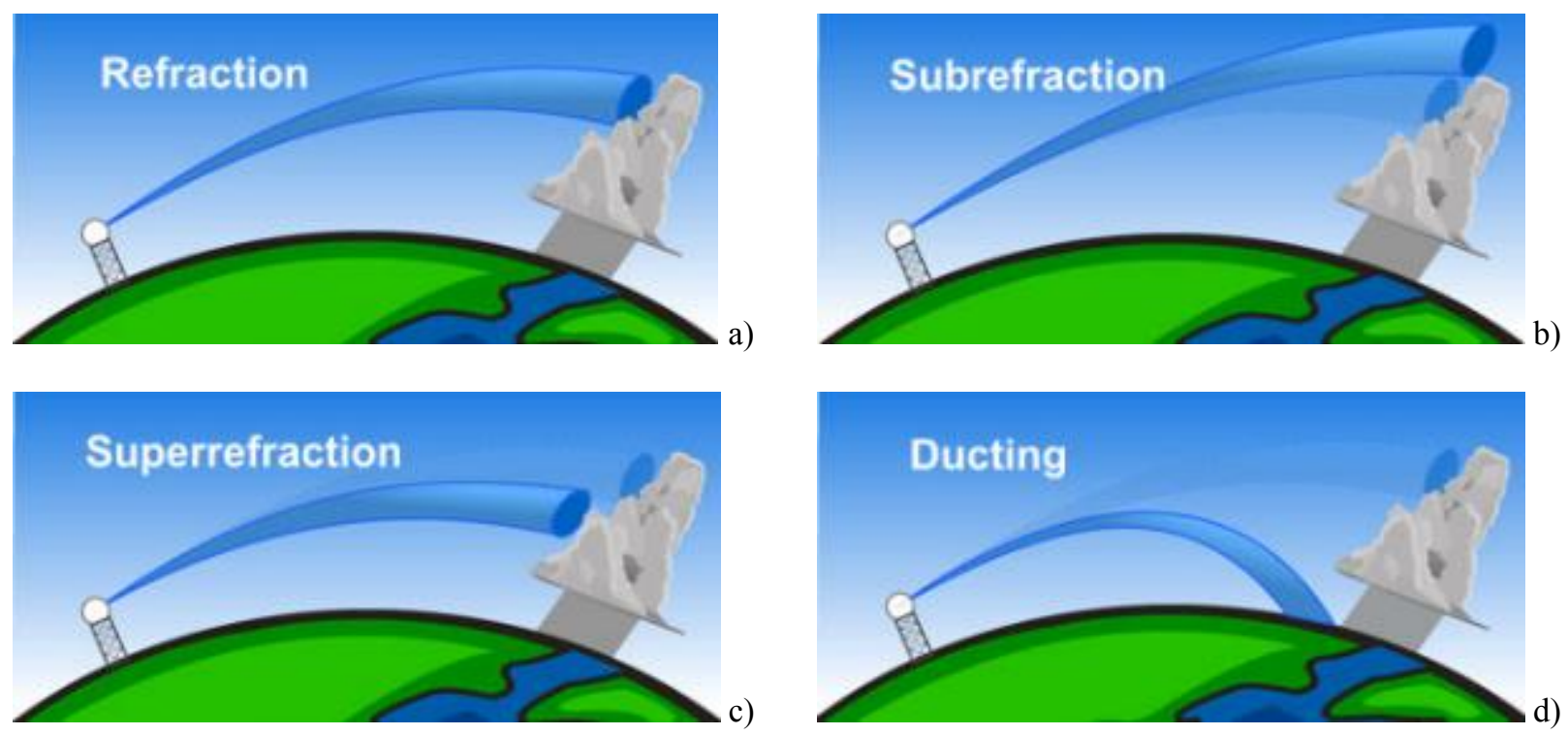

Figure 3. Illustration of the impacts of normal beam refraction (a), subrefraction (b), super-refraction (c), and ducting (d) on a radar pulse beam. Figures courtesy of the National Oceanic and Atmospheric Administration (http://www.srh.noaa.gov/jetstream/doppler/beam_max.html).

In general, the center height of the radar's beam at a given elevation angle $(H)$ can be described by Equation (6):

$$
H=\sqrt{r^{2}+R^{\prime 2}+2 r R^{\prime} \sin (\phi)}-R^{\prime}+H_{o}
$$

where $H_{o}$ is the radar antenna height, $r$ is the distance from the radar to the target, and $\phi$ is the radar beam angle. $R$ ' is related to the atmospheric propagation and refraction and is related to the Earth's radius $(R)$ when standard conditions apply by $R^{\prime}=4 / 3 R$ (Oddsson et al. 2012). Additionally, the absolute width of the beam pulse $(w)$ increases as a function of the distance from the radar $(r)$ and the beam width angle $(\theta)$ as shown in Equation (7) (Oddsson et al. 2012):

$$
w=r \theta
$$

Equations (6) and (7) are shown in pictorial form in Figure $4 \mathrm{a}$ and 4b, respectively. 

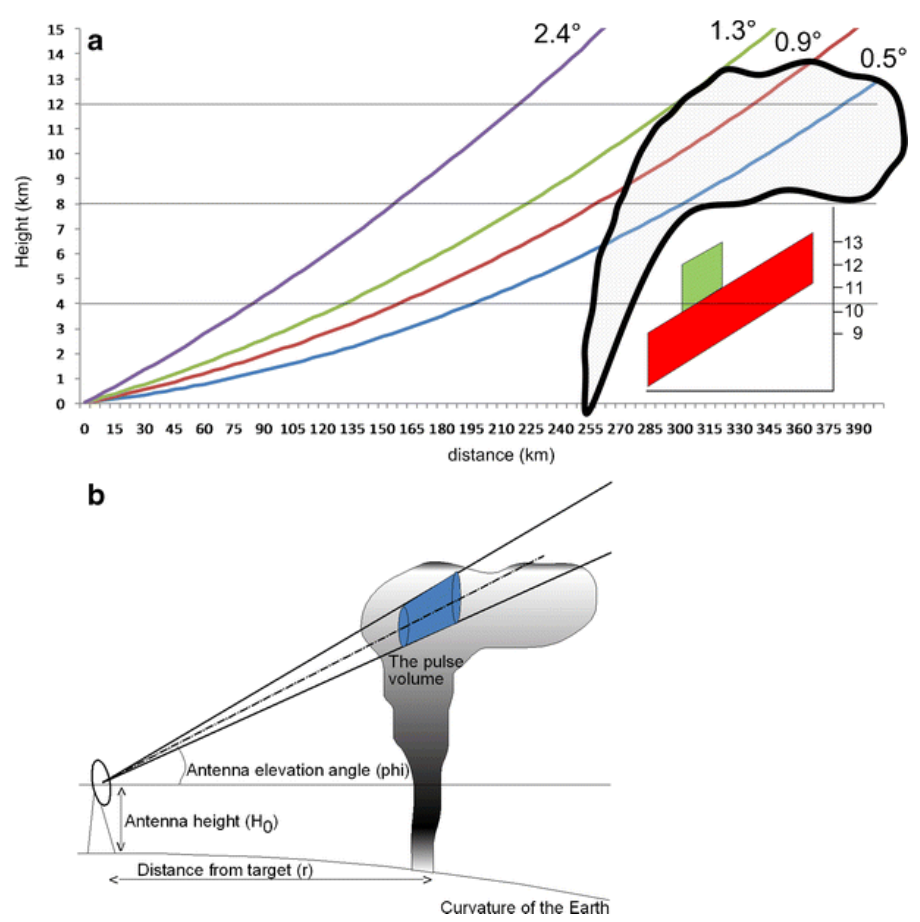

Figure 4. Radar beam height as a function of distance and beam angle (a) and beam width as a function of distance (b). Figure from Oddsson et al. (2012).

Weather radars (X-, C-, and S-band with bands shown in Table 1), operate under the assumption that particles (rain drops in this case) are spherical and satisfy the Rayleigh approximation to Mie's solution of Maxwell's equations for the scattering of electromagnetic radiation (Jones and Christopher 2009). These two bands were chosen for weather radar because most of the scatterers in the volume observed by the radar (rain drops) fall well within the Rayleigh scattering region. The radar signal is also attenuated (less signal) at these bands than at shorter wavelengths by such things as atmospheric water vapor, oxygen, and during precipitation events. Figure 5 illustrates the attenuation effects at various wavelengths. The maximum particle size at which this approximation holds is when the particle diameter is less than 1/10 of a wavelength (Mead et al. 1994), while other literature provides a more refined approximation of 1/16 of a wavelength (Jones and Christopher 2009). If the Rayleigh approximation is violated and the particle diameter is approximately equal to or greater than the wavelength of the radar, Mie scattering occurs, and a three-body scatter spike return can be observed (Lindley and Lemon 2007). This phenomenon typically occurs in the presence of large hail in a thunderstorm (Figure 6).

Table 1. Microwave frequency bands as designated by the Institute of Electrical and Electronics Engineers (IEEE) and defined in IEEE Standard 521-1984

\begin{tabular}{c|c|c}
\hline Designation & Frequency range (GHz) & Wavelength range \\
\hline L band & $1-2$ & $30 \mathrm{~cm}-15 \mathrm{~cm}$ \\
$\mathrm{~S}$ band & $2-4$ & $15 \mathrm{~cm}-5 \mathrm{~cm}$ \\
$\mathrm{C}$ band & $4-8$ & $5 \mathrm{~cm}-3.75 \mathrm{~cm}$ \\
$\mathrm{X}$ band & $8-12$ & $3.75 \mathrm{~cm}-2.5 \mathrm{~cm}$ \\
Ku band & $12-18$ & $2.5 \mathrm{~cm}-1.6 \mathrm{~cm}$ \\
$\mathrm{~K}$ band & $18-26$ & $1.6 \mathrm{~cm}-1.2 \mathrm{~cm}$ \\
Ka band & $26-40$ & $1.6 \mathrm{~cm}-750 \mathrm{~mm}$ \\
V band & $40-75$ & $750 \mathrm{~mm}-40 \mathrm{~mm}$ \\
W band & $75-111$ & $40 \mathrm{~mm}-28 \mathrm{~mm}$ \\
millimeter & Above 111 & "millimeter wave" \\
\hline
\end{tabular}




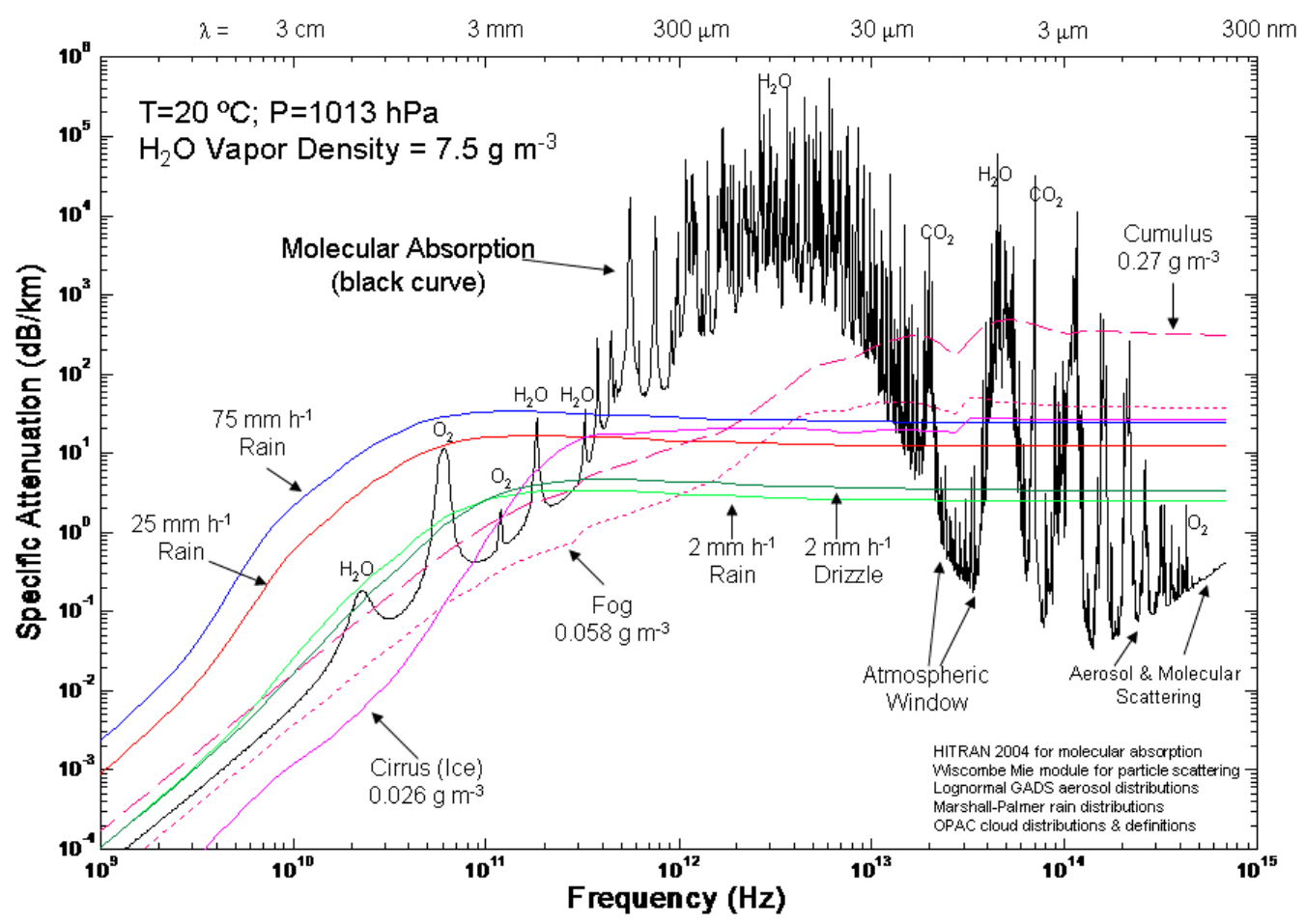

Figure 5. Attenuation ( $y$-axis) effects of various phenomena [ambient atmosphere (solid black line); rainfall rates (red, blue, dark green and light green lines); and clouds (pink solid, dashed, and dotted lines)] as a function of wavelength $(x$-axis). Figure provided by Steven Fiorino (AFIT).

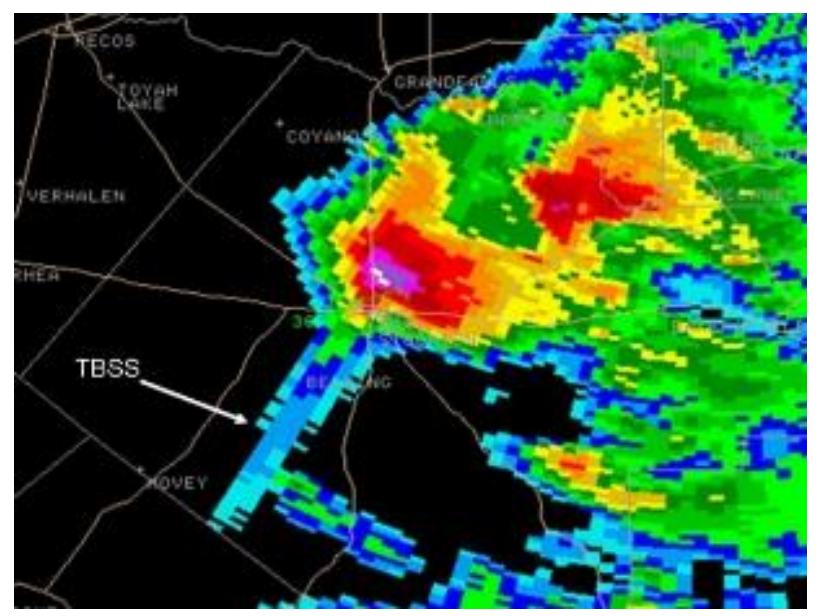

Figure 6. Example of a three-body scatter spike (or Mie scattering) associated with large hail in a severe thunderstorm. Figure courtesy of Lindley and Lemon (2007).

With respect to weather radars operated from World War II through the late 2000s, the pulse transmitted to the atmosphere was oriented horizontally (Figure 7). Harris et al. (1981), citing a study by Atlas (1964), showed that as the particle shape became more distorted, as the refractive index increased, and the orientation of the particles became less random, there would be an impact on the reflectivity seen by the radar. Additionally, they found that the general orientation of the particles with respect to the alignment of the radar wave may increase or decrease the reflectivity. With the advent of dual-polarization (dual-pol) technology (Figure 7) for operational weather radars in the United States in the early-2010s, a cross section of the particles in a volume can be measured. This, however, does not solve the issues cited by 
Atlas (1964) and Harris et al. (1981). Quantifying the reflectivity loss of elongated particles is something that must be further studied.
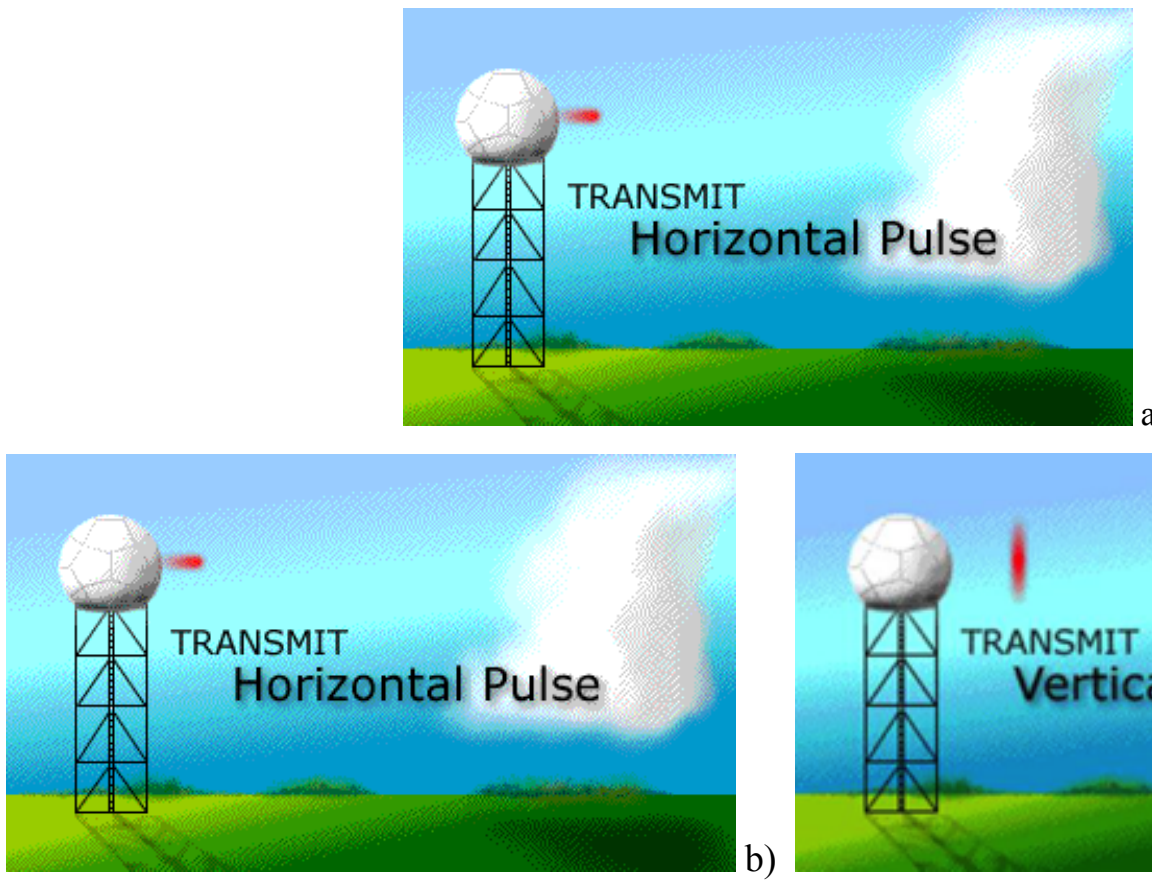

a)

Figure 7. Radar beam orientation for traditional radar (a) versus dual-pol radar (b). Images courtesy of NOAA’s National Severe Storms Laboratory (NSSL; http://www.nssl.noaa.gov/tools/radar/).

Dual-pol technology allows for easily distinguishing between precipitation and non-precipitation echoes by comparing differences between the signal from the horizontally and vertically oriented pulses.

Correlation coefficient interrogates the behavior similarity of the particles in a volume, with values near one indicating a perfectly spherical particle (such as a rain drop) while values generally less than 0.9 indicate an irregular or wobbling volume of particles. Differential reflectivity evaluates the difference in returned energy between the two pulses, giving an indication that the particles in the volume are oriented horizontally (positive differential reflectivity) or vertically (negative differential reflectivity). Lastly, the differential phase provides insight into whether the particles are spherical (value near zero), horizontally oriented (positive values), or vertically oriented (negative values). Figure 8 provides an illustration of the ability to use differential reflectivity to distinguish between a dust storm and a cluster of thunderstorms. 


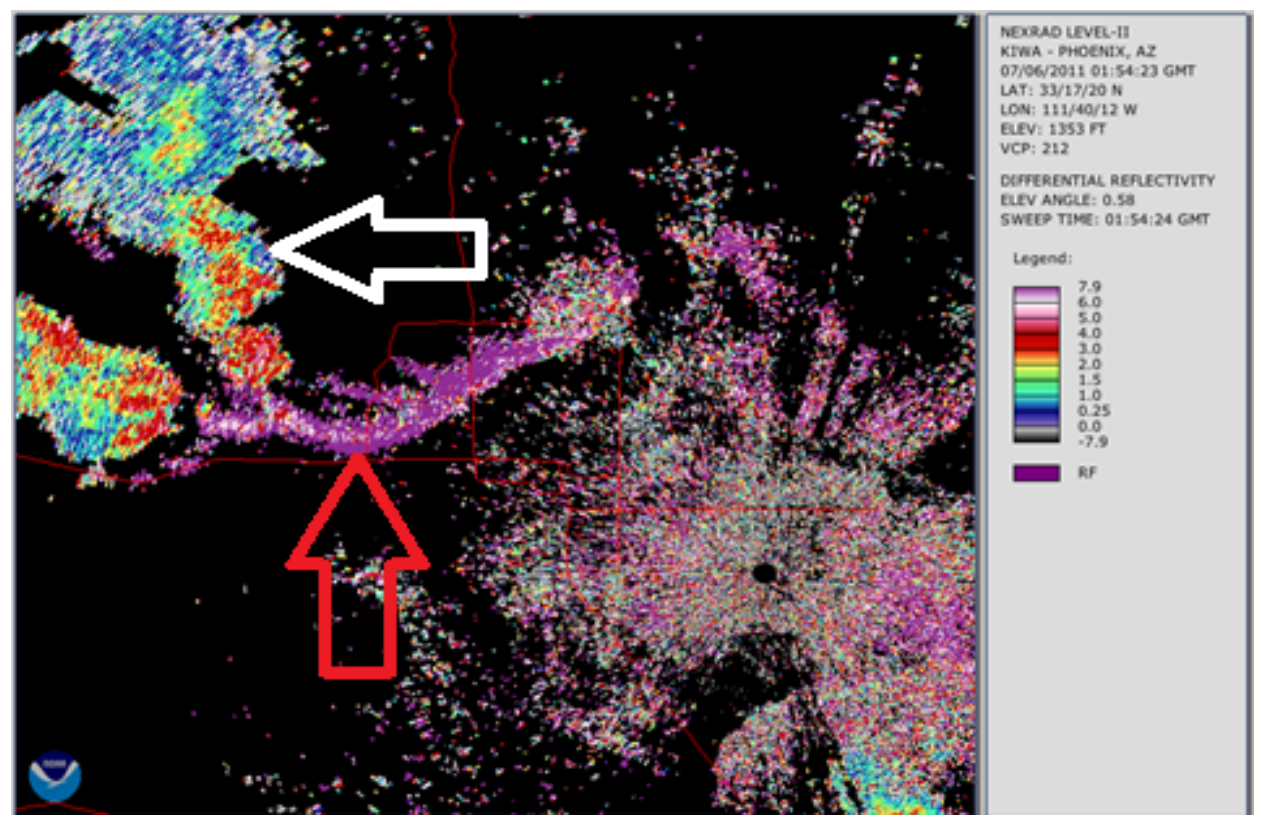

Figure 8. Plot of differential radar reflectivity from the Phoenix, AZ WSR-88D radar. The white arrow highlights a cluster of thunderstorms to the west-northwest of the Phoenix metropolitan area. The red arrow highlights a dust storm in the same general location as the thunderstorms.

Utilization of radar for plume tracking can be done; however, the detectability and information extracted from the radar is a function of each of the four equations discussed in this section. The most important aspects of the potential to observe and track a plume appear to be mostly a function of the plume's distance from radar, particle size distribution and concentration in the measured volume, and potentially the orientation of the particles. Additionally, a distance threshold at which the plume can be detected is finite, because as particle size and concentration get smaller with downwind transport, the radar beam increases in size and height above ground, decreasing the ability of the radar to detect the plume.

\subsection{UNITED STATES OPERATIONAL RADAR}

Use of the Weather Surveillance Radar, 1988, Doppler (WSR-88D) network in the immediate aftermath of an explosion or other plume-generating emergency response events may provide plume characterization information before standard emergency response fate and transport (F\&T) or consequence assessment models can be utilized. The WSR-88D radar, a $10 \mathrm{~cm}$ wavelength system, is one such tool which is already established with data fed in near real-time to a central database hosted on Amazon Web Services. The United States WSR-88D radar network is composed of 159 Department of Commerce (National Weather Service [NWS]), Department of Defense (DoD), and Federal Aviation Administration (FAA) locations within the contiguous United States, Alaska, Hawaii, Puerto Rico, Guam, the Azores, South Korea, and Japan (Figure 9). 

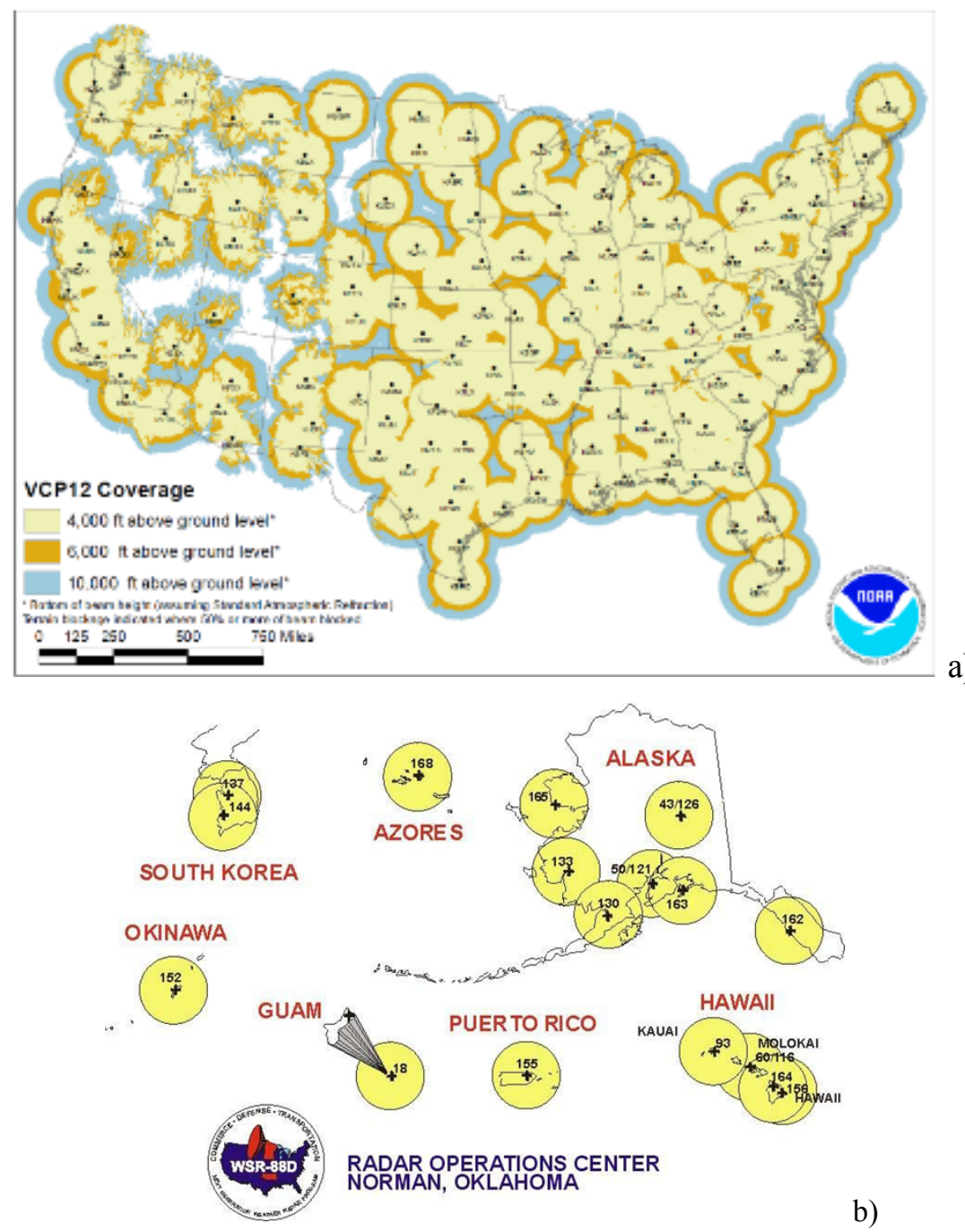

Figure 9. US installations of WSR-88D radar, continental United States (a) and outside the continental United States (b). Image courtesy of NOAA (http://www.roc.noaa.gov/wsr88d/maps.aspx).

Since 2008, two major upgrades to the NEXRAD radars have created opportunities to utilize the radar data for emergency management applications that were not previously available. The first upgrade increased spatial resolution data, called Super Resolution. Super Resolution improved reflectivity data to 0.5 degree azimuthal by $250 \mathrm{~m}$ range gate resolution to a range of $460 \mathrm{~km}$, and Doppler velocity and spectrum width at 0.5 degree azimuthal by $250 \mathrm{~m}$ range gate resolution to a range of $300 \mathrm{~km}$. The second upgrade, completed in 2013, added dual polarization (dual-pol) capability to all NEXRAD sites. The dual-pol capability adds vertical polarization to more accurately discern the return signal, allowing the radar to better distinguish between types of precipitation and aids in the removal of non-weather artifacts (NOAA 2017).

The NWS employs two general radar scanning modes (with several sub-strategies within each mode) to accommodate differing atmospheric conditions. "Clear Air" mode is employed when precipitation is not expected within the operating range of the radar and is characterized by a slow volume scan. This type of scanning strategy is very sensitive to atmospheric scatterers due to the long dwell time as the radar rotates. A full volumetric scan is conducted in approximately $10 \mathrm{~min}$. Figure 10a illustrates the typical volumetric scanning profile with only five beam angles. When the radar operates in "precipitation 
mode,"; the radar rotates much faster and is less sensitive to atmospheric scatterers. A volumetric scan is typically completed in 4-5 min with approximately 14 beam angles (Figure 10b).
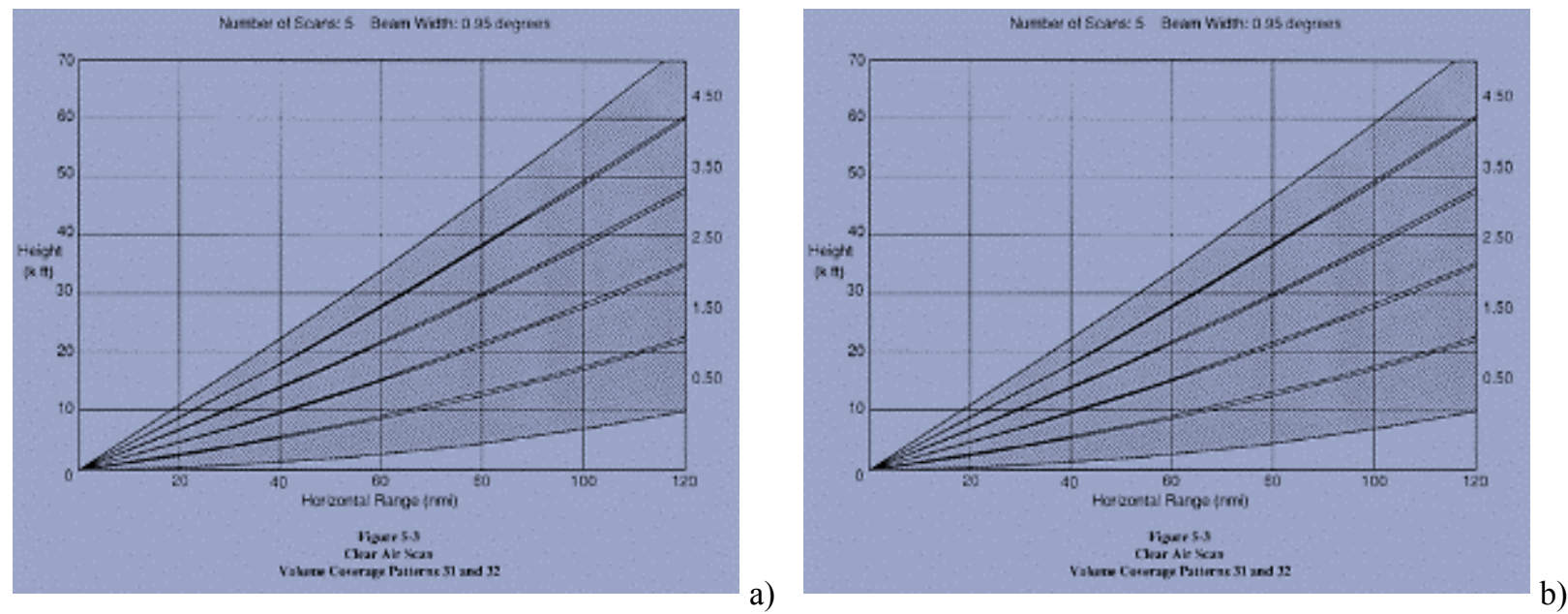

Figure 10. Typical beam profiles for the "clear air" (a) and "precipitation" (b) scanning strategies for the National Weather Service WSR-88D radars.

Another operational radar system at the disposal of decision makers are the Terminal Doppler Weather Radars (TDWRs) operated by the FAA. TDWR data, similar to the WSR-88D data, are fed in near realtime to the Amazon Cloud Services database. The TDWR operates in the C-band ( $5 \mathrm{~cm}$ wavelength). The primary mission for the TDWRs is to provide turbulence and rain information close to major airports at a resolution greater than that of the WSR-88Ds. Figure 11 provides a coverage area map for the TDWRs. Table 2 provides basic characteristics of the two operational radars.

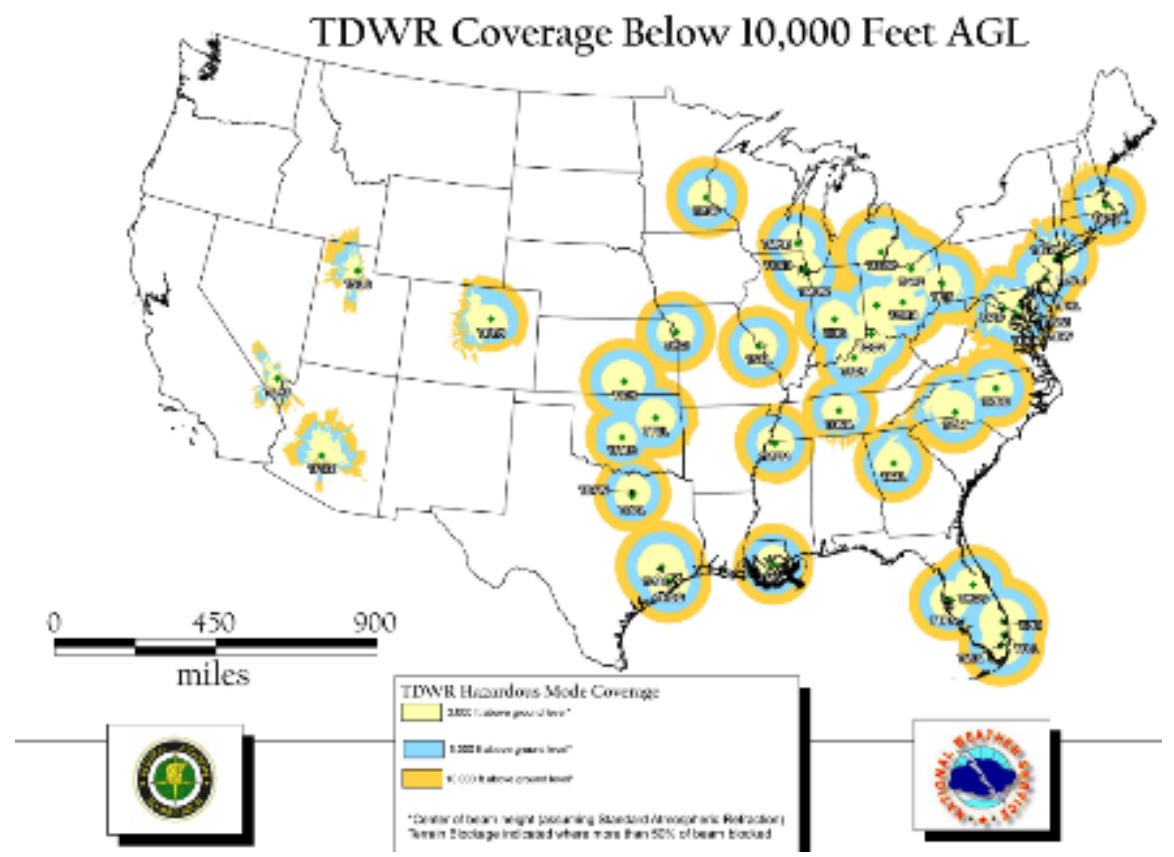

Figure 11. US installations of Terminal Doppler Weather Radars (TDWRs). Image courtesy of the National Oceanic and Atmospheric Administration (http://www.roc.noaa.gov/wsr88d/maps.aspx). 
Table 2. Radar characteristics of the WSR-88D and TDWR

\begin{tabular}{|c|c|c|}
\hline & NWS Radar (WSR-88D) & FAA TDWR \\
\hline Wavelength & $10 \mathrm{~cm}(\mathrm{~S}-$ band $)$ & $5 \mathrm{~cm}$ (C-band) \\
\hline Volume scan time & $\begin{array}{c}4-5 \min \text { (precipitation mode) } \\
10 \text { min (clear air mode) }\end{array}$ & $1 \mathrm{~min}$ \\
\hline Beam width & 1.0 degree & 0.5 degree \\
\hline Minimum beam angle & 0.5 degree & $0.1-0.3$ degree \\
\hline Range gate & $250 \mathrm{~m}$ & $\begin{array}{c}150 \mathrm{~m} \text { at }<135 \mathrm{~km} \text { distance } \\
300 \mathrm{~m} \text { at } 135-460 \mathrm{~km} \text { distance }\end{array}$ \\
\hline Maximum unambiguous velocity & Up to 62 knots & $23-30$ knots \\
\hline Maximum Doppler range & $230 \mathrm{~km}$ & $90 \mathrm{~km}$ \\
\hline
\end{tabular}

\subsection{NOAA WEATHER RADAR DATA}

Through the National Centers for Environmental Information (NCEI), NOAA provides public access to radar and weather-related products at no charge. In the case of the NEXRAD data, the data are provided as two levels of data. Level II, or base, data includes reflectivity, mean radial velocity, and spectrum width. Data are collected and available in files with data for that specific volume coverage pattern. Level III products are much more extensive, with of 75 different products maintained (NCEI 2018). A number of the radar products used throughout this feasibility study are Level III products.

\subsection{PLUME DETECTION}

Kabela et al. (2016) provides an extensive review of instances in which radar was used to detect and track plumes. These plumes ranged from those created by aboveground weapons testing in the United States during the 1950s and 1960s (Figure 12) to more recent examples of volcanic ash and fire-generated plumes (Figure 13). General conclusions reached by the literature review from Kabela et al. (2016) indicate that weather radar used for plume tracking can provide the following benefits:

- Increased spatial and temporal data resolution over satellite-based systems.

- Cloud height detection which can aid downwind transport calculations.

- Determine cloud shape, movement, and volume.

- Determine total mass of ejected material from volcanic eruptions if a particle size distribution is assumed.

- Estimate fallout from plumes via dual-pol measurements. 

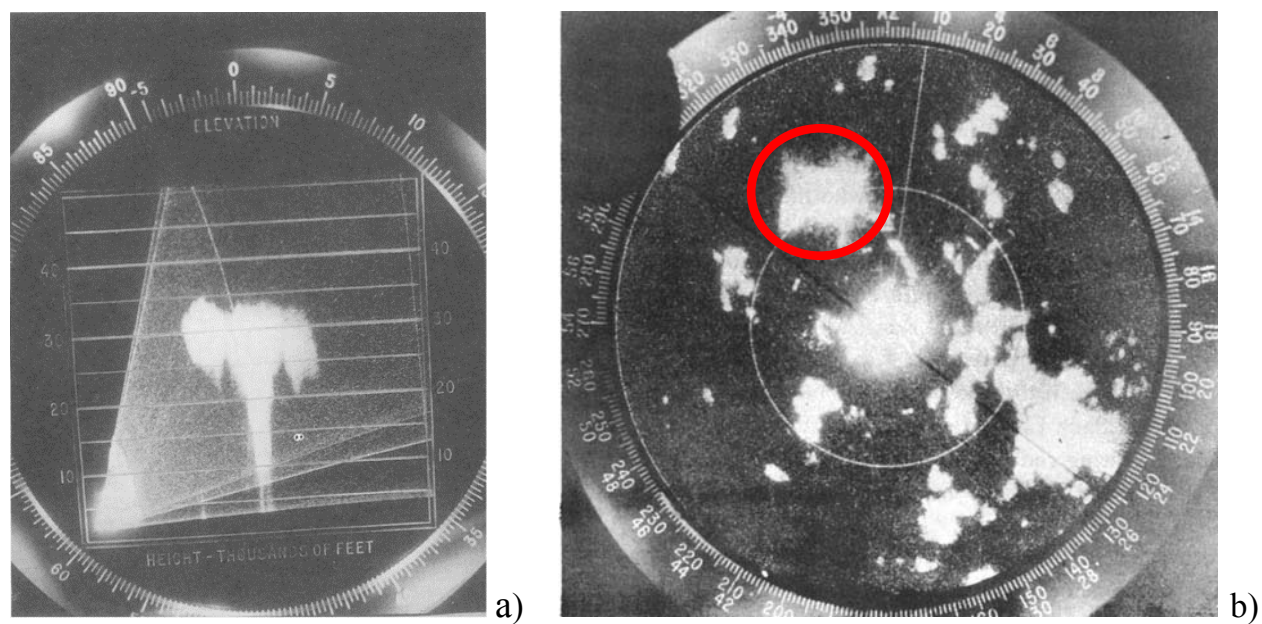

Figure 12. Atomic cloud echo on an X-band Range Height Indicator (a), and an atomic cloud as shown on the Plan Position Indicator (b). The red circle highlights the atomic cloud. Figure 14a courtesy of Atlas (1990). Figure $14 \mathrm{~b}$ courtesy of Swingle (1958).
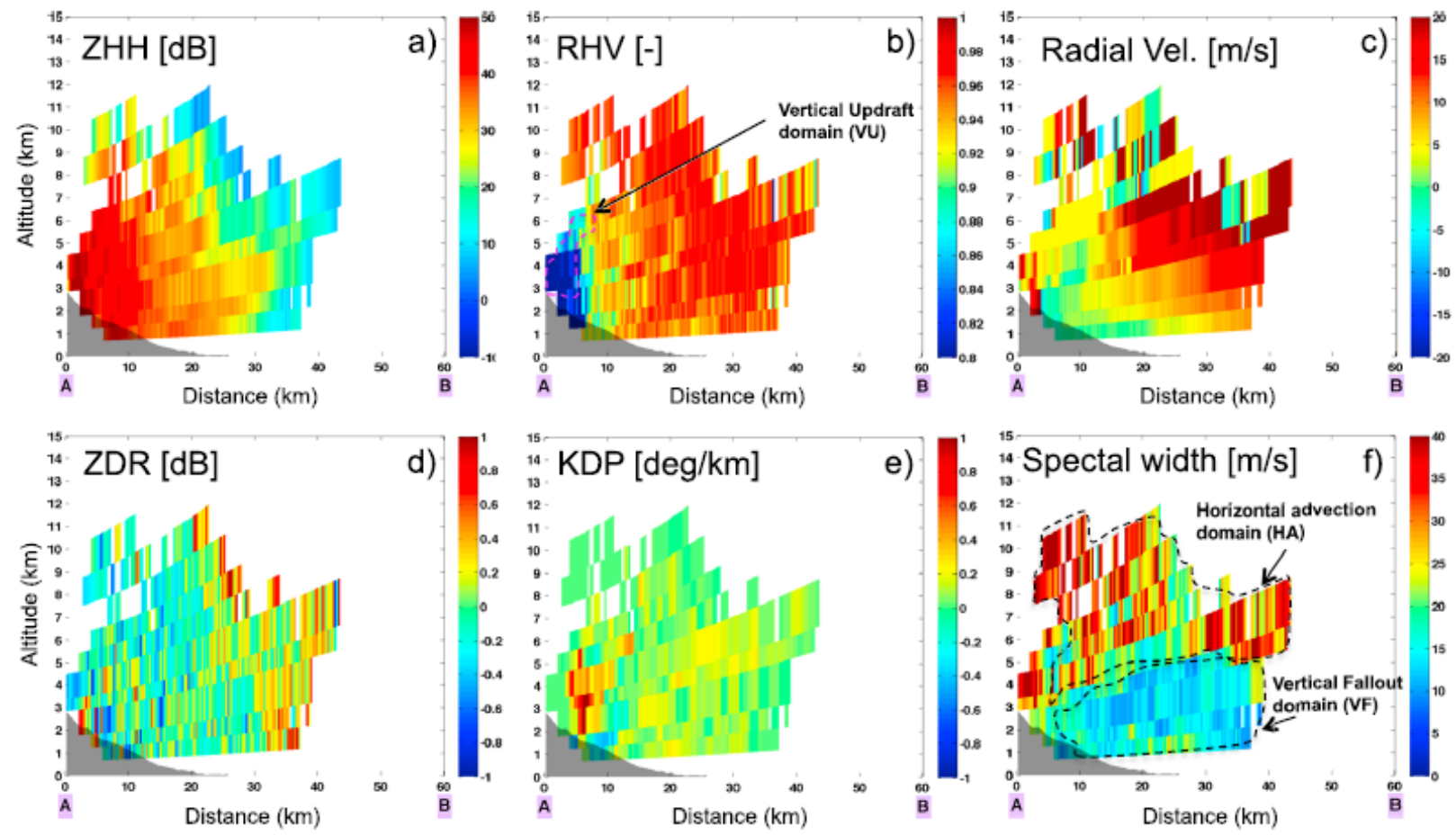

Figure 13. Radar cross sections of reflectivity factor (a), correlation coefficient (b), radial velocity (c), differential reflectivity (d), differential phase shift (e), and spectrum width (f) from a volcanic ash plume. Areas of vertical updraft, horizontal advection, and vertical fallout are denoted. Figure courtesy of Montopoli (2016).

Kabela et al. (2017) discuss current capabilities of existing US civilian radars to detect plumes under current operational modes and provides recommendations about improvements that can be built on the existing WSR-88D and TDWR radar systems. Additionally, a more detailed analysis and discussion of radar characteristics and their ability to detect and track plumes can be found in Zrnic et al. (2017b). 
With the recent improvements in the NOAA WSR-88Ds, the ability of radar to provide timely and relevant information to decision makers for plume generating events is a real potential. Incorporating radar information into the decision-making process can increase the fidelity and accuracy of decisions such as shelter-in-place, evacuations, and establishing the Incident Command post. Work needs to be done to understand current decision-making processes and find where radar-derived information can enhance operations.

\section{RADAR MEASUREMENTS IN FATE AND TRANSPORT MODELS}

Fate and transport models are a valuable tool in emergency management, and during the early phases of an event can have significant uncertainty in both source term and meteorology conditions. Radar measurements can provide valuable information for early model generation to reduce this uncertainty.

Recommendations:

1. Adopt a validation step within the current operational procedures which compares model output with radar-derived plume information.

2. F\&T models should ingest radarderived VAD wind profile information to improve transport and deposition calculations.

3. Conduct research to utilize opensource software allowing F\&T models to efficiently use threedimensional radar-derived wind information.
Fate and transport (F\&T) models are valuable tools used to simulate the atmospheric dispersion, diffusion, and deposition of pollutants released into the atmosphere. Their complexity ranges from simple Gaussian models to Eulerian and Lagrangian models to computational fluid dynamics codes. All models are meant to estimate the complex interactions and processes pollutants have with the atmosphere as they are carried downwind from their source location at scales from the local/micro-scale to the regional and global scales. Although F\&T models are great tools to use for decision making, they are not perfect. The main source of error in model results is the uncertainty in source terms, with atmospheric phenomena such as convection and inversions and uncertainty in wet deposition as important sources of error (Leelossy et al. 2018).

Utilizing radar information in F\&T models is one method in which model results and their associated uncertainties can be reduced. Radar provides measurement of what is taking place in the atmosphere, rather than relying on model parameterizations to estimate atmospheric conditions. For instance, WSR-88D radar measures the radial wind field via Doppler detection. This information alone can provide a realtime quality assured/quality controlled wind profile to help drive a F\&T model's downwind dispersion. Additionally, currently produced and publicly available WSR-88D Level II and Level III products can provide information on a plume's horizontal dimensions, cloud top height, movement, deposition, and space-varying intensity. Further, with some research and development, information on particle size distribution may be another variable radar can provide.

This section describes a case study utilizing information collected by the WSR-88D radar from Melbourne, FL in the aftermath of the SpaceX rocket explosion at Cape Canaveral, FL on September 1, 2016. Figure 14 provides a series of images of the explosion on Launch Pad 41, while Figure 15 shows the radar return from the Melbourne WSR-88D approximately 50 min after the explosion. The Melbourne WSR-88D is 31 miles from the launch pad where the explosion took place. It was operating in hazardous mode (complete volumetric scans every $5 \mathrm{~min}$ ) and the lowest bean angle was $1968 \mathrm{ft}$ above the launchpad. Interestingly, the radar captures the main plume generated from the explosion (larger cluster of green and yellow returns several miles to the east of Ariel, FL) and ongoing fire on the pad (weak radar returns oriented parallel to the coastline). 

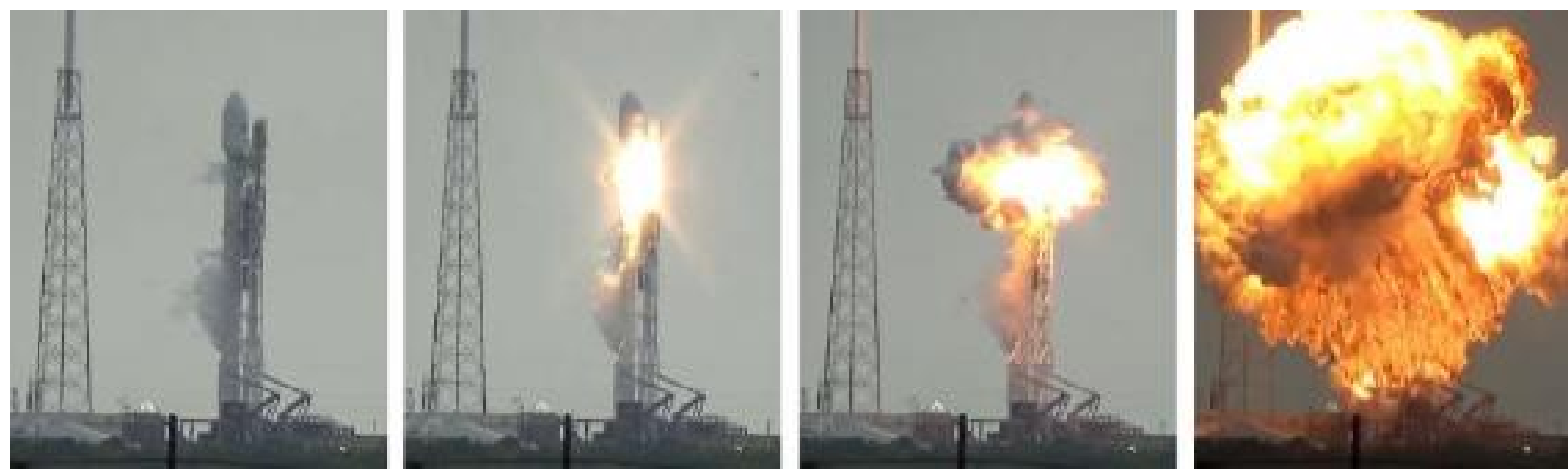

Figure 14. Series of images from the SpaceX rocket explosion on September 1, 2016, at Cape Canaveral, FL at approximately 1305 UTC. Figures courtesy of Spaceflight Now.

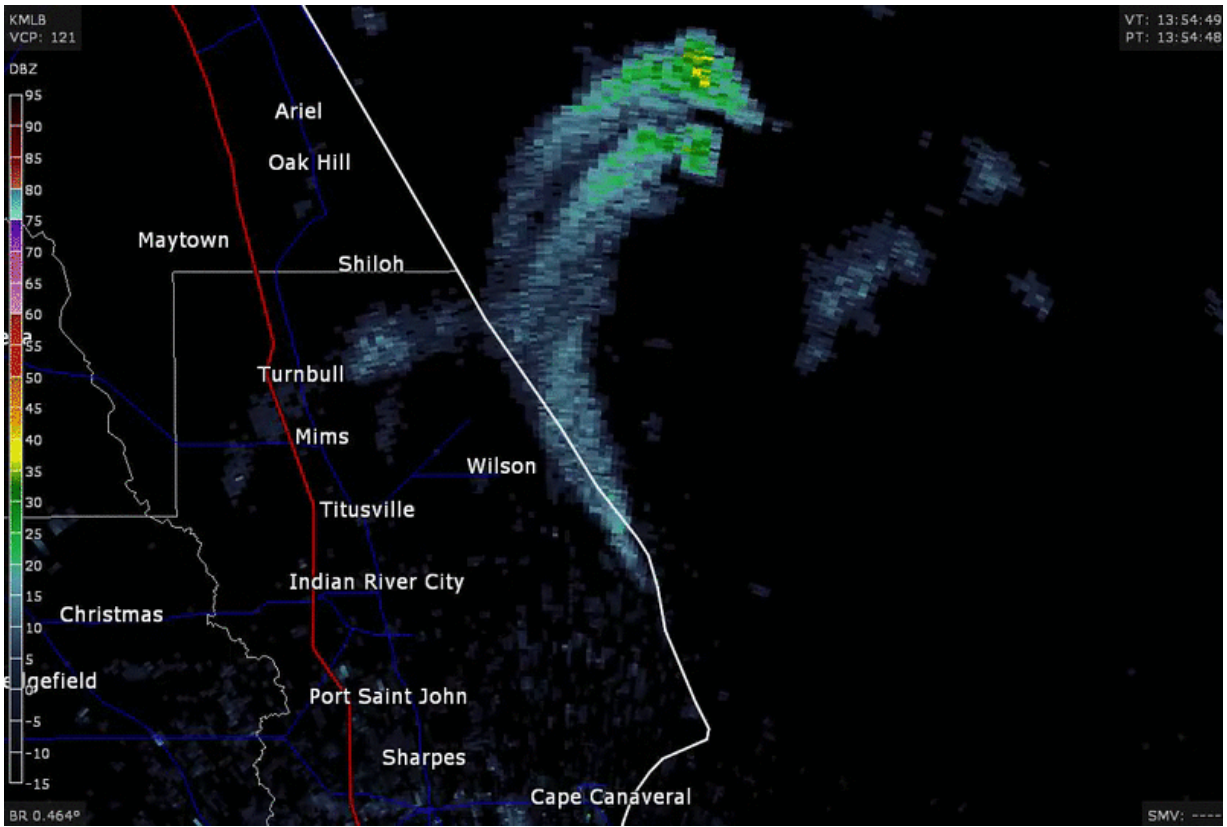

Figure 15. Radar image of the plume from the SpaceX rocket explosion from the Melbourne, FL WSR-88D on September 1, 2016, at 1354 UTC. The radar return was captured approximately $50 \mathrm{~min}$ after the explosion.

The following subsections illustrate uses of radar-derived information for F\&T modeling through simple procedural changes to overlay F\&T model output with observed radar measurements of the plume to determine the efficacy of the modeled results. The second subsection points to the importance of utilizing rapidly updated radar-based wind measurements to ingest into F\&T models. To illustrate the utility of radar data for use in F\&T modeling, Doppler-derived wind information was extracted, and the data were ingested into the Department of Defense Land Interpretive Fallout Code (DELFIC) (Norment 1979a and b).

\subsection{F\&T MODEL EFFICACY}

A primary goal of utilizing radar observations in the F\&T community should be to realize radar's place as an observed dataset. As long as a plume generated by an event reaches a height that radar can "see," radar can provide better information than models alone during the consequence assessment phase of the response. This occurs because radar is a direct measurement rather than a series of assumptions or physics-based calculations or parameterizations. The first recommendation presented in this study is that 
emergency response/consequence assessment model procedures should adopt a validation step that reviews model results against observed radar-derived information. Simply overlaying the modeled plume over radar reflectivity would provide a good indication of model efficacy.

Figure 16 illustrates this process. In Figure 16a, modeled deposition from DELFIC is shown with meteorological data taken from the closest surface weather station to the explosion (Table 3). This plot shows a plume that would have moved from the south-southeast toward the north-northwest. When we look at the radar data (Figure 16b) as a compilation over the first hour, we see the plume is greatly influenced by winds above the surface level. In this case, the plume is moving out to sea and away from populated areas.
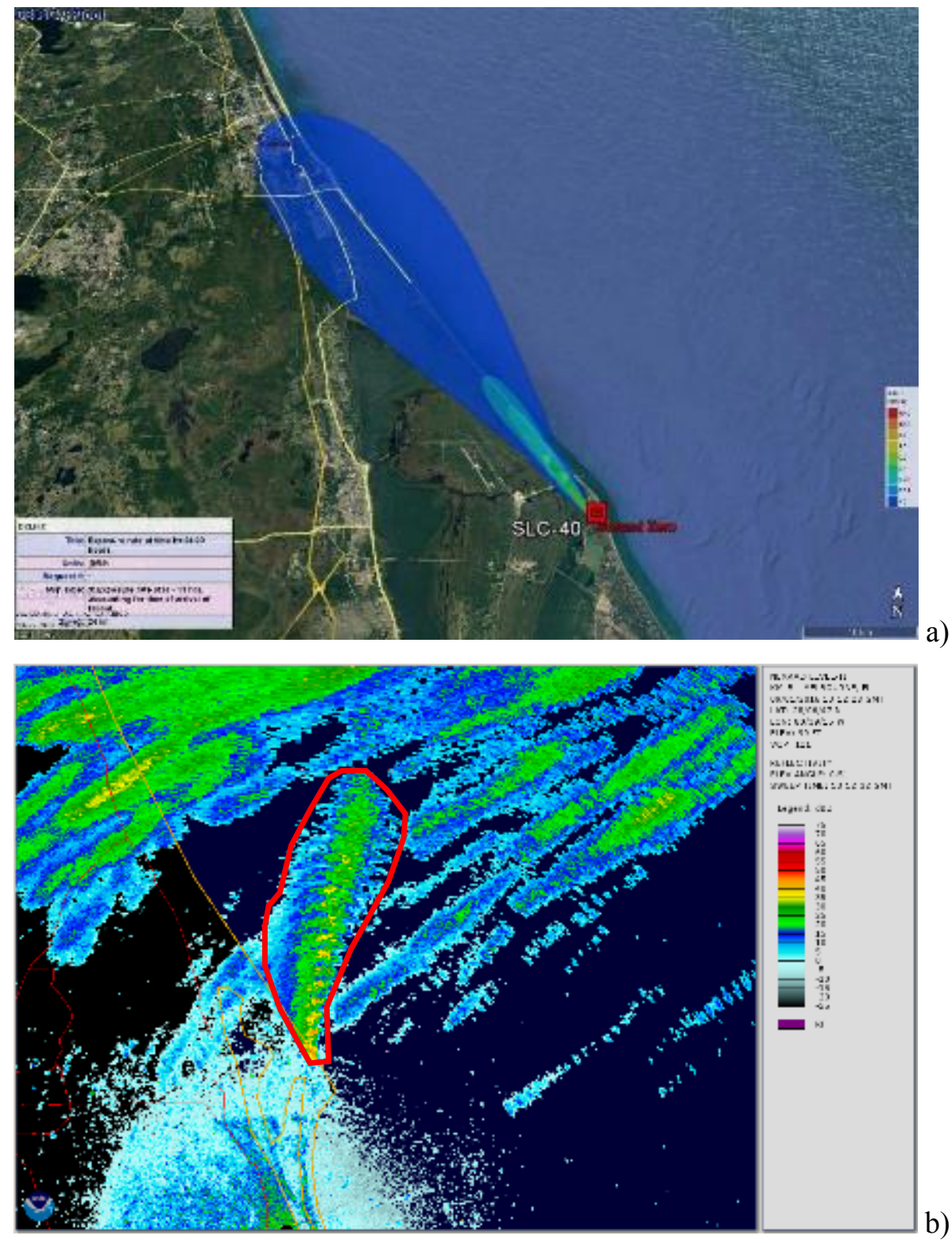

Figure 16. (a) DELFIC-modeled dose rate based on surface observations from 1258 UTC on September 1, 2016, from Cape Canaveral, FL and (b) a 1 hour composite of maximum radar reflectivity from the Melbourne, FL WSR-88D. The red outline in Figure $3 b$ represents the location of the observed plume from radar. 
Table 3. Surface weather observations from Cape Canaveral, FL on September 1, 2016

\begin{tabular}{|c|c|c|c|c|c|}
\hline $\begin{array}{c}\text { Time } \\
(\mathbf{U T C})\end{array}$ & $\begin{array}{c}\text { Wind Direction } \\
(\mathbf{d e g r e e s} \text { from) }\end{array}$ & $\begin{array}{c}\text { Wind Speed } \\
(\mathbf{m} / \mathbf{s})\end{array}$ & $\begin{array}{c}\text { Temperature } \\
\left({ }^{\circ} \mathbf{C}\right)\end{array}$ & $\begin{array}{c}\text { Dew Point } \\
\left({ }^{\circ} \mathbf{C}\right)\end{array}$ & $\begin{array}{c}\text { Pressure } \\
(\mathbf{m b})\end{array}$ \\
\hline 1258 & 150 & 4.0 & 26.6 & 25.0 & 1013.8 \\
\hline 1358 & 160 & 6.3 & 28.3 & 25.5 & 1014.2 \\
\hline
\end{tabular}

This example provides an illustration of the model performing poorly when compared to the observed plume path measured by radar due to poor or incomplete meteorological data. In this case, the consequence assessment team would know that additional information would need to be input into the model to make it better represent reality. When using radar information as a validation of model results, there should be general agreement between the model output and radar data with respect to direction of plume travel.

\subsection{WEATHER-MODEL-DRIVEN FATE AND TRANSPORT VERSUS RADAR OBSERVATIONS}

In Section 2.1 we looked at the case of a F\&T model initiated with a single point surface observation. For the example in this section, we looked at the same event but used NOAA's North American Mesoscale Forecast System (NAM) model information as input. The NAM is one of the major weather models used by the National Centers for Environmental Prediction (NCEP) to produce weather forecasts. Dozens of weather parameters are available from the NAM grids, from temperature and precipitation to lightning and turbulent kinetic energy. The NAM model is updated every 6 hours with hourly model output and is run with a horizontal resolution of $12 \mathrm{~km}$.

In this example, DELFIC's stabilized cloud is transported downwind by using NOAA's Hybrid Single Particle Lagrangian Integrated Trajectory (HYSPLIT) model (Rolph et al. 2014) with the meteorological data source being the NAM model (Figure 17). Model results are overlaid with Level II radar reflectivity for the first hour after the explosion. In this case, the modeled results are in fair agreement with observations of the plume from radar.

Figure 18 illustrates the difference in the surface dose rate field when using only observed surface weather data versus four-dimensional weather model data. This point is addressed further in Section 2.3. 

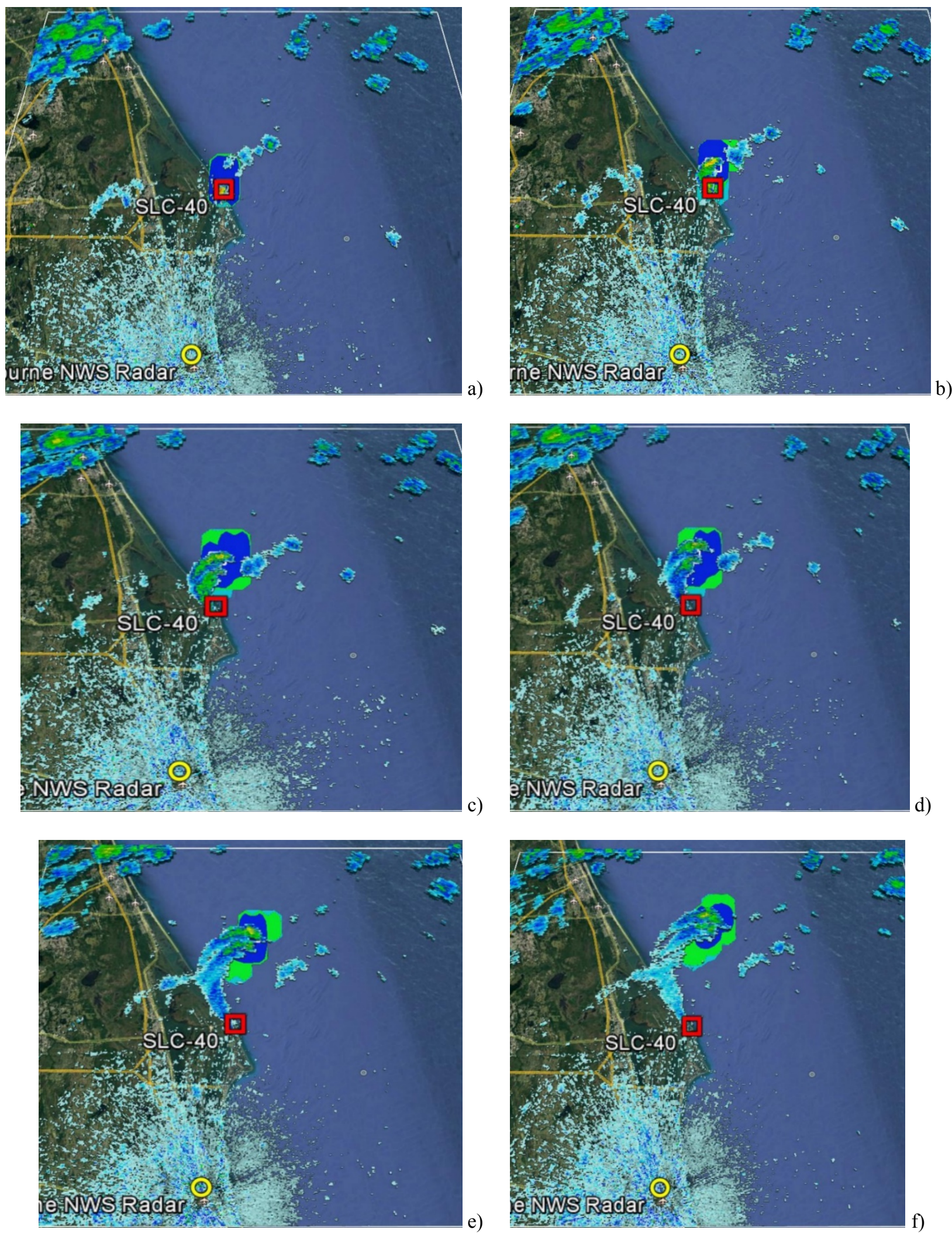

Figure 17. Level II radar reflectivity overlaid on DELFIC-HYSPLIT model results for a) 1312 UTC, b) 1322 UTC, c) 1333 UTC, d) 1338 UTC, e) 1354 UTC, and f) 1405 UTC on September 1, 2016. 


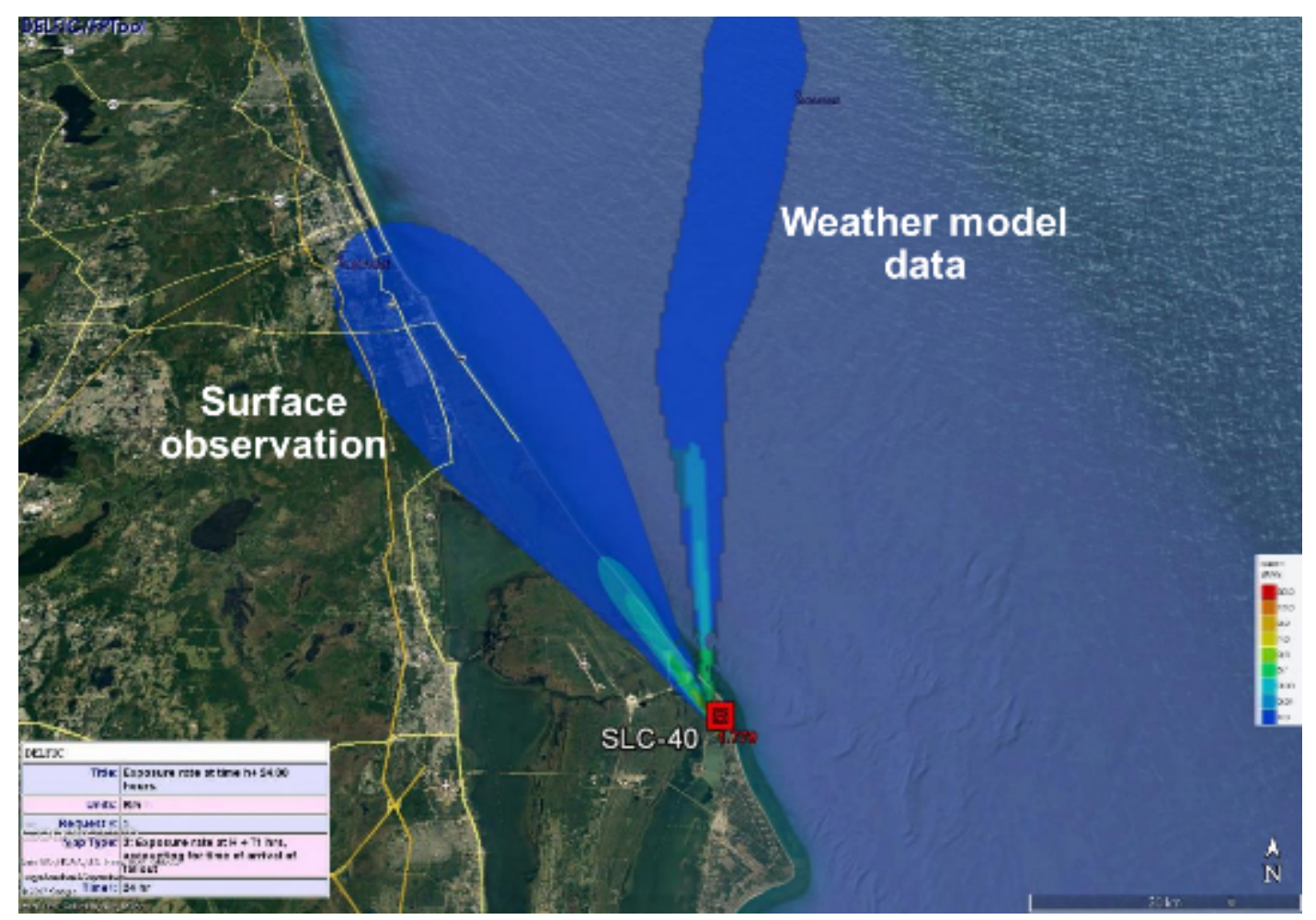

Figure 18. Modeled dose rate using two weather data sources.

\subsection{INGESTION OF RADAR-DERIVED WIND MEASUREMENTS}

All NWS WSR-88Ds measure Doppler wind speed and direction as a function of the reflected phenomenon's movement relative to the radar beam. Measurement of wind speed and direction is expressed as movement toward or away from the radar. One of the Level III radar products calculated and available in near real time is called the velocity-azimuth display (VAD) wind profile (VWP). Figure 19 shows an example of the VWP calculated for the Melbourne, FL radar every (approximately) 5 min during the first hour following the SpaceX explosion. Chrisman and Smith (2009) provide a general overview of how the VAD wind profile is calculated, including enhanced quality assurance/quality control (QA/QC) procedures. In short, the VAD wind profile is calculated by using Doppler velocity data at a constant range that equates to a desired height. In the case of measurements taken during the SpaceX explosion, measurements were calculated as little as $500 \mathrm{ft}$ above ground level (AGL) up to a height of $24,000 \mathrm{ft}$ in some instances. Interestingly, the radar does a good job of measuring the wind shear seen in Figure 17. Winds near the surface are generally from the south-southeast (as also seen in the surface weather observations), shift to south through about 5,000 ft AGL, and then shift from the southwest. 


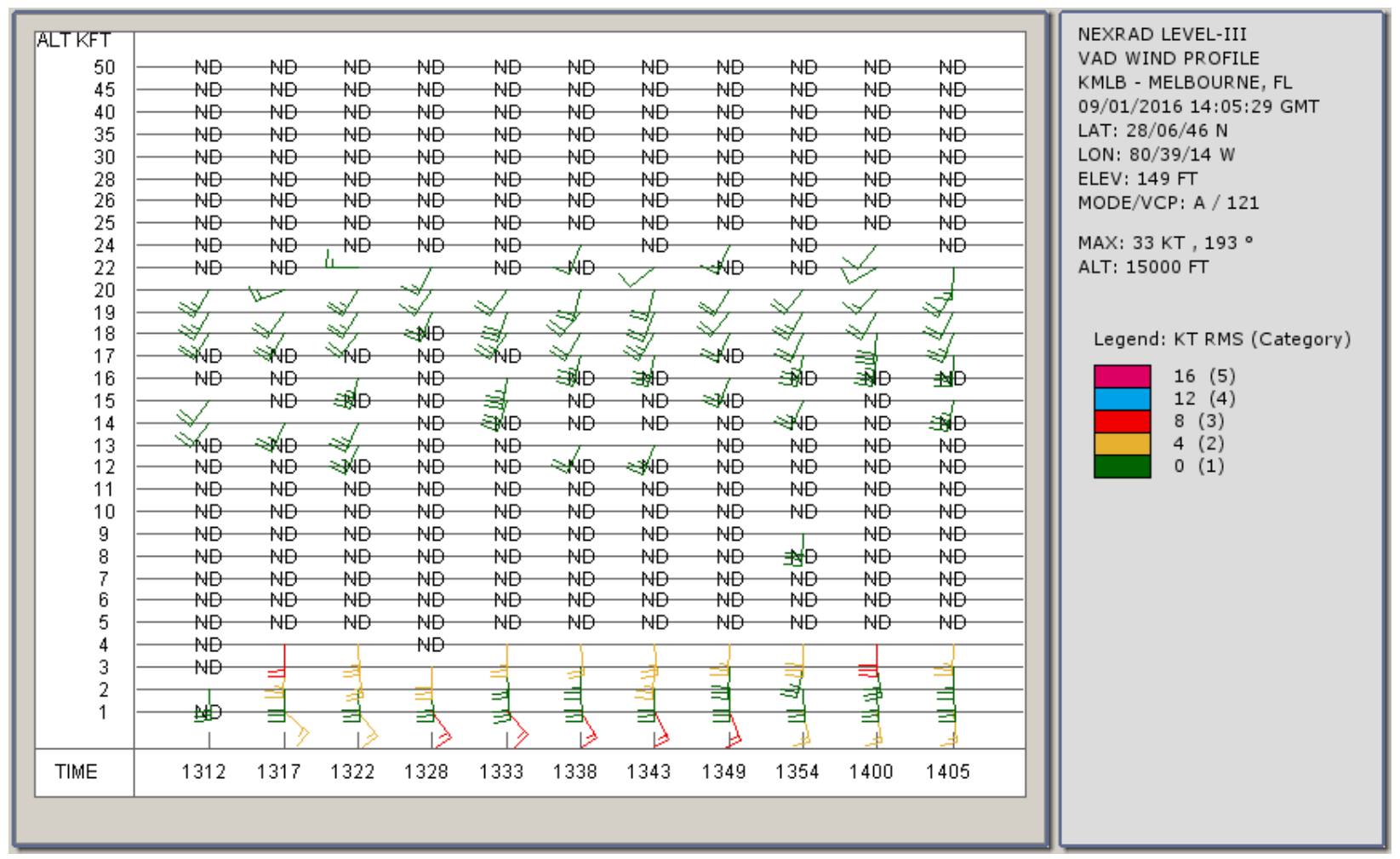

Figure 19. VAD wind profile for the Melbourne, FL radar from 1312 UTC to 1405 UTC on September 1, 2016.

The impact of utilizing VAD wind information can be seen in the cloud rise visualization from DELFIC in Figure 20. Figure 20 (left image) illustrates the cloud growth and advection over the first $7 \mathrm{~min}$ following the explosion. The right image in Figure 20 illustrates the impact of substituting VAD wind information in place of weather model winds. The cloud reaches the same stabilized height (approximately 9,000 $\mathrm{ft}$ AGL); however, the cloud is advected more to the north-northwest during early to middle cloud rise when the VAD wind profile is used.

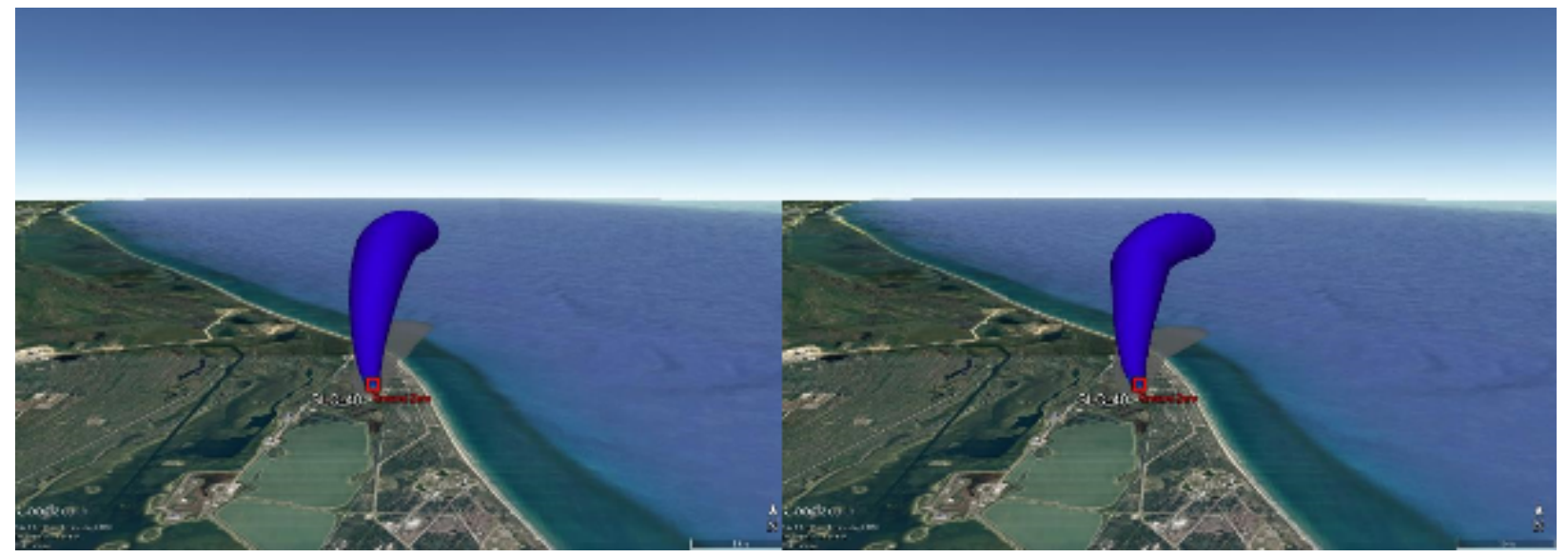

Figure 20. Cloud rise from DELFIC using only weather model data (left) and substituting VAD wind profile data (right).

Incorporation of VAD wind profile data also has an effect on the modeled surface dose field. Figure 18 illustrates the effect that different weather data sources have on modeled deposition/dose calculations. 
Figure 21 illustrates the effect that the VAD wind profile has on the surface dose field. In this example the differences are subtle; however, the surface dose field is shifted slightly more to the west in the case that includes VAD wind profile data as compared to the case using only weather model data. In this case, DELFIC was updated with new wind information every $10 \mathrm{~min}$ (or six observations) over the first hour of the simulation; in contrast, the weather model data did not update in the first hour. This illustrates the point that leads to the second recommendation, that F\&T models should ingest VAD wind profile information to improve transport and deposition calculations.

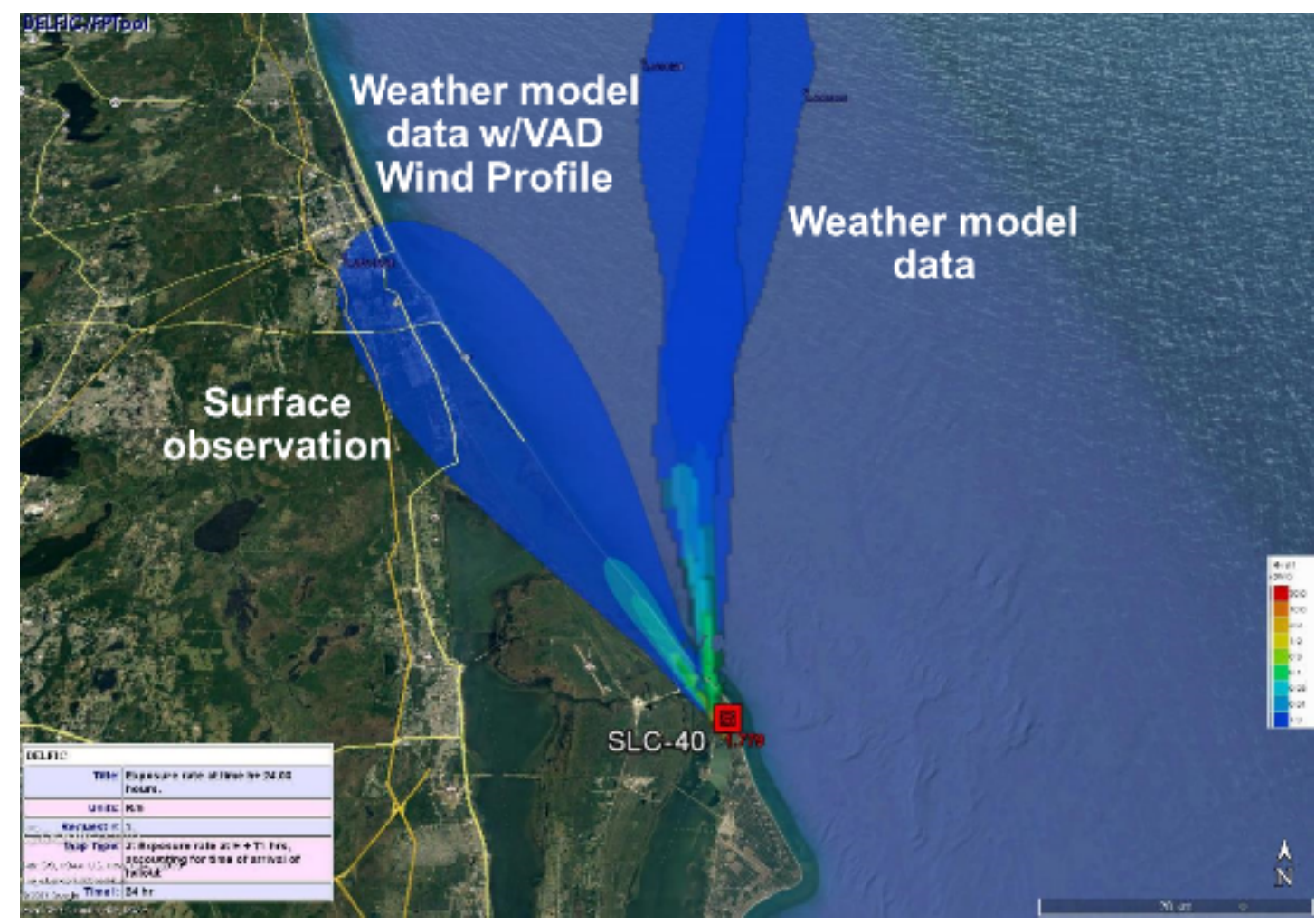

Figure 21. Same as Figure 18 but with the inclusion of the modeled dose field using VAD wind profile data.

Although the VAD wind profile is already an available Level III radar product and is extremely useful, the third recommendation is that research should be conducted to use open-source software for threedimensional radar-derived wind information. One example of this approach could include a Python Py-ART module coupled with the SingleDop library developed by NASA (Helmus and Collins 2016). The SingleDop module interpolates the radial Doppler velocity information to a uniform grid for a given radar beam angle. An interpolation algorithm will need to be developed to calculate three-dimensional wind fields on a regular height grid, rather than utilizing radar-beam-based values (a radar beam's height increases exponentially as it moves radially from the radar site) calculated by Py-ART and SingleDop. A QA/QC methodology must also be developed to ensure calculated results are physically accurate. The strength of this approach is that it takes into account the spatially varying winds (horizontally and vertically) rather than using the single wind profile from the VAD algorithm.

\subsection{OTHER RADAR PRODUCTS}

Lastly, other Level III radar products currently being generated could prove quite useful for inclusion into the decision-making cycle and as part of F\&T model input. For example, the Enhanced Echo Top product provides an indication of a radar return's maximum height above ground. An example of this product is shown in Figure 22. Some of the radar returns from the SpaceX plume are shown to reach a height of 
approximately 9,000 ft AGL, which is about the same height as the stabilized cloud modeled by DELFIC. Another Level III radar product is the Hydrometeor Classification display (Figure 23). This product takes Level II dual-pol radar information and classifies the echoes into bins such as biological, rain, snow, and hail. Currently, a plume is classified as a biological return, but algorithms are being developed and tested to include a "plume" class, as discussed in Section 3.
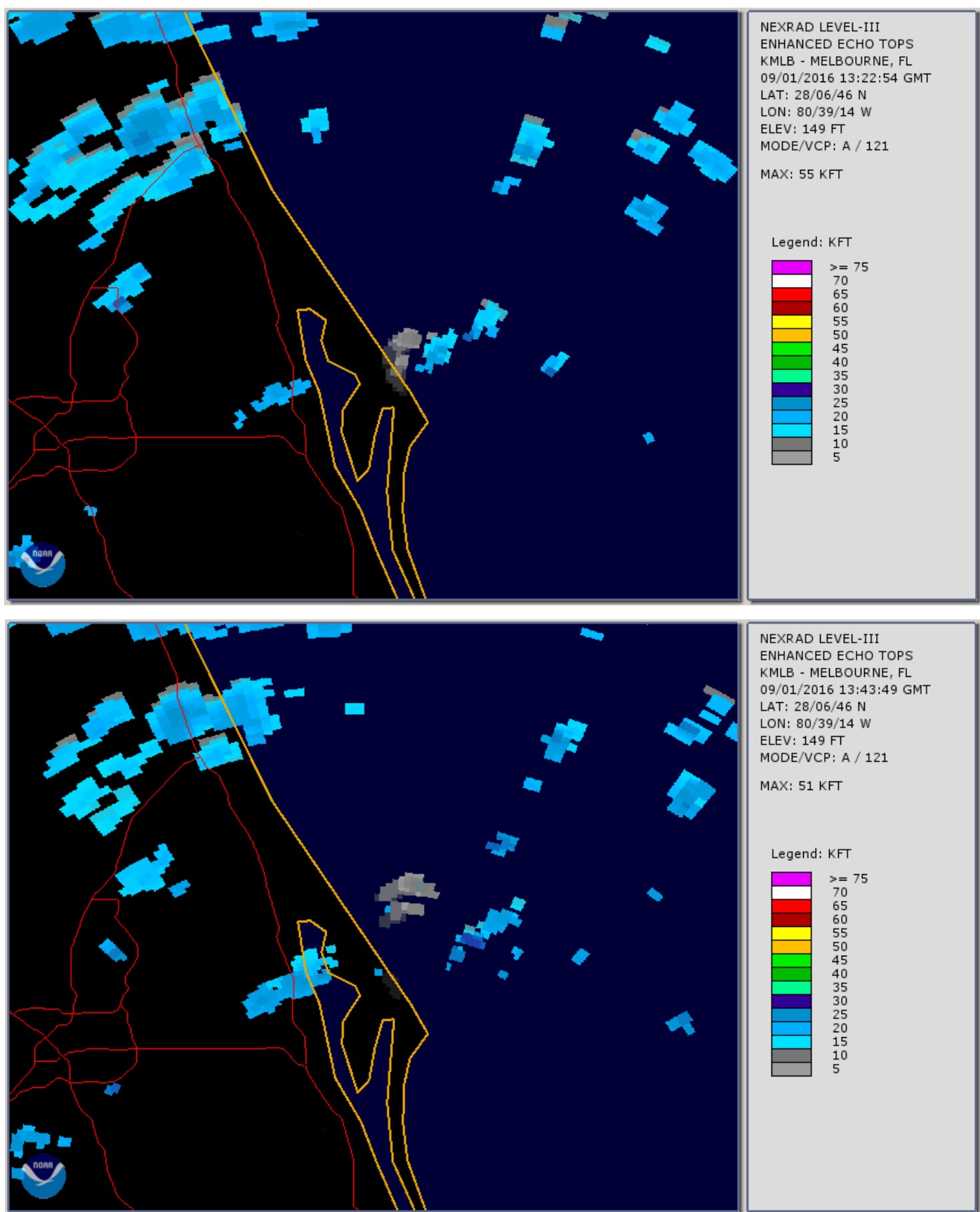

NEXRAD LEVEL-III ENHANCED ECHO TOPS KMLB - MELBOURNE, FL

09/01/2016 13:43:49 GMT

LAT: $28 / 06 / 46 \mathrm{~N}$

LON: $80 / 39 / 14$ W

ELEV: $149 \mathrm{FT}$

MODE/VCP: A / 121

MAX: $51 \mathrm{KFT}$

Legend: KFT

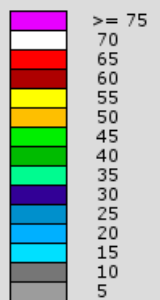

Figure 22. Enhanced Echo Top Level III radar product shown for (top) 1322 UTC and (bottom) 1343 UTC on September 1, 2016. The gray radar returns in the middle of the image depict the maximum height of the plume from the SpaceX rocket explosion, while the blue returns depict rain. 

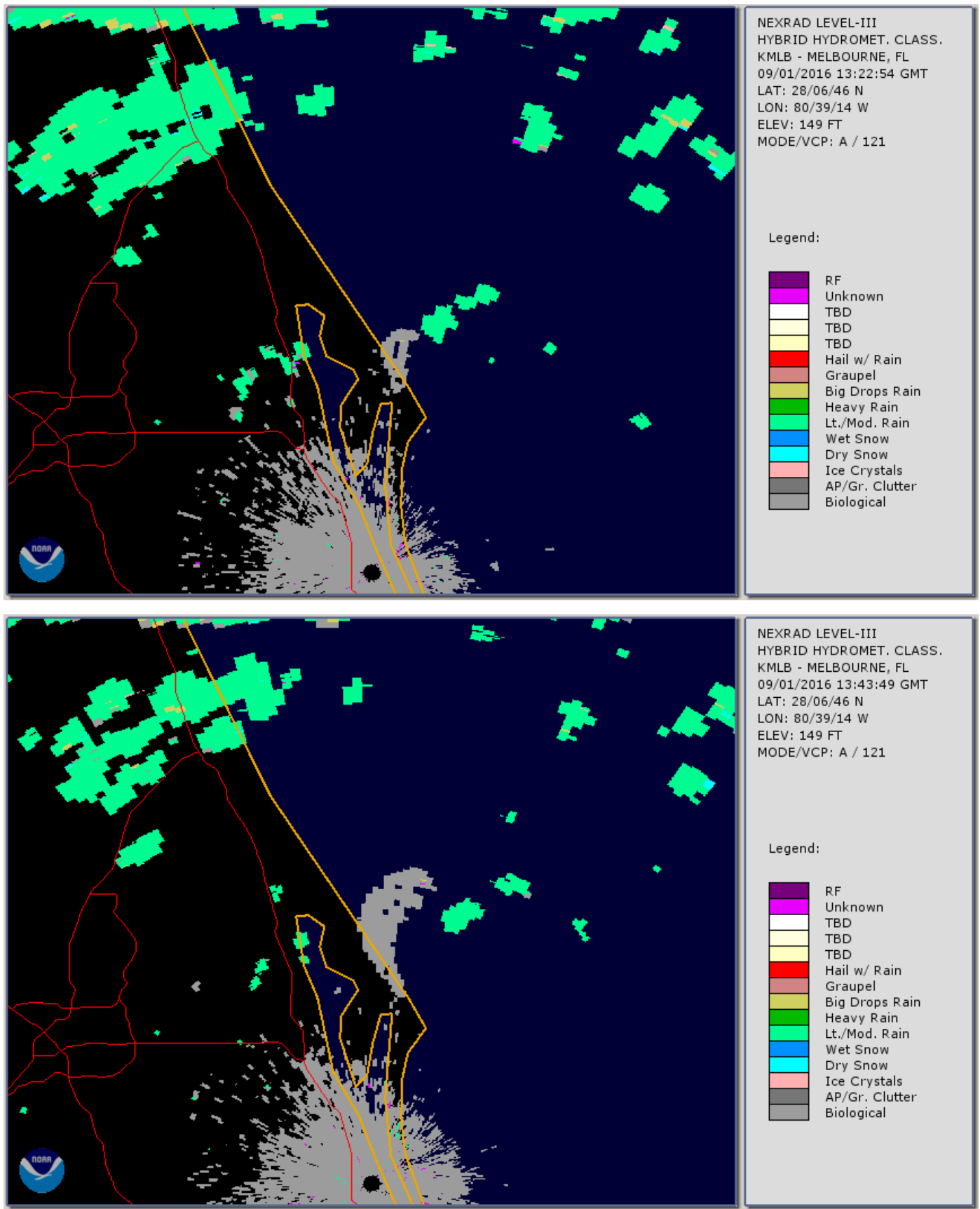

Figure 23. Hydrometeor Classification Level III radar product shown for (top) 1322 UTC and (bottom) 1343 UTC on September 1, 2016. The gray radar returns in the middle of the image depict the plume from the SpaceX rocket explosion classified as "biological" while also showing areas of light-to-moderate rain (light green) in the vicinity of the plume.

\subsection{RADAR DATA CONSIDERATIONS}

Currently, NWS WSR-88D Level II and Level III products are generated at each NWS forecast office after the completion of their radar's full volumetric scan. These data are then sent to the NCEI data servers and made available via Amazon Web Services. Additionally, the data are streamed over NOAAPort and the local data manager (LDM) streams. NOAAPort is a satellite-based data streaming capability in which data flows from various NOAA entities such as NWS and NCEP to a user with 
hardware to receive the near-real-time data feed. The LDM is an internet-based data streaming service that is similar to NOAAPort in that it provides data from NOAA entities in near real time via the internet.

A few options are available for gaining access to additional information from the WSR-88D radars. One option is to install a processor at the location of the radar product generator (RPG) at the NWS forecast office, ingest the Level II data, and apply to a plume detection algorithm (PDA). Currently, an operational PDA algorithm does not exist, but one possibility of such an algorithm is discussed in Section 4.2.

The other possibility is to transmit the data from the RPG location to a location specified by the US Department of Homeland Security and process the data there. If the PDA is on a workstation collocated with the RPG, it may be possible to obtain additional RPG data that could be incorporated into the PDA algorithm. For example, the polarimetric data are pre-processed in the RPG. Pre-processing involves filtering of the Level II data, adding quality indexes, and generating texture parameters of differential reflectivity and differential phase, among others. These have been intensely vetted by the NWS and are one step behind the best that science can offer. Over time, the NWS will change how it pre-processes the data on the basis of findings and suggestions by research organizations such as the National Severe Storms Laboratory/Cooperative Institute for Mesoscale Meteorological Studies (NSSL/CIMMS) and the National Center for Atmospheric Research. This will improve the data's quality and usefulness.

A potentially important aspect for the PDA could be to use the existing NWS algorithm, which separates the data into "meteorological" and "non-meteorological." This algorithm, called MetSig (Krause 2016), exists on the RPG and continues to improve and evolve over time. A potential scenario could include the PDA taking the non-meteorological data (the "Non MetSig)" and within these Non MetSigs, search for the plume signatures. In addition, the PDA would use the pre-processed data and could take into account spatial continuity, height above ground, and other attributes of interest. The advantage of this approach is the savings in long-term labor costs for maintaining a good part of the algorithm. Further, the latest and best of the pre-processing would be automatically added as the NWS makes upgrades (planned at about 6 month intervals). For this option, NWS would have to provide the pre-processed data, which would be a one-time and relatively small effort to make such a stream available.

\subsection{USE OF RADAR IN MODELING RECOMMENDATIONS}

Fate and transport models, a valuable tool in emergency management during the early phases of an event, have potentially significant uncertainty in both the source terms and the meteorological conditions. Radar measurements can provide valuable information to early model generation to reduce this uncertainty. Work must be done, however, to incorporate radar measurements into the decision process and for utilization by F\&T models. The first recommendation is to adopt a validation step within the current operational procedures in which model output is compared to radar-derived plume information. This will allow for a qualitative QA/QC step to ensure that model results do not deviate significantly from observations. The second recommendation is that F\&T models should ingest radar-derived VAD wind profile information to improve transport and deposition calculations. VAD wind profiles are calculated at the conclusion of the radar's full volumetric scan. Typically, these scans are completed every 5 to $10 \mathrm{~min}$, meaning new wind profile data are available every 5 to $10 \mathrm{~min}$. The timeframe of available data generated by the radar exceeds that of surface-based weather observations (available every hour), weather balloon observations (available every 12 hours), or weather model data (a new model run every 6 hours with hourly model output). By ingesting VAD wind profile data, the F\&T model is assured of having observed data from the plume. The third recommendation is to conduct research to utilize open-source software that allows F\&T models to efficiently use three-dimensional radar-derived wind information. Open-source options are available to read WSR-88D and TDWR data and interpolate a three-dimensional wind field. This method would enable the use of spatial Doppler wind measurements from the radar, to obtain more localized information about the plume. 


\section{RADAR COVERAGE GAP ANALYSIS}

To be of value, radars need to "see" plumes of interest in emergency management. Considering urban and terrain effects, radars could be effective at measuring plumes above heights of $1,640 \mathrm{ft}(500 \mathrm{~m})$ or lower in specific applications.

\section{Recommendations:}

1. Perform a radar coverage analysis for all urban areas of interest to determine the height at which aboveground coverage exists and if the coverage is appropriate for areas of interest.

2. Assess modifications to existing radars and their scanning setups, or determine alternative radar systems whose deployment could close current radar coverage gaps.
A planning consideration for the use of radar to detect, measure, and track plumes is the radar's coverage area. Coverage area is influenced by factors such as radar type, beam angles, and scanning strategies. In tracking plumes, this study considered a range of plume heights, from less than $1000 \mathrm{ft}$ AGL, to tens of thousands of feet AGL. For plumes less than $1000 \mathrm{ft} \mathrm{AGL}$, terrain, urban environment (building heights), and distance from the radar all must be considered. Further, for plume detection, the radar type (wavelength and sensitivity) must also be considered.

This study investigated both NEXRAD and TDWR Doppler radar coverage of a representative urban area for suitability in detecting smoke plumes. WSR-88D has an advantage over TDWR in that it is dual-pol radar. The number of WSR-88Ds nationally deployed is greater than the number of TDWRs, about 160 WSR-88Ds compared to 47 TDWRs. The TDWR's advantages are its smaller beam width ( 0.5 degree vs 1 degree), more rapid update of the lowest elevation scans (on average $\sim 1 \mathrm{~min}$ ), and better detection capability ( $-26 \mathrm{dBZ}$ at $10 \mathrm{~km}$ vs $-21 \mathrm{dBZ}$ ) in the typical operation mode.

\subsection{LINE-OF-SIGHT COVERAGE ANALYSIS}

In both radar systems, the antenna sweeps the surrounding environment fully in azimuth but only at prescribed elevation angles. The current minimum elevation angle for Doppler operation in both radars is 0.5 degree. Although the TDRW radar can mechanically scan at the lower elevation angle of 0.1 degree, Doppler operation utilizes the 0.5 degree limit. This tilt means that returns come from an increasing height above ground level as range increases. A series of coverage maps presented here for Washington, DC show, for a given plume height, the maximum distance from the radar the plume could be and still be intercepted by the radar beam. The maps consider radar antenna position and height and use Level 0 Digital Terrain Elevation Data with average terrain height posted every 30 seconds $(\sim 900 \mathrm{~m})$. 
NEXRAD and TDWR radars have nominal Doppler ranges of 230 and $90 \mathrm{~km}$, respectively. Figure 24 shows both the NEXRAD and TDWR radars within a $230 \mathrm{~km}$ radius of Washington, DC. For typical smoke plumes up to $1 \mathrm{~km}$ in height, only KLWX, TDCA, TIAD, TADW, and TBWI radars will be useful for plume detection. Other radars farther out will have beam heights too great.

A line-of-sight tool was used in a geographic information system package to calculate the beam height above ground level for each of the five radars listed above. Four beam heights were considered: 250 $\mathrm{m}, 500 \mathrm{~m}, 750 \mathrm{~m}$, and $1 \mathrm{~km}$. Figure 25 shows the result for the KLWX radar, which is a NEXRAD system located in Sterling, VA near Dulles International Airport. This plot shows that a plume at least $500 \mathrm{~m}$ high will be detected in a portion of the District, while plumes $750 \mathrm{~m}$ and $1 \mathrm{~km}$ high will be seen over the entire District. Shorter plumes within the District will not be seen by this radar. The shadow area to the southwest is caused by the Bull Run Mountains.

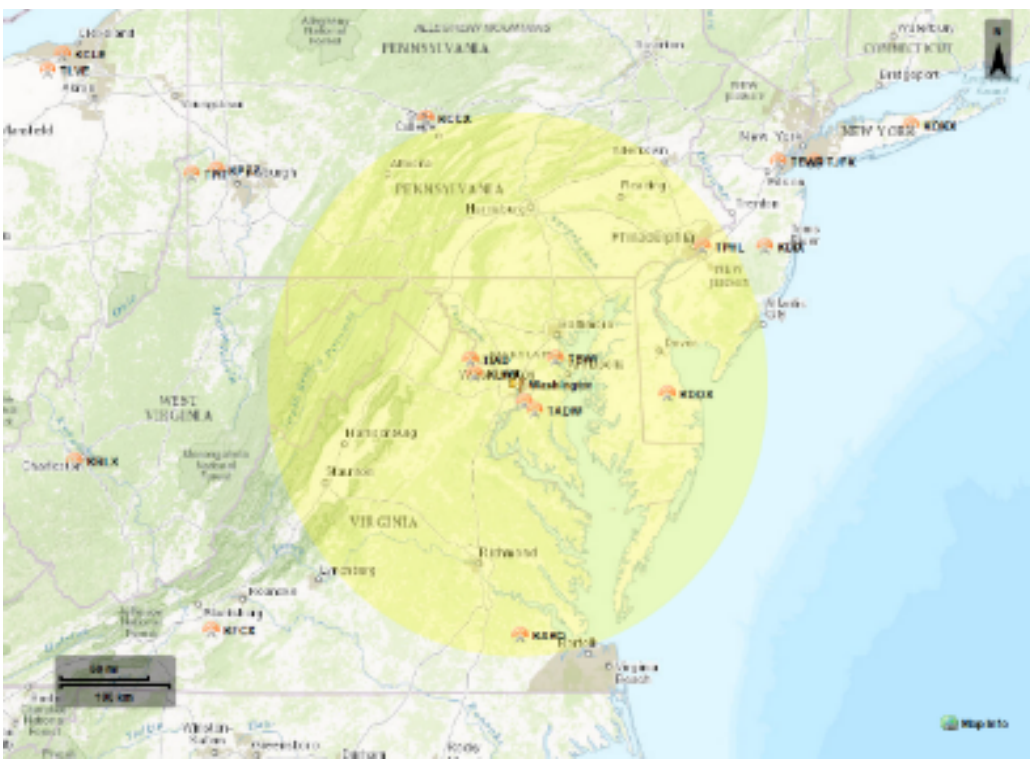

Figure 24. NEXRAD and TDWR radar locations within a $230 \mathrm{~km}$ radius around Washington, $\mathrm{DC}$.

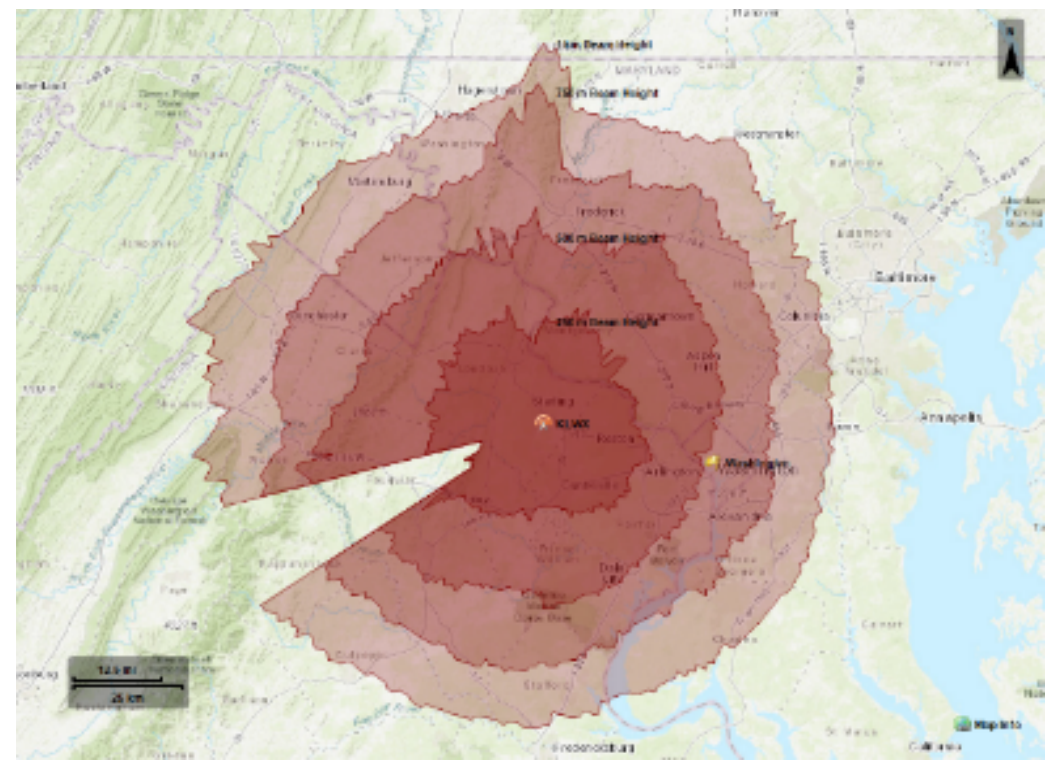

Figure 25. KLWX beam height contours. 
TDCA is a TDWR located at Reagan National Airport. Figure 26 shows the same four beam height contours. A plume height of $250 \mathrm{~m}$ will be seen only in the southeastern part of the District while plume heights of $500 \mathrm{~m}$, $750 \mathrm{~m}$, and $1 \mathrm{~km}$ will be detected over the entire District. The smoothness of the $750 \mathrm{~m}$ and $1 \mathrm{~km}$ beam height contours to the east is due to the flat terrain.

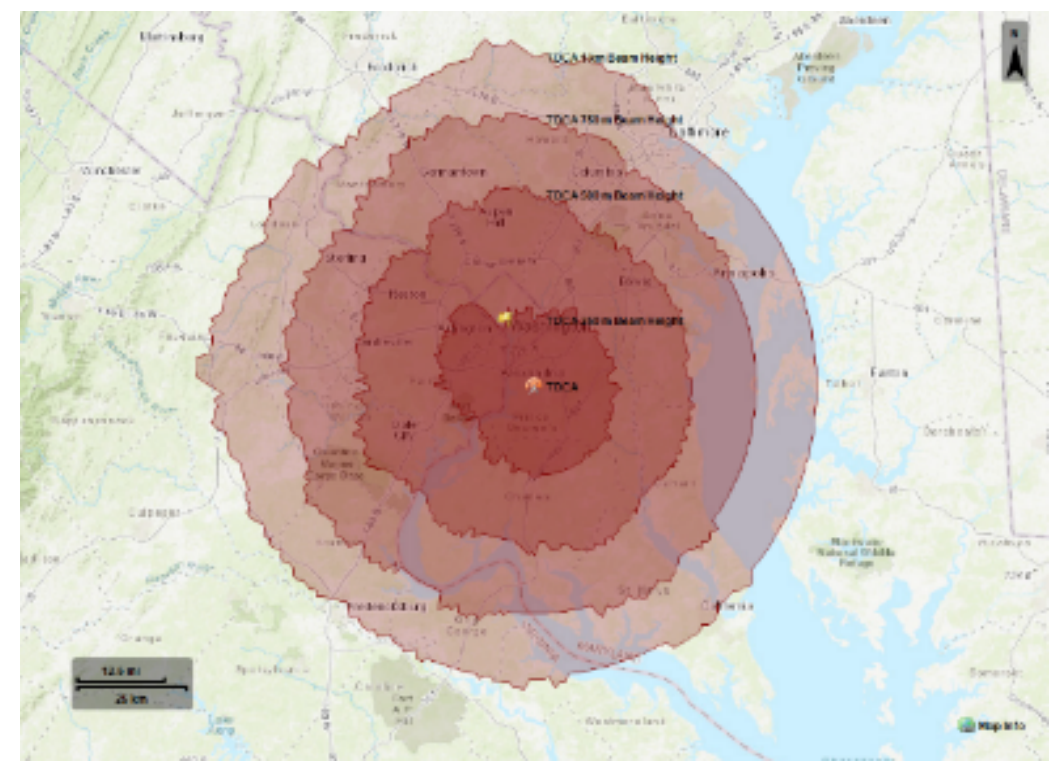

Figure 26. TDCA beam height contours.

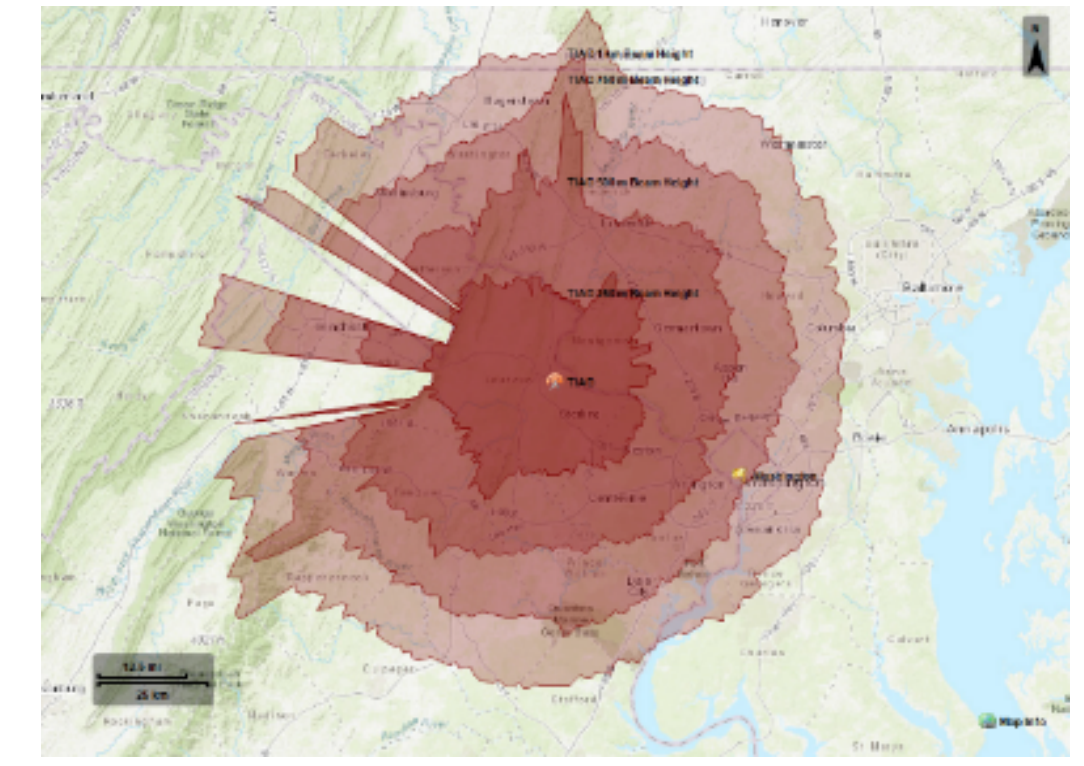

Figure 27. TIAD beam height contours.

The next TDWR to be inspected is TIAD located at Dulles International Airport. Figure 27 shows the contours. In this case a $750 \mathrm{~m}$ plume will be seen for about half of the District while a $1 \mathrm{~km}$ plume will be seen for all of it. The shadow to the northwest is caused by a line of ridges along the Virginia-West Virginia border. 
TADW is located at Andrews Air Force Base southeast of and close to TDCA at Reagan National Airport. Coverage is similar to TDCA, as shown in Figure 28. Plumes that are $500 \mathrm{~m}, 750 \mathrm{~m}$, and $1 \mathrm{~km}$ high would be detected over the entire District.

The last radar to be inspected is TBWI located at BaltimoreWashington International Airport. Figure 29 presents the beam height contours for this radar. Here the $500 \mathrm{~m}$ contour covers only the northeast portion of the District, while the $750 \mathrm{~m}$ and $1 \mathrm{~km}$ contours cover the entire District.

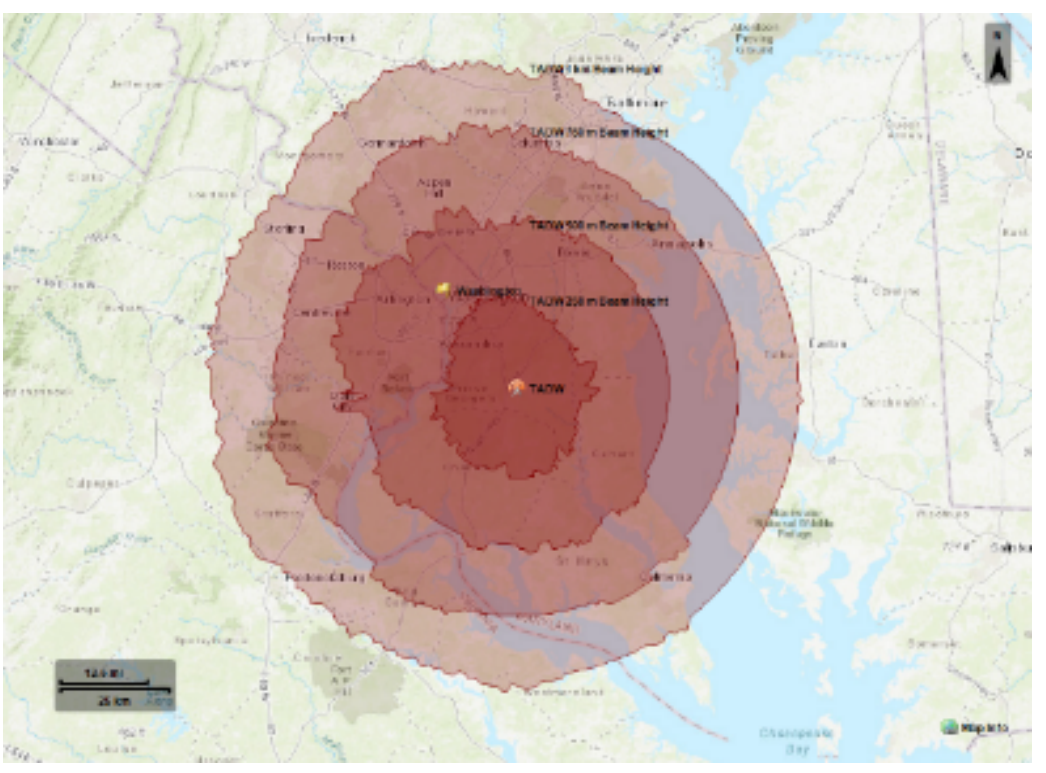

Figure 28. TADW beam height contours.

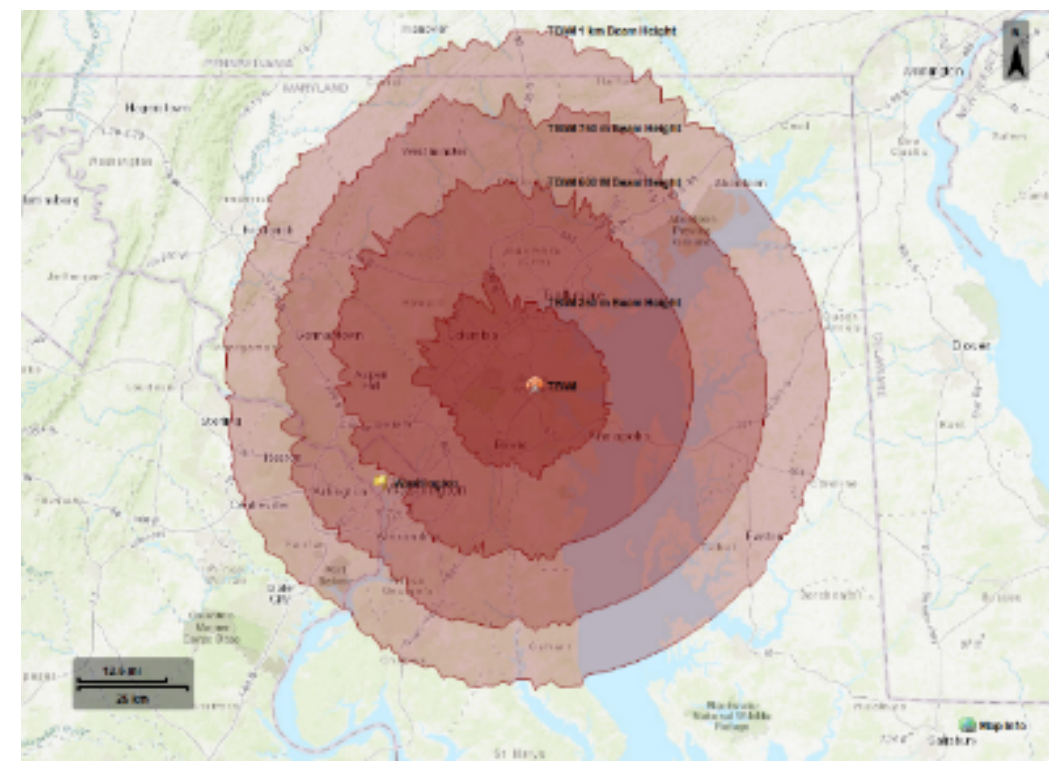

Figure 29. TBWI beam height contours. 
Figure 30 shows a composite map for the $500 \mathrm{~m}$ contours. In this case, at least one of the radars will see a plume of this height. It should be noted that both TDCA and TADW are capable of this alone, each covering the entire District.
While tall plumes are well covered by all the radars inspected, only a few of them will detect shorter plumes. Figure 31 shows the $250 \mathrm{~m}$ contour for all the radars in this study. Only a small portion of the District is covered by the TDCA radar.

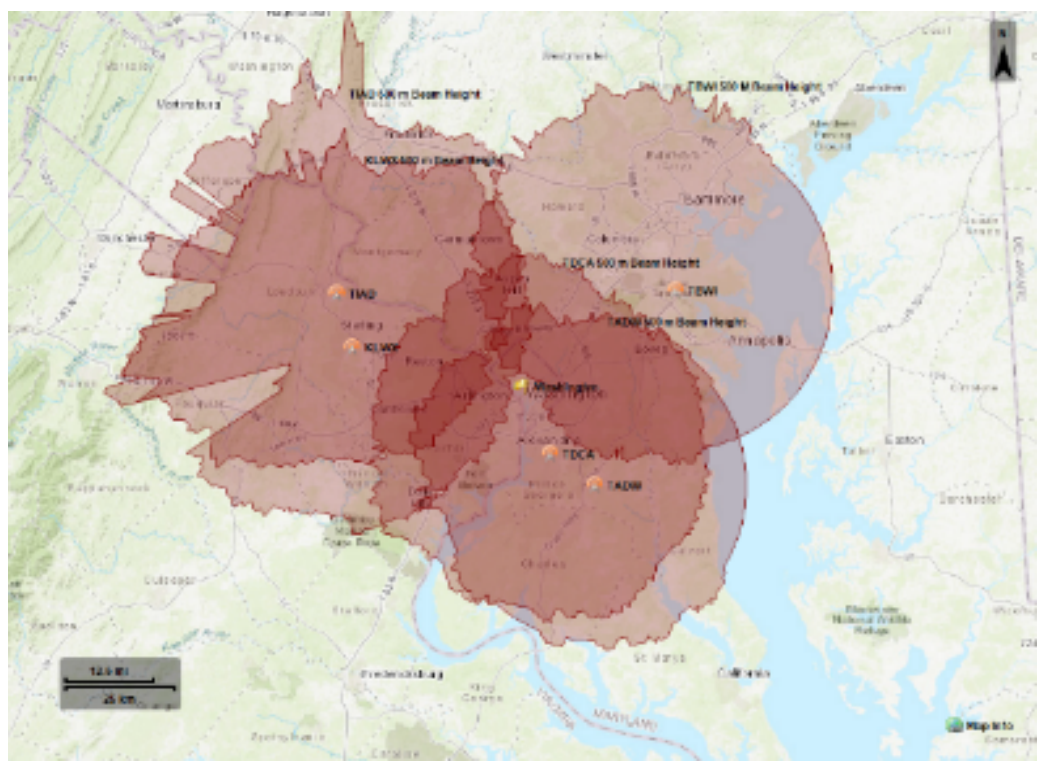

Figure 30. A 500 m contour composite.

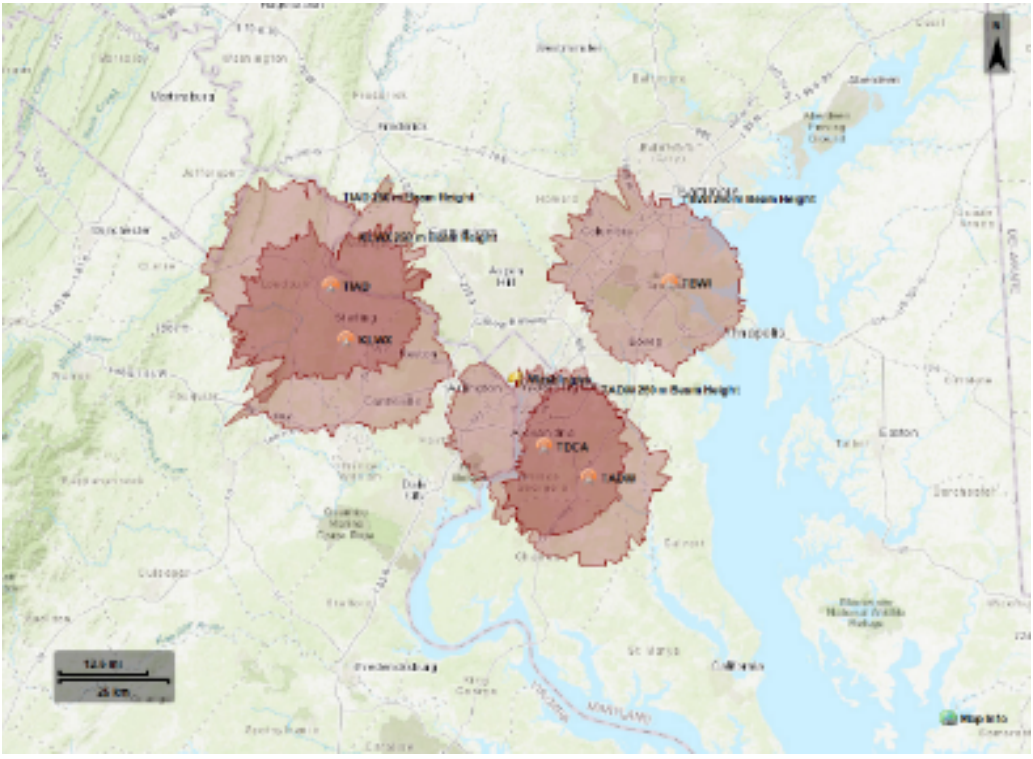

Figure 31. A 250 m contour composite. 
None of the radars in this study would be capable of detecting a shorter plume in the District. The tallest buildings are on the order of $100 \mathrm{~m}$, excluding the Hughes Memorial (radio) Tower at $232 \mathrm{~m}$ and the Washington Monument at $169 \mathrm{~m}$. Using $100 \mathrm{~m}$ as a guide, the beam contours for the five radars is shown in Figure 32. To detect plumes of $100 \mathrm{~m}$, additional radar systems would need to be deployed.

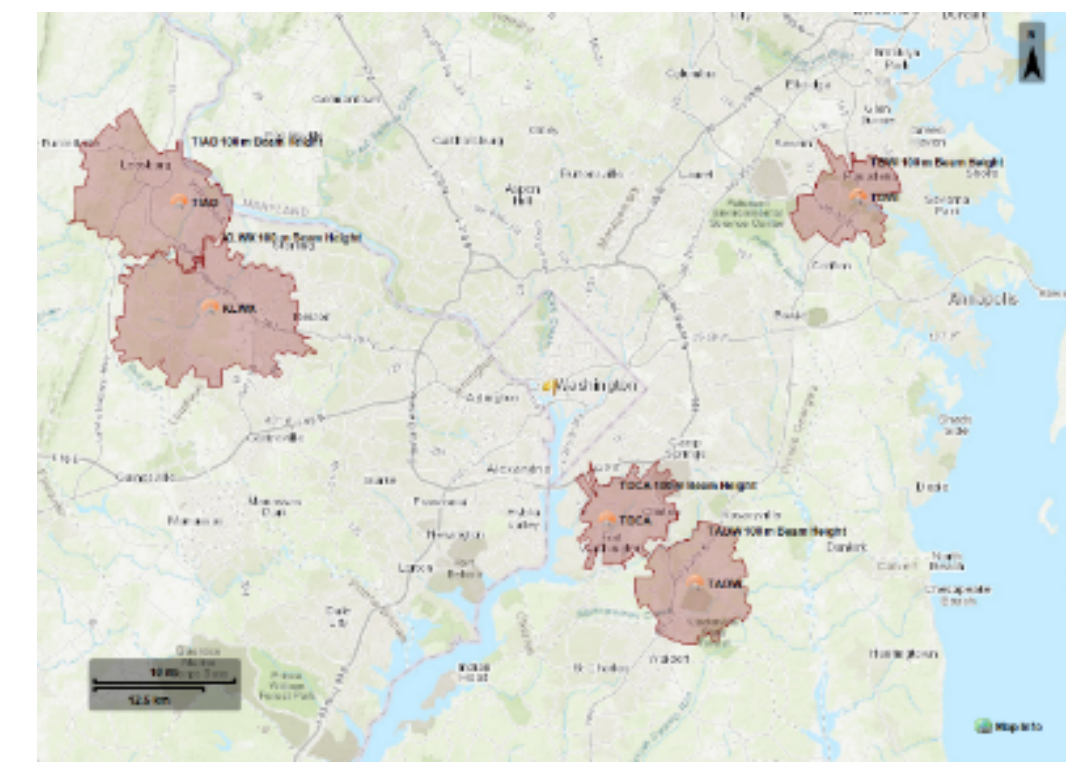

Figure 32. A 100 m contour composite.

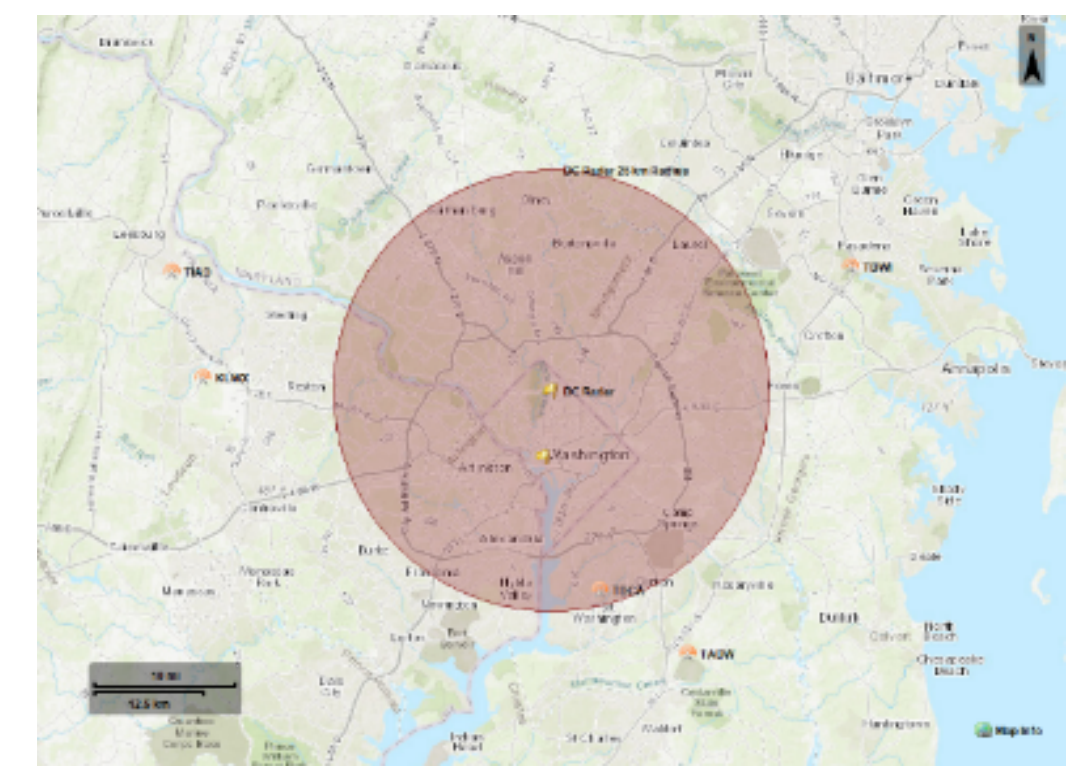

Figure 33. Example coverage for a $100 \mathrm{~m}$ plume.

If a new radar were co-located with the Hughes Memorial Tower on Washington Police Department property at a height of $100 \mathrm{~m}$ with no antenna tilt and a range of $25 \mathrm{~km}$, the entire district could be covered for short plumes of at least $100 \mathrm{~m}$ in height as shown in Figure 33. Additionally, radars with a wavelength ranging from $3 \mathrm{~cm}$ to $10 \mathrm{~cm}$ (X-through S-band), a minimum reflectivity threshold of less than $-15 \mathrm{dBz}$, and ample power are most appropriate for plume detection and tracking.

\subsection{RADAR BEAM COVERAGE ANALYSIS}

An experiment was conducted on July 4, 2017 in Norman, OK to observe and document the radar return from the fireworks at Reeve Park. Figure 34 shows the location of radars during this experiment. The TDWR radar, which serves the Will Rogers airport in Oklahoma City, is located $11.25 \mathrm{~km}$ from Reeve Park, where fireworks are held every Fourth of July. To obtain additional measurements, a 3-cmwavelength NSSL radar (XEREX) was positioned about $1.5 \mathrm{~km}$ south of the park. A video camera was also employed for visual confirmation of the events. Polarimetric data were anticipated from the 10-cmwavelength KOUN radar, which is NSSL's WSR-88D located about $6 \mathrm{~km}$ from the park; however, the radar experienced a technical issue and data were not obtained. Inspection of data from the KTLX (operational WSR-88D) radar did not find obvious returns from the fireworks. 
Data were collected with the $3 \mathrm{~cm}$ polarimetric radar starting at about 2 degrees elevation and ending close to 10 degrees. The sector scans were taken at about 35 degrees. The pulse repetition time was $1 \mathrm{~ms}$ with 32 samples taken per one degree in azimuth, making the rotation rate about 31 degrees per second. The event lasted about 15 min with data collected throughout.

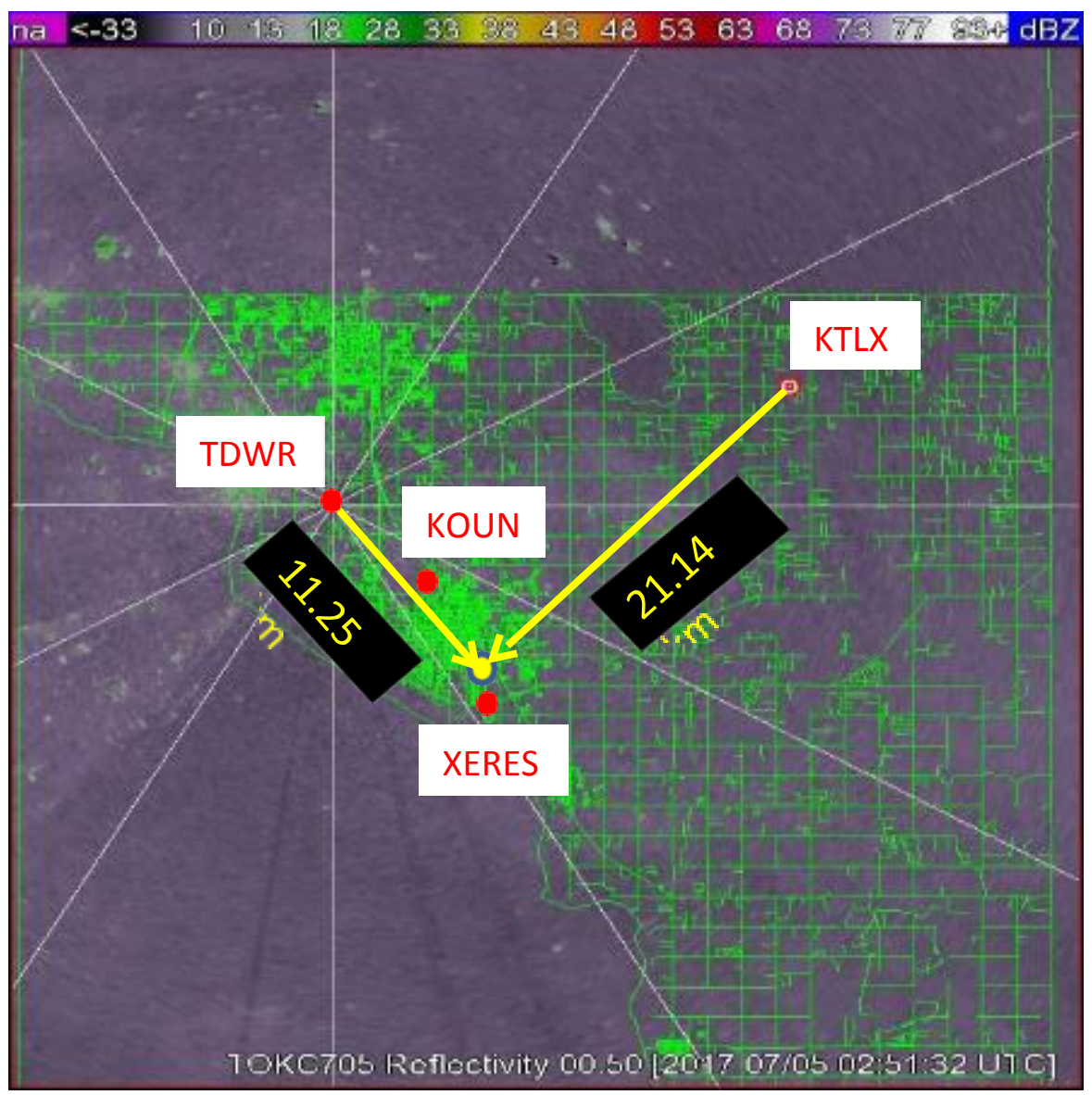

Figure 34. Location of radars during the experiment of July 4, 2017 in Norman, OK. The location of Reeve Park is indicated with the yellow dot.

The reflectivity at 9.85 degrees elevation (Figure 35) shows some returns mainly from insects and objects close to the ground. The height above ground at the $1.5 \mathrm{~km}$ range at this elevation is about $250 \mathrm{~m}$ and the fireworks did not exceed $200 \mathrm{~m}$, thus there is no evidence in Figure 35 of smoke or debris. The background reflectivity is less than about $-6 \mathrm{dBZ}$. Seven seconds later at the 3.83 degree elevation (height above ground is $100 \mathrm{~m}$ ), there is clear evidence of an increase in reflectivity, with the maximum between 22 and $26 \mathrm{dBZ}$ in the patch centered at about $1 \mathrm{~km}$ north of the radar. The patch persisted in consecutive scans and coincides with the location of the fireworks' launch. Throughout the event, the patch intensified and decayed but did not exceed $26 \mathrm{dBZ}$ in reflectivity. New maxima formed and drifted with the wind. The highest elevation at which we detected the faint presence of a firework signature was 8.8 degrees, corresponding to beam center at about $230 \mathrm{~m}$ above ground. The reflectivity factor at this height was less than $10 \mathrm{dBZ}$, suggesting that the fireworks were in the lower part of the beam. Based on this observation, it was estimated that scatterers contributing to this return were about $200 \mathrm{~m}$ AGL. This is estimated from the maximum reflectivity value of $26 \mathrm{dBZ}$ at beam center (at lower elevations) minus the $10 \mathrm{dBZ}$ at the lower part of the beam (at the elevation of 8.8 degrees). If the $16 \mathrm{dBZ}$ difference is due solely to the antenna pattern, the scatterers would be about 0.8 degree away from beam center, that is, at 
about 8 degrees, which puts them at 200 m AGL. Only on few occasions were echoes seen at a high altitude, as most of the strongest returns were observed at about $100 \mathrm{~m}$ AGL.
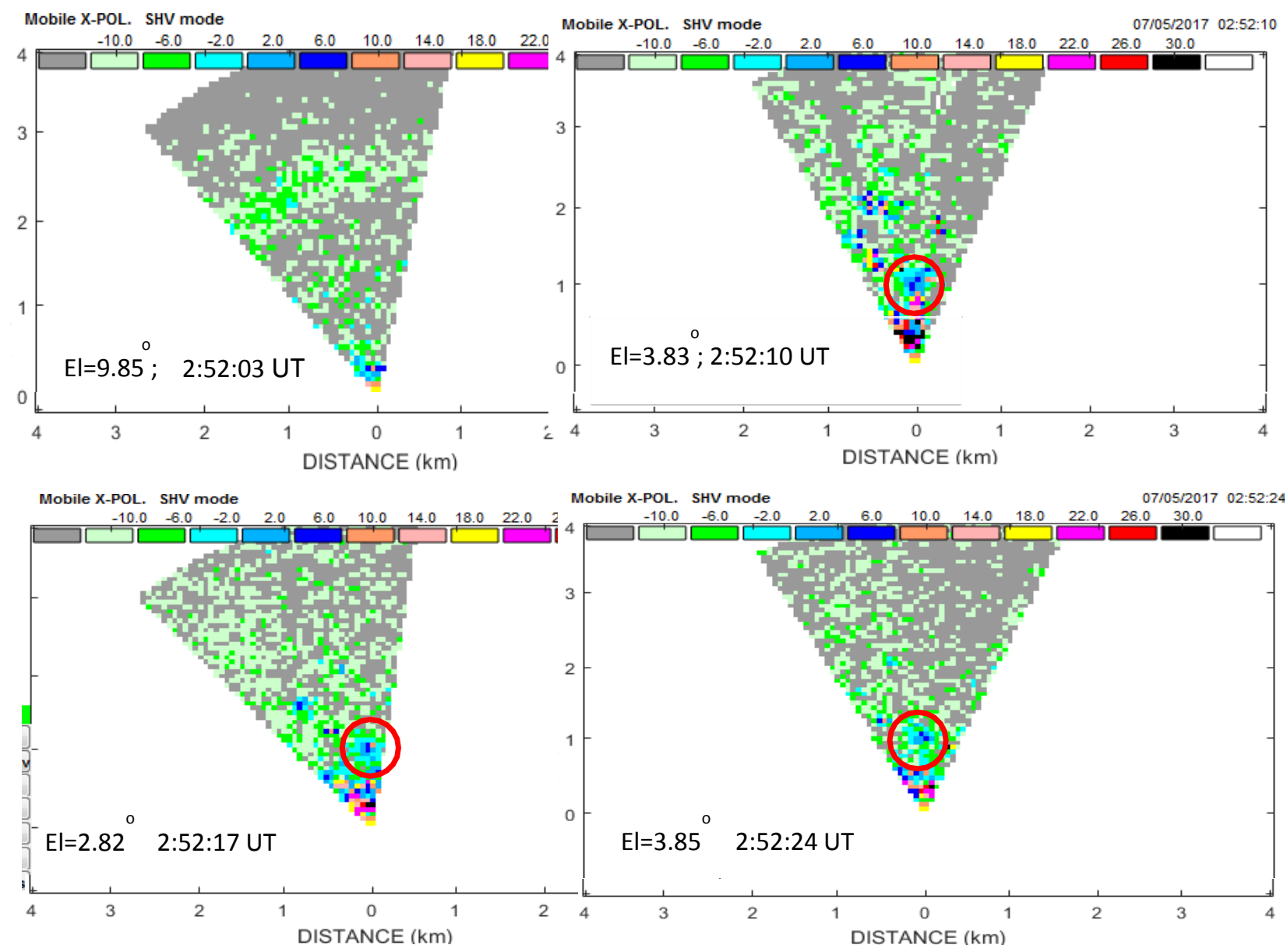

Figure 35. Reflectivity obtained on July 4, 2017 (July 5 UTC) with the XERES (3 cm wavelength) dualpolarization radar. The red circle indicates the fireworks signal. Elevation angles and times (UTC is 5 hours ahead of the local time) are shown.

The polarimetric variables $Z_{\mathrm{DR}}$ (differential reflectivity) and $\rho_{\mathrm{hv}}$ (differential phase) have no discernible features associated with the fireworks (Figure 36). This is likely caused by the presence of insects that produce values similar to the ones from the fireworks. 


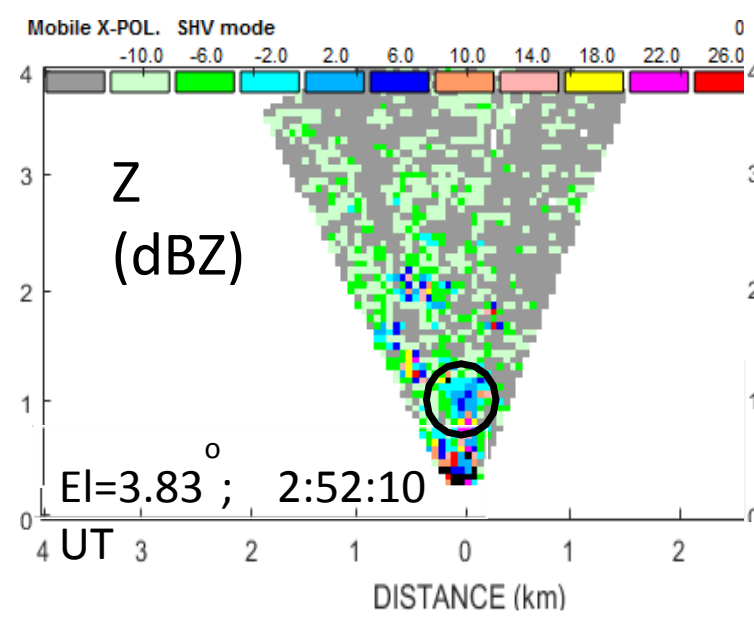

0 Mobile X-POL. SHV mode
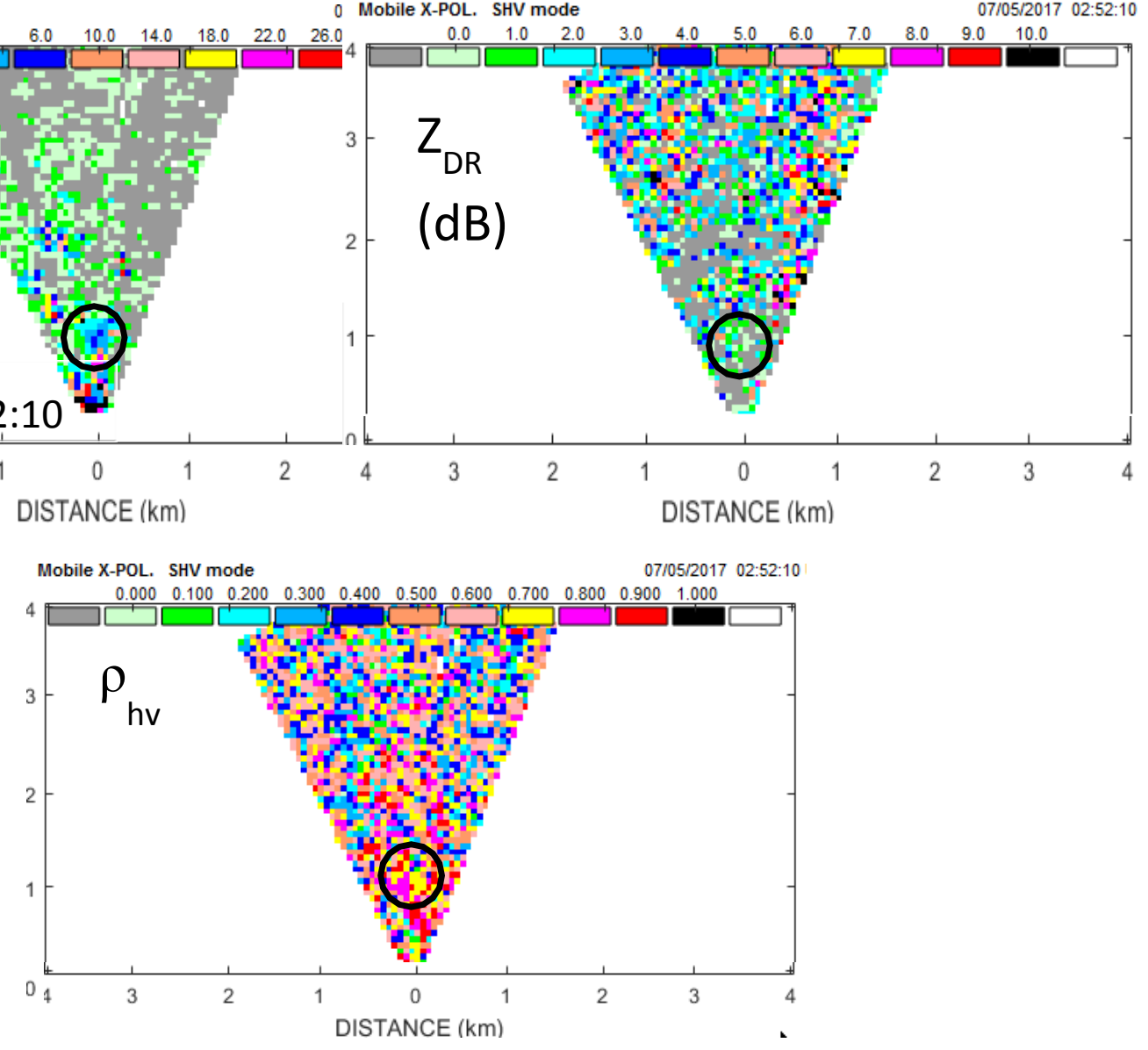

Figure 36. The field of reflectivity factor $(Z)$, differential reflectivity $\left(Z_{\mathrm{DR}}\right)$, and correlation coefficient $\rho_{\mathrm{hv}}$ at the elevation angle of 3.83 degrees and about 2:52:10 UTC, local time 9:52 pm on July 4, 2017.

Lack of observation of the fireworks by KTLX is attributed to the 5 min sparse temporal sampling and to a beam height greater than $200 \mathrm{~m}$ AGL.

Last, the reflectivity field (Figure 36) obtained with the TDWR radar (location shown in Figure 34) for the Oklahoma City airport was analyzed. Prior to the start of the fireworks (at 2:39 UTC), there was no evidence of returns from the fireworks location. After the start of fireworks, the TDWR detected echoes at the correct location until the end of the event. As shown in Figure 37, four images were taken 6 min apart. The scan pattern consisted of volume updates at 6 min intervals in which two scans at 0.5 degree elevation were repeated. These repeated scans are not shown here as they are redundant. The maximum reflectivity is $20.5 \mathrm{dBZ}$, and there are no clear features in the velocity and spectrum width field that could be associated with the fireworks. 

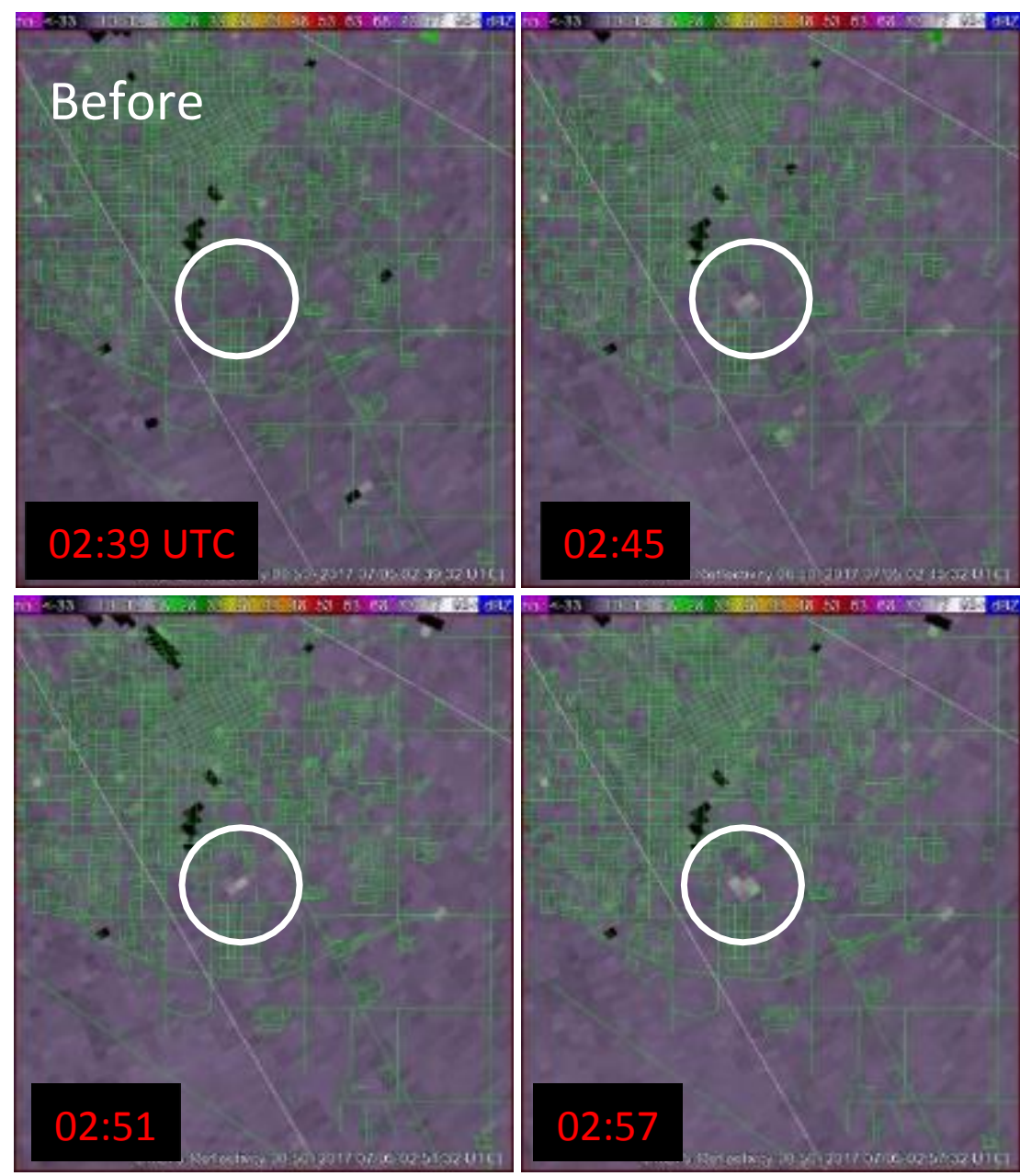

Figure 37. Reflectivity field obtained from the TDWR radar on July 4, 2017 (July 5, according to UTC), at three different times. Elevation angle is 0.5 degree.

\subsection{COMMERCIAL SOLUTIONS TO OPERATIONAL COVERAGE GAP}

A handful of companies produce small radar systems that are marketed as "gap filling" radar systems. Such radars typically operate in the X- or C-band and can be mounted on anything from a tripod to a vehicle to a pedestal/tower. Nominally, a small X-band radar capable of covering a horizontal distance out to $75 \mathrm{~km}$ costs approximately $\$ 200 \mathrm{~K}$. These radars are not dual-pol capable but can detect the wind field via Doppler measurements. Mid-range systems cost approximately $\$ 500 \mathrm{~K}$ to $\$ 600 \mathrm{~K}$ and add dualpol capability. Since these radars are slightly larger than the lower cost radars, they can detect at greater distance and have increased spatial resolution. The largest systems cost $\$ 800 \mathrm{~K}$ to $>\$ 1 \mathrm{M}$ and are usually mounted on a pedestal or tower. The distance necessary to fill the coverage gap, resolution of the measurements, dual-pol capability, Doppler capability, and mounting options must all be assessed before recommending a particular system for purchase and deployment to fill coverage gaps.

\subsection{RADAR COVERAGE RECOMMENDATIONS}

To be of value, radars need to "see" the plume of interest so that emergency management can make informed decisions based on radar observations. Considering urban and terrain effects, radars could be effective at measuring a plume above $1,640 \mathrm{ft}$ ( or $500 \mathrm{~m}$ ) or lower in specific applications. The fourth recommendation from this study is to perform a radar coverage analysis for all urban areas of interest to 
determine at what height above ground coverage exists. Additionally, an assessment should be conducted to determine if the coverage of current radar systems is appropriate for these areas of interest. The fifth recommendation is to assess potential modifications to existing radar system parameters and their volume coverage patterns. An assessment also should be made to identify alternative radar systems that could be deployed to close the current radar coverage gap. Additionally, consideration should be given to the feasibility of utilizing plume detection capabilities aboard NOAA's new Geostationary Operational Environmental Satellite (GOES) satellites.

\section{PLUME IDENTIFICATION, TRACKING, AND CHARACTERIZING}

Though optimized for meteorological applications, current weather radars detect particulate plumes and provide valuable information for decision makers and modeling efforts. Development or modification of algorithms specific to particulate plumes could realize significant improvements with little effort.

Recommendations:

1. Improve the Hydrometeor Classification Algorithm (HCA) currently used operationally by the National Weather Service to include a "plume" class.

2. Conduct research into determining what falls out of a plume, such as different-sized material or constituents, and fall rates.

3. Assess the ability of radar to track nonparticulate plumes such as aerosols and gases.

4. Develop the optical properties of different chemicals, particles, and gases of interest.
This feasibility study focused on data from NEXRAD and TWRD radar systems due to their widespread coverage and data availability. These systems, however, are optimized for meteorological application and not measurement of particulate plumes, though they still detect and measure these non-meteorological events. A number of plume events were reviewed to understand (1) the full potential of radars if optimized for measurement of particulate plumes and (2) the adjustments to existing radar capabilities that could be made to improve plume measurements.

\subsection{DATA ANALYSIS}

An analysis of a wildfire case is presented to illustrate the capabilities and issues. The Little Bear fire occurred in New Mexico near Ruidoso on June 8, 2012 and was started by lightning strike. The fire quickly progressed, burning 44,330 acres and consuming 254 buildings. Fire progression over 1 hour is mapped in Figure 38, with corresponding satellite images in Figure 39 and fields of polarimetric variables in Figures 40 through 42 . These fields were obtained by the Holloman weather radar (WSR-88D designated as KHDX). Figure 43 shows the polarimetric fields in the fire areas. 


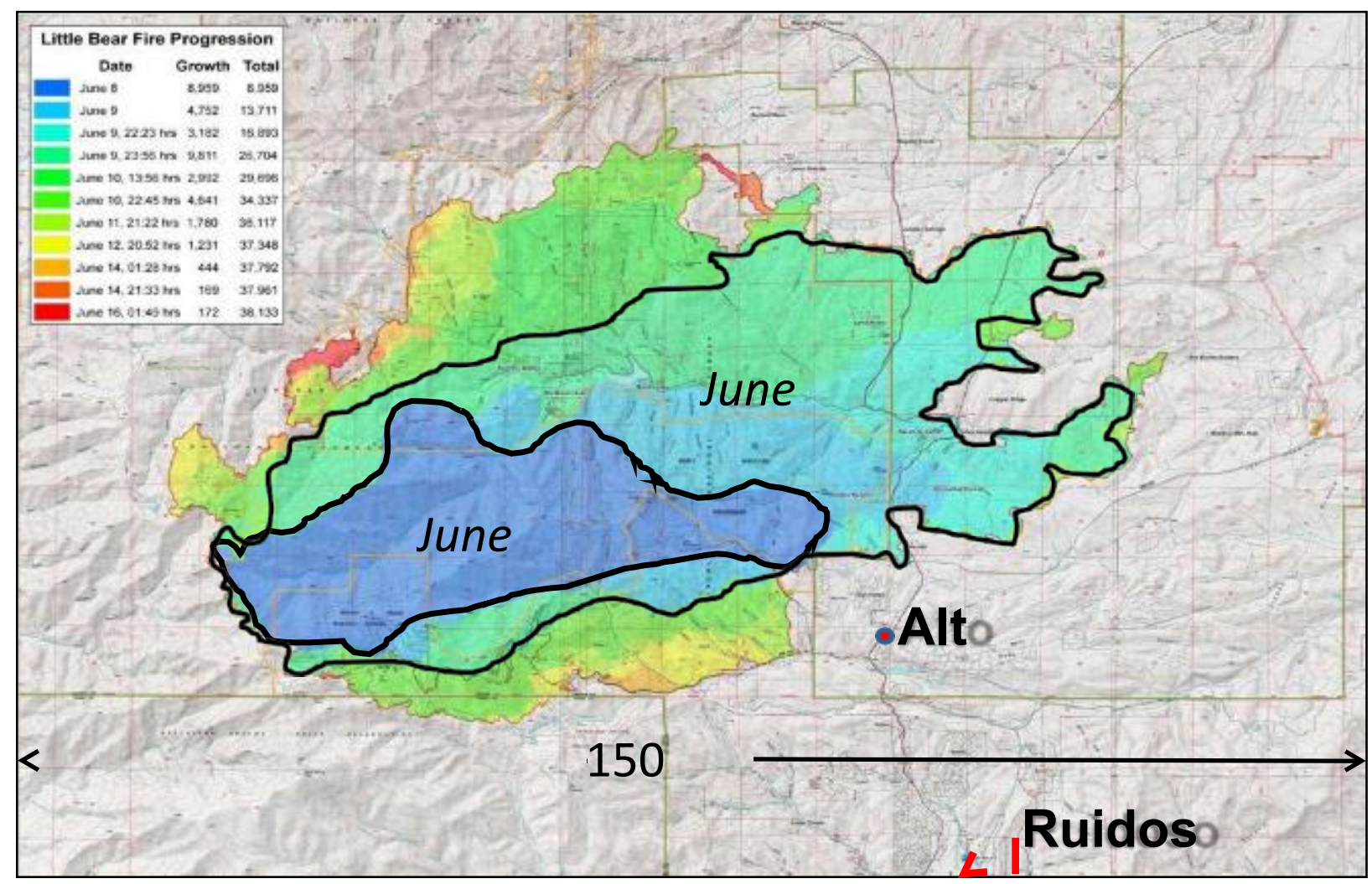

Figure 38. Map of Little Bear fire progression (New Mexico, June 2012).

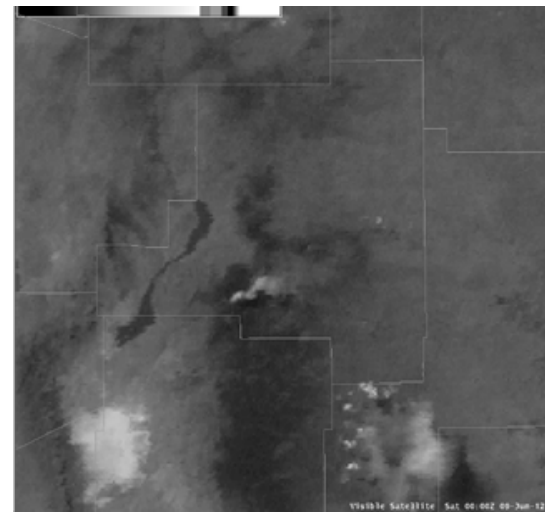

6:00pm

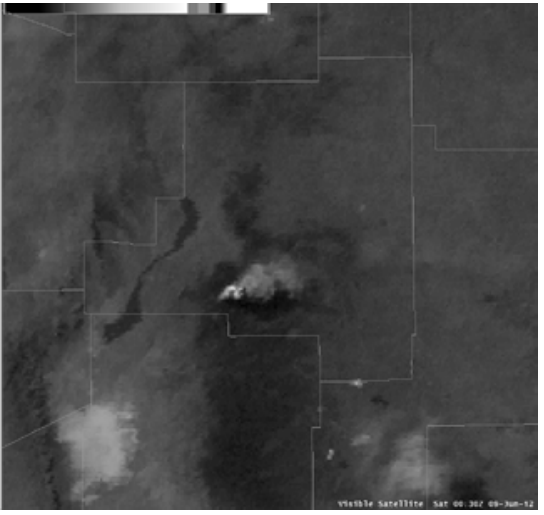

$6: 30 \mathrm{pm}$

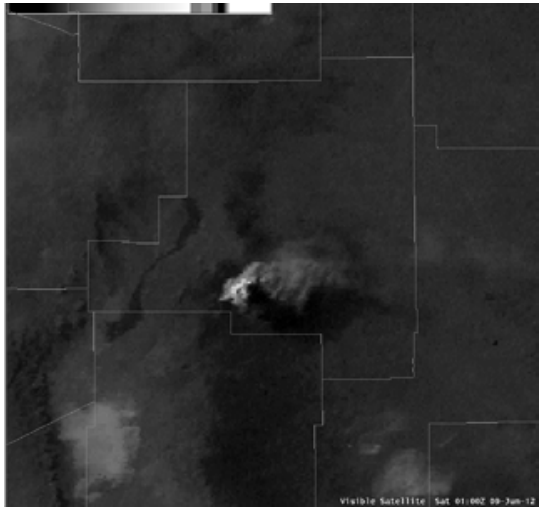

$7: 00 \mathrm{pm}$

Figure 39. Satellite image of the Little Bear fire at three consecutive times on June 8,2012. 


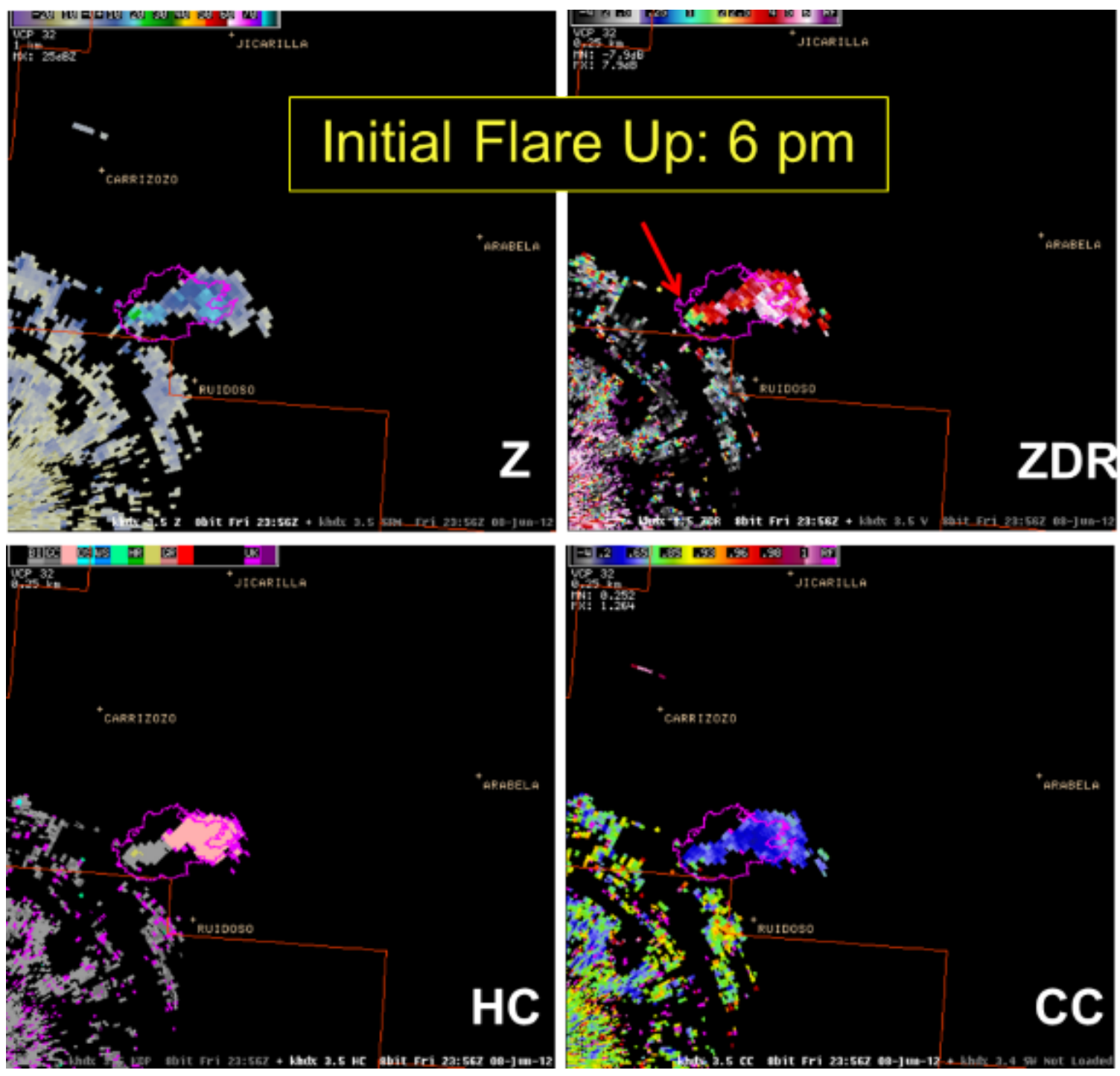

Figure 40. Fields of reflectivity $Z$, differential reflectivity $Z_{\mathrm{DR}}$, and correlation coefficient $\rho_{\mathrm{hv}}$ obtained with the Holloman Air Force Base radar on June 8, 2012. This image corresponds to the satellite imager (leftmost in Figure 39).

Noteworthy are the relatively high values $(\sim 30 \mathrm{dBZ})$ of the reflectivity field. The highest values are to the southwest, which is the location of intense burning. The fire-generated updraft lofted a high concentration of debris that contained the largest scatterers (possibly carbonated grass, leaves, etc.). The relatively low values of $Z_{\mathrm{DR}}(\sim 1 \mathrm{~dB})$ indicate that the particles tended to be horizontally oriented, but were likely wobbling, lowering the effective $Z_{\mathrm{DR}}$. Further downwind (to the northeast), there was a secondary maximum of reflectivity coincident with very large differential reflectivity. The exact composition of the scatterers is unknown, but it is speculated that either the burned debris was moving away from the updraft or smoke particles were acting as condensation nuclei, which causes crystal formation (needles and plates). In either case, the low value of the correlation coefficient (0.6) suggests a significant flutter (random canting) of the particles. The hydrometeor classification algorithm was applied to these data, but the results are erroneous. At the updraft location, the majority of the pixels are classified as "biological scatterers," which clearly they are not. Some scatterers (pink category) are classified as horizontally oriented crystals, which is doubtful. The classification algorithm, as mentioned previously and discussed in the next section, has not been adjusted to discriminate smoke plumes. 


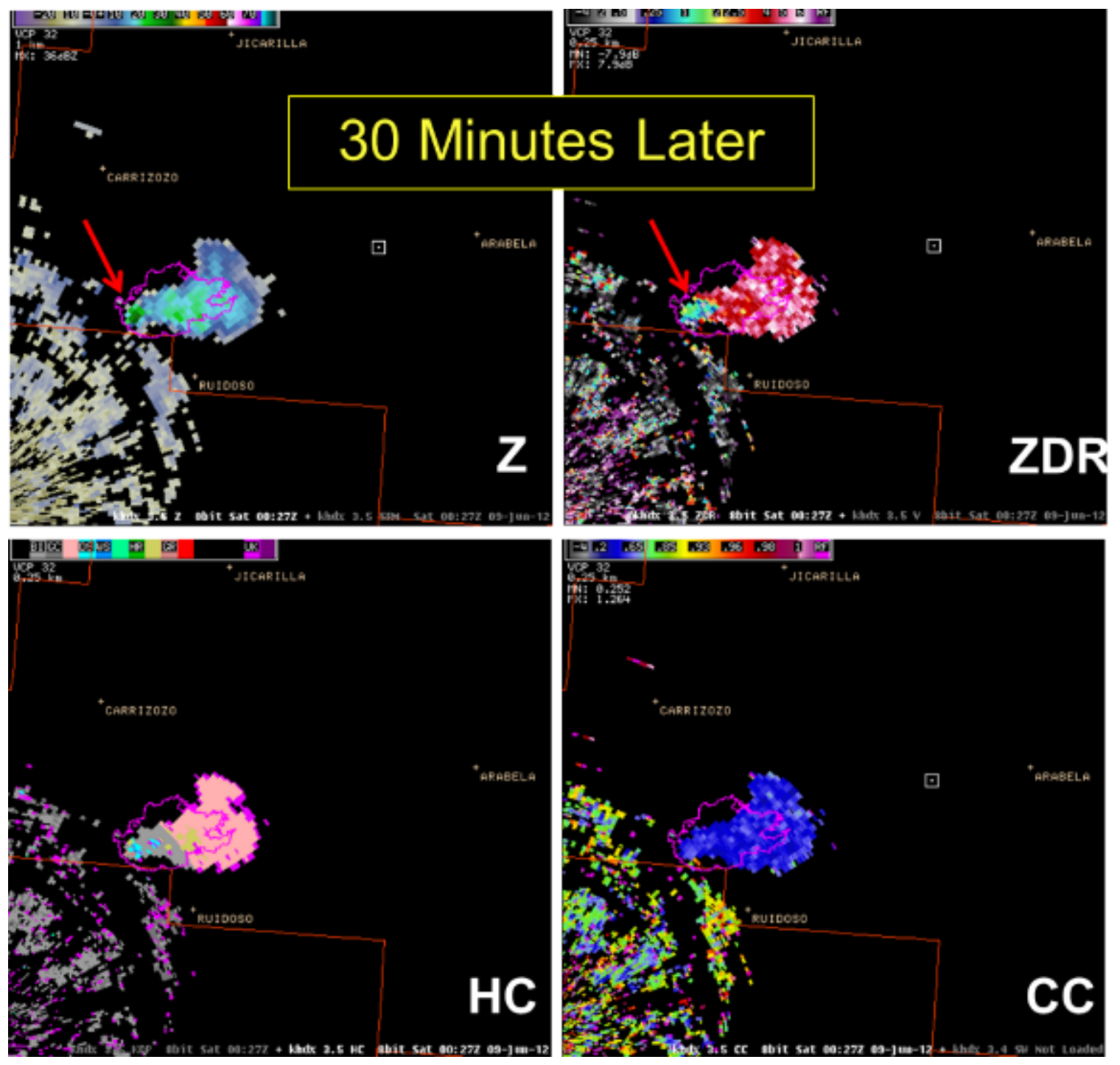

Figure 41. Fields of reflectivity $Z$, differential reflectivity $Z_{\mathrm{DR}}$, and correlation coefficient $\rho_{\mathrm{hv}}$ obtained with the Holloman Air Force Base radar on June 8, 2012. This image corresponds to the satellite imager (middle image of Figure 39). 


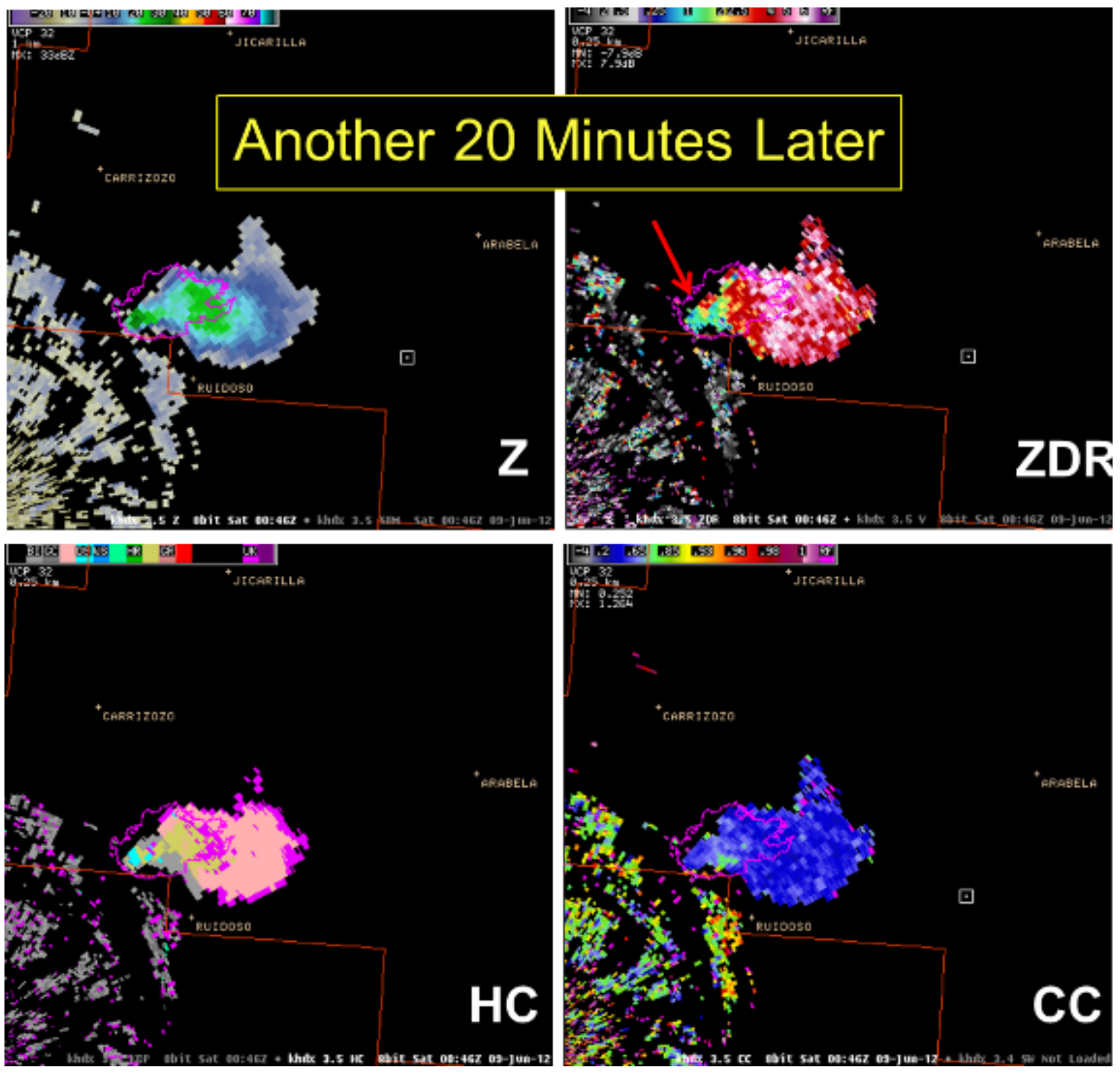

Figure 42. Fields of reflectivity $Z$, differential reflectivity $Z_{\mathrm{DR}}$, and correlation coefficient $\rho_{\mathrm{hv}}$ obtained with the Holloman (Air Force Base) radar on June 8, 2012. This image corresponds to the satellite imager (rightmost image in Figure 39). 

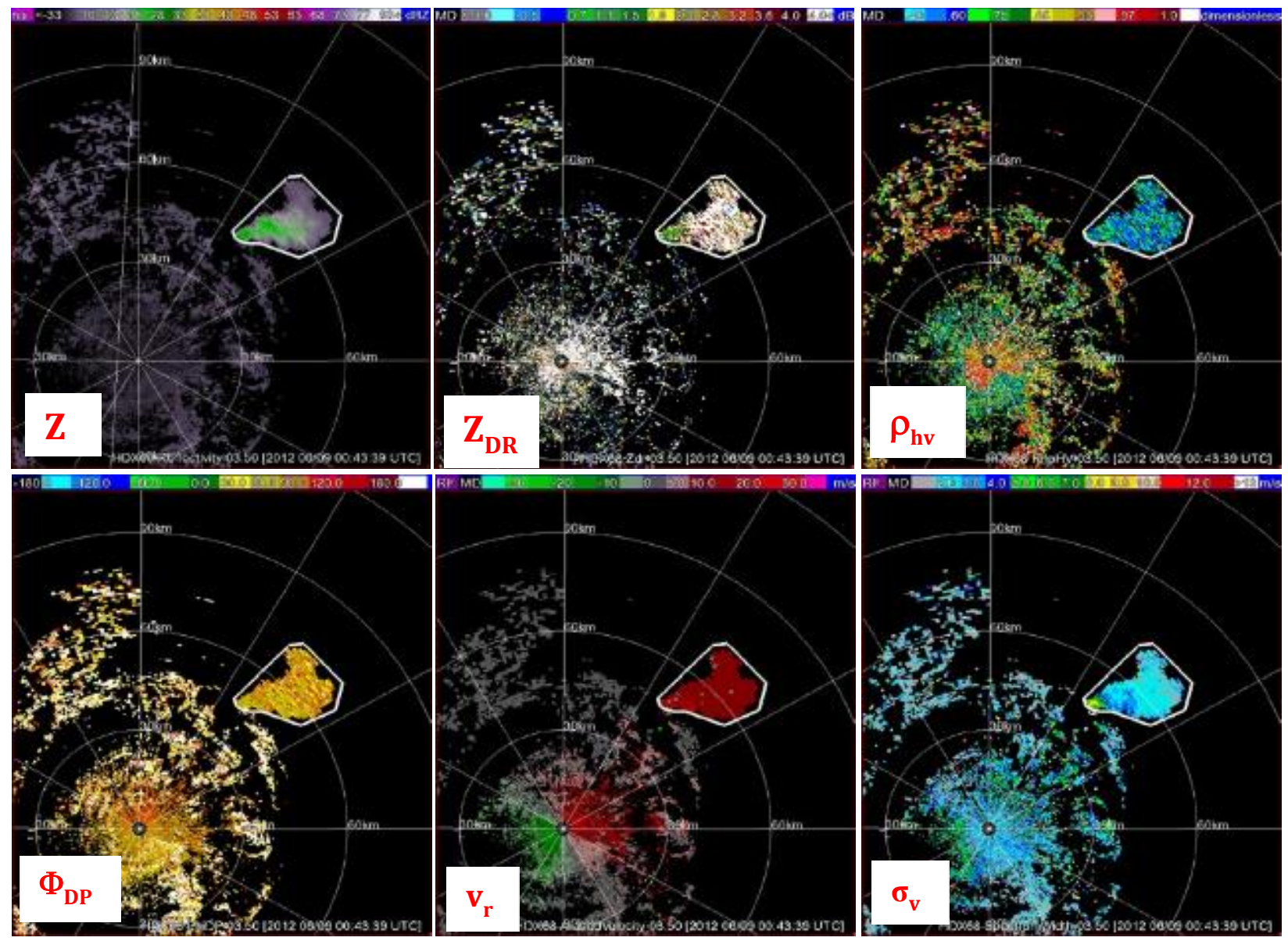

Figure 43. Polarimetric variables of the smoke plume (encircled with polygons).

\subsection{UNSUPERVISED MACHINE LEARNING FOR DETECTION AND TRACKING OF PLUMES}

There are two driving questions behind the development of an unsupervised machine learning algorithm to supplement the current NOAA operational HCA:

1. Can radar be used to detect and characterize non-meteorological plumes, including those caused by dispersions of chaff, volcanic eruptions, forest fires, grass fires, building fires, tornadoes, dust storms, and explosive events?

2. If plumes can be detected and characterized to a specific plume type, can the particulate densities of the plumes be assessed well enough to predict the fallout rates of plume particulates?

The feasibility of utilizing Level II WSR-88D data to detect and characterize non-meteorological plumes was assessed in this study. This work extended the available research on plume analysis of chaff (Kurdzo et al. 2017), volcanic eruptions (Marzano et al. 2010), fires (Melnikov et al. 2008; Jones and Christopher 2009; Jones et al. 2009; Melnikov et al. 2009a and b; Jones and Christopher 2010), tornadic debris (Van den Broeke and Jauernic 2014; Snyder and Ryzhkov 2015), and dust storms to develop fuzzy logic representations for different classes of non-meteorological plumes. These fuzzy logic representations were developed utilizing supervised and unsupervised learning techniques, and progress was made in inserting this into the current HCA for testing and optimization of the fuzzy logic representations.

A general overview of the plume identification process is shown in Figure 44. 


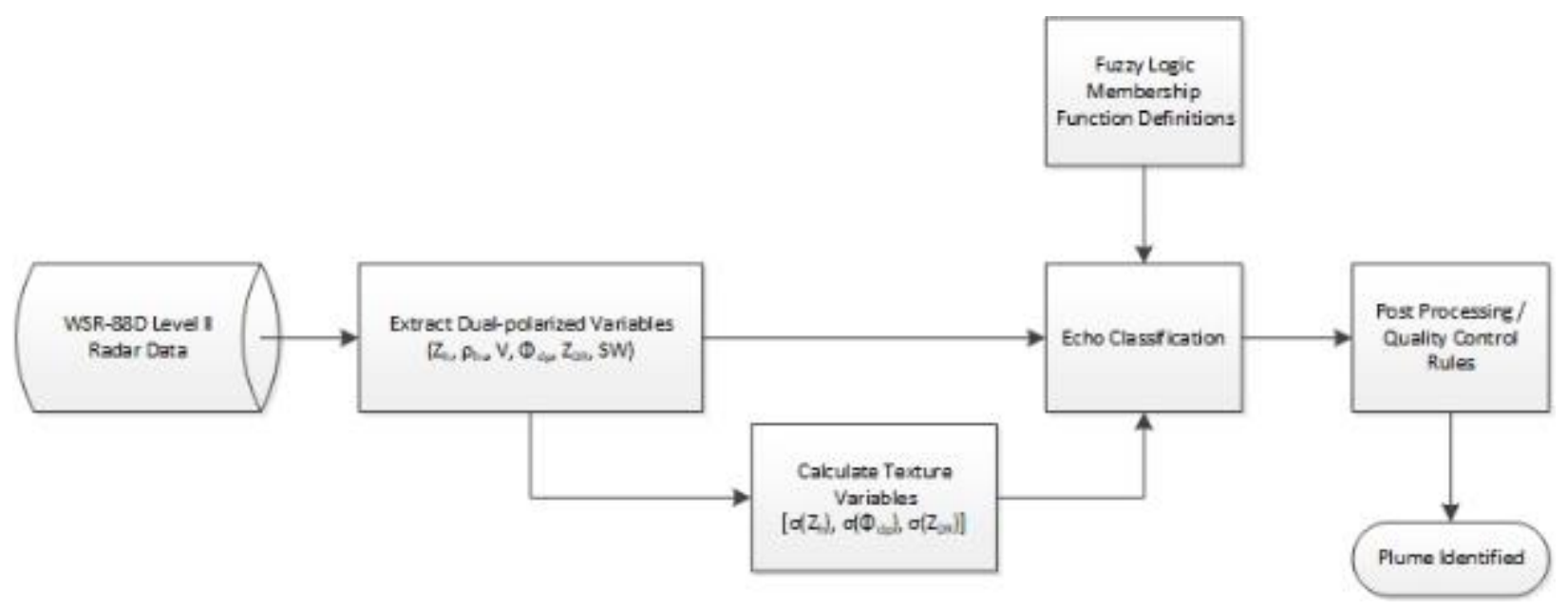

Figure 44. General plume identification process.

The process for developing fuzzy logic member functions for non-meteorological plumes is shown in Figure 45. The shaded green blocks in Figure 45 identify the stages that were completed successfully. The shaded yellow block identifies a stage that was only partially completed, whereas the unshaded block signifies a stage that cannot be achieved without future research.

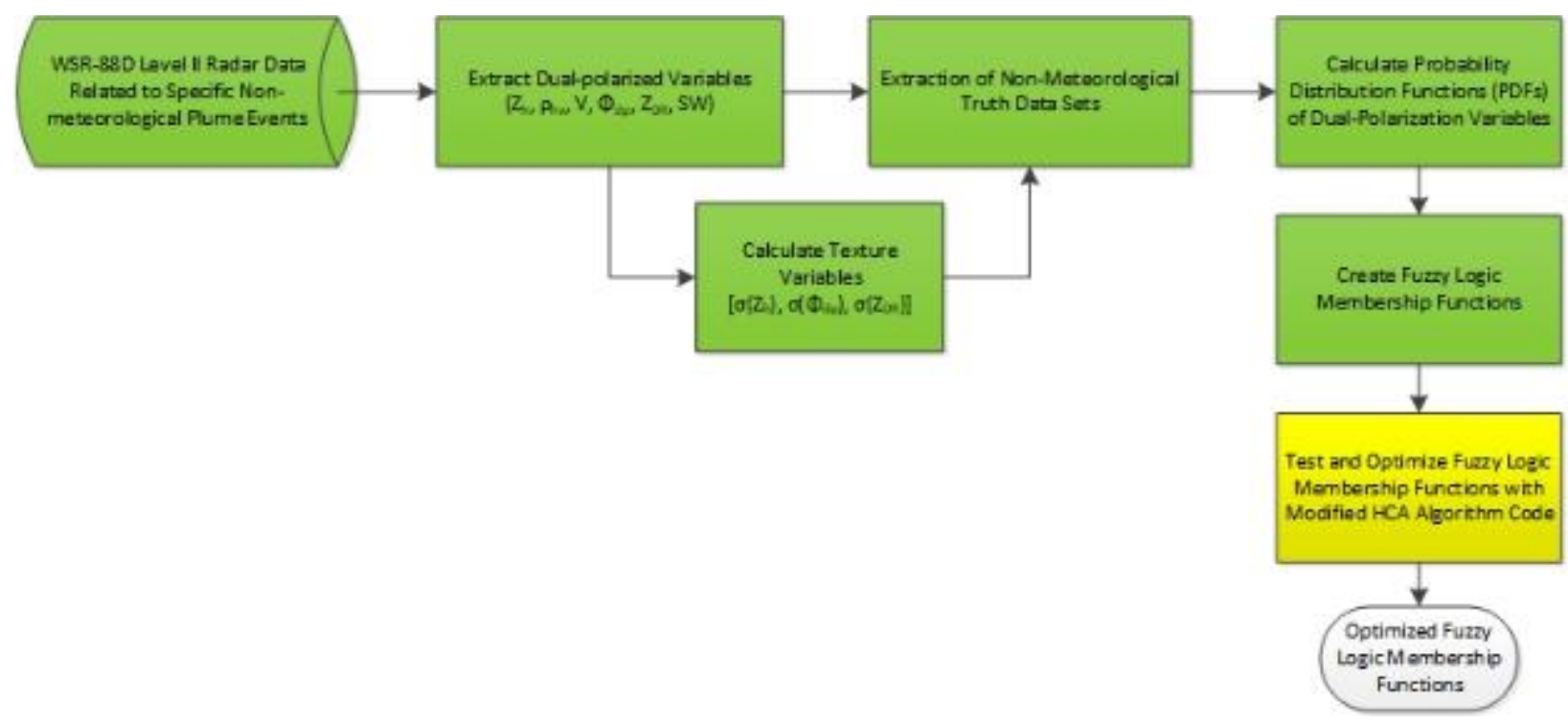

Figure 45. Process for developing fuzzy logic membership functions.

Data collection was accomplished primarily by searching the Internet for events corresponding to nonmeteorological plume events. Once a plume event was identified, Level II data was collected from the nearest radar to the event's location. The weather radar data were verified with satellite images, when possible. Using the NOAA Weather and Climate Toolkit, the data were animated and saved as an AVI movie that can be watched to show the progression of the event, further building confidence that the signatures represent the intended event. Data collection was also accomplished via references given in various research papers on similar topics. The WSR-88D Level II archive data were obtained from NOAA's NCEI Data Library located at https://www.ncdc.noaa.gov/nexradinv/choosesite.jsp.

Python scripts were developed to extract the dual-pol variables from the compressed WSR-88D archive data files. These Python scripts also calculate the texture variables that are utilized, along with the raw 
dual-pol variables, to develop the fuzzy logic membership functions. A truth data selection tool was developed based on an unsupervised machine learning technique that utilizes a density-based clustering scheme from the Density-Based Spatial Clustering of Applications with Noise (DBSCAN) algorithm. The DBSCAN clustering algorithm is applied to a plot of the cross correlation versus differential reflectivity variables. These fields were chosen because they have the biggest differentiation between meteorological and non-meteorological phenomena. An example output of this clustering algorithm is shown in Figure 46.
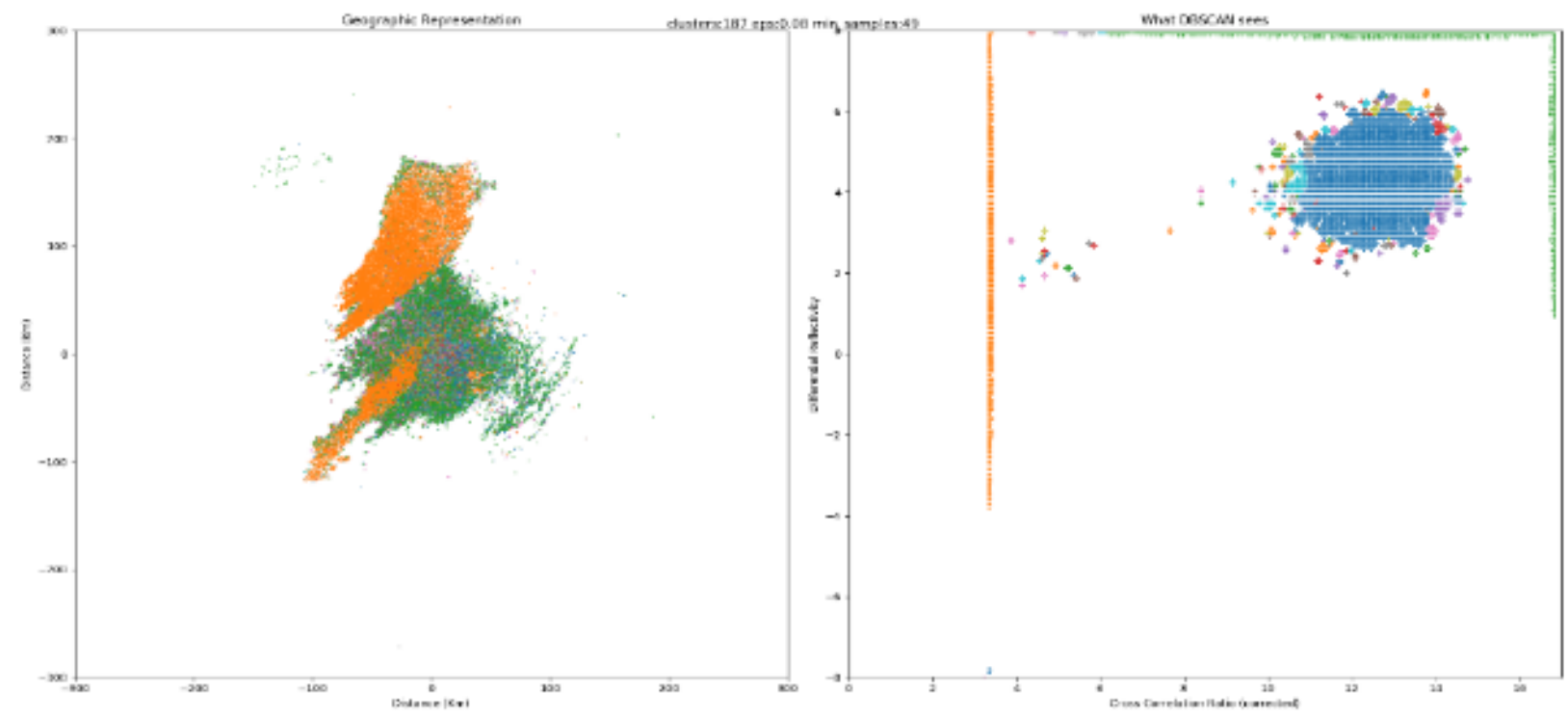

Figure 46. Density-based clustering algorithm applied to smoke plume (orange cluster, left).

The data analyst can select which of the clusters to group together and keep as a truth data source for a specific plume class. An example of a filtered radar image showing only the clusters to be utilized as truth data is shown in Figure 47. 

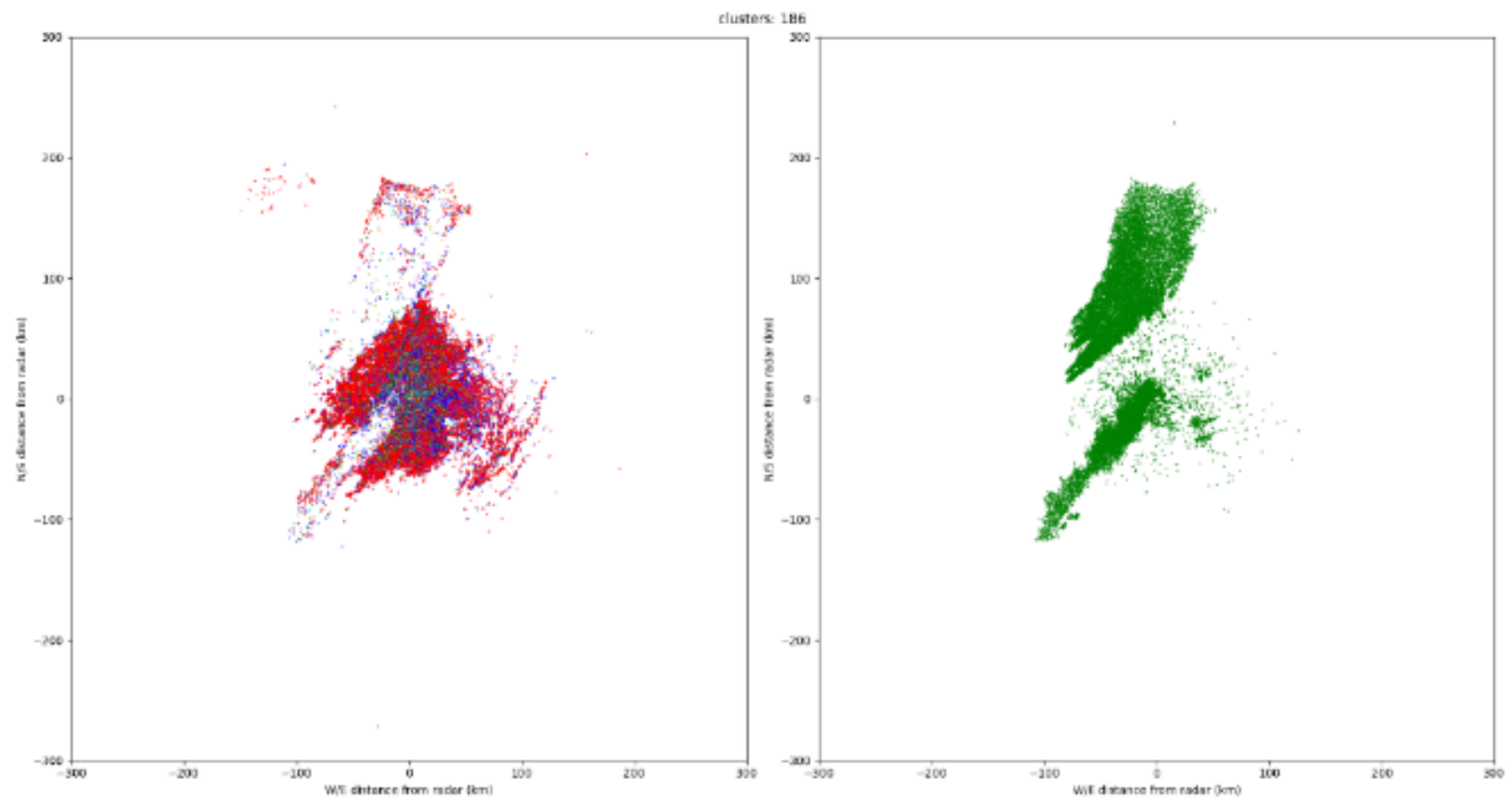

Figure 47. The unwanted clusters (left) are filtered from the wanted smoke cluster (right).

After the truth data sets have been created, probability density functions (PDFs) are created for the dualpol radar variables associated with the truth data set. An example PDF is shown in Figure 48.

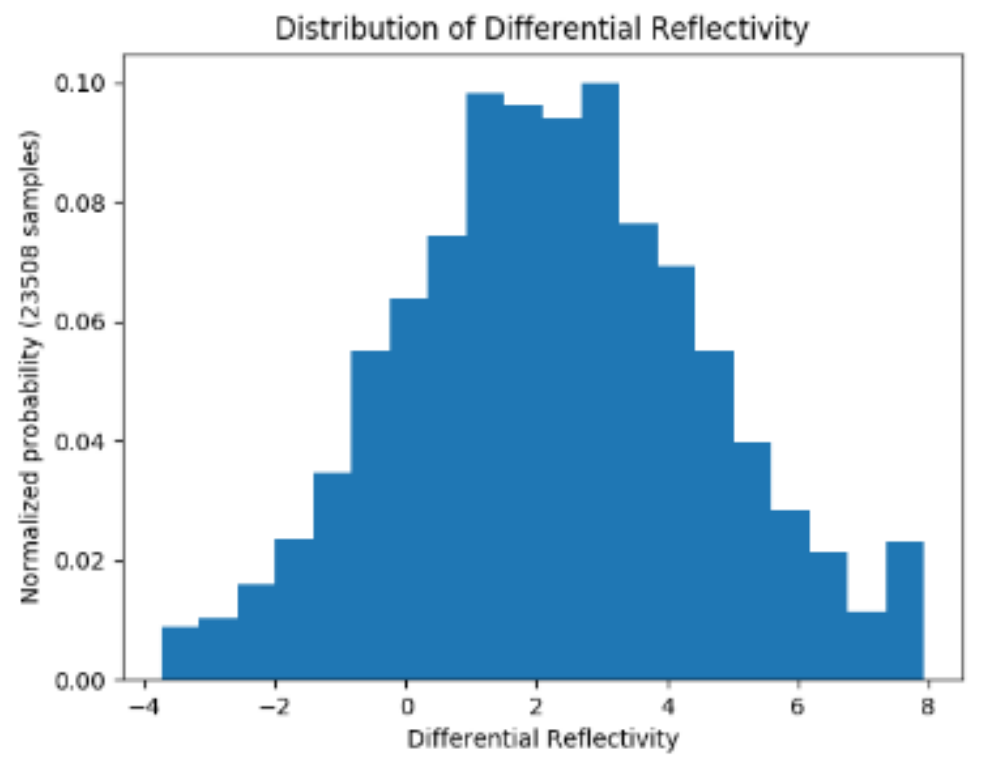

Figure 48. PDF of the truth data for a single variable.

The envelope of each PDF is described by creating a non-symmetrical trapezoid membership function. This trapezoidal membership function simplifies the distribution so that the HCA algorithm can process the data rapidly. The four points of the trapezoid of each PDF representing each dual-pol variable is initialized via visual inspection. Then the points of the trapezoids are optimized with a genetic algorithm, which uses a fitness function to maximize/minimize the area of the distribution function contained/not 
contained by the trapezoid, respectively. An example of a PDF and its membership function is shown in Figure 49.

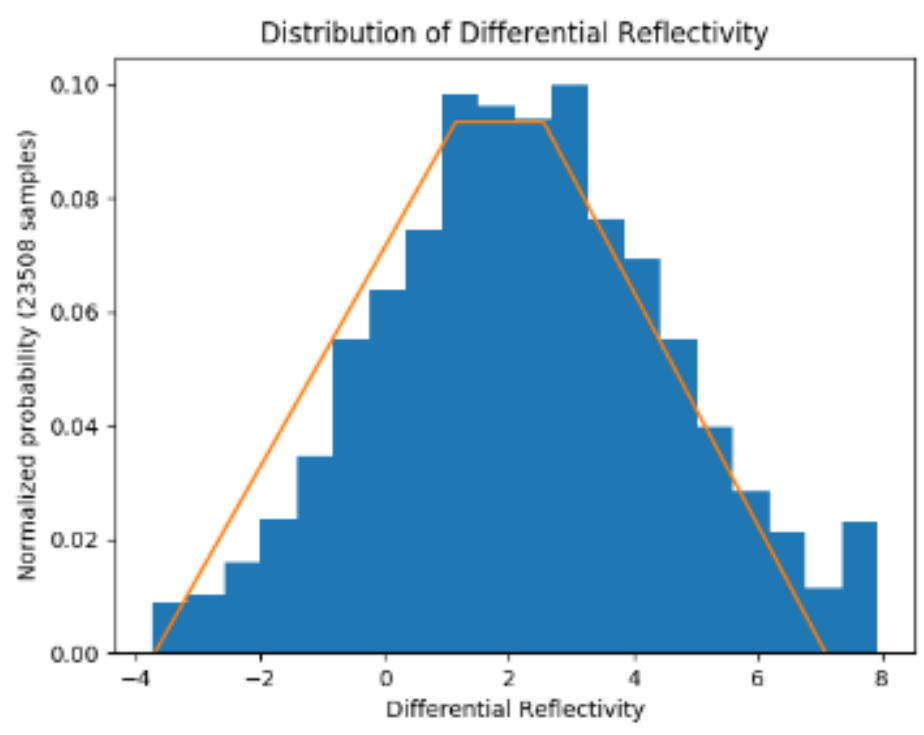

Figure 49. Optimized membership function overlaid on PDF.

The optimized membership functions are then inserted into the HCA for testing purposes. Another genetic algorithm optimizes the weighting that is utilized for each of the six dual-pol membership functions per plume class. This genetic algorithm utilizes a fitness function that maximizes the recall [True Positive / (True Positive + False Negative)] of the classification coming out of the HCA algorithm. Many test datasets will be passed through the modified HCA to test for accuracy of identification and classification of plume classes. Future testing will also assess if there is any appreciable increase in meteorological classification errors.

\subsection{FUTURE CHALLENGES}

\subsubsection{WSR-88D Level II Radar Data Related to Specific Non-meteorological Plume Events}

The current methodology of generating a new "plume" class uses data from smoke plumes to refine the process of characterizing non-meteorological plumes because the data for smoke plumes is readily available. The data for other non-meteorological plumes such as explosive events is much more difficult to obtain as events are rare or not captured by radar. Specialized test events may need to be captured to build a dataset sufficient to create accurate fuzzy logic representations for non-meteorological plume types having scarce archived data. Additionally, utilizing Level I data, or "raw" radar data, may yield results different from those of processed Level II data. We propose that Level I data be collected for purposes of comparison and algorithm building, to test if plumes can be better identified from Level I data.

\subsubsection{Extraction of Non-meteorological Truth Data Sets}

The best method for selecting the truth data utilizes a two-pass DBSCAN script. The first DBSCAN path attempts to classify clusters based on separation in the dual-pol parameters. This first pass is currently limited to using only two selected dual-pol parameters. The algorithm uses cross-correlation ratio and differential reflectivity as the two parameters; however, due to computer memory limitations, choosing more than two parameters is currently not an option. This method also has difficulty with larger radar 
source files because of this memory limitation. More work in this area could provide an incremental clustering algorithm that could process large radar files in all six moments that are available (reflectivity, differential reflectivity, differential phase, cross-correlation ratio, velocity, and spectrum width). For robustness, the algorithm could also be modified to process multiple radar files. Because the PDFs of many meteorological and non-meteorological classes overlap significantly, DBSCAN may not be the best clustering algorithm to use in this first pass; however, more testing must be done.

The second pass uses a DBSCAN algorithm to further separate clusters on the basis of geographic location. This is helpful because the first pass does not always make clear separations of distant smoke clouds and clutter near the radar. Once the user has manually selected the clusters that they wish to associate with the truth data, binary data files of the available moments for these cluster points are generated. The script currently outputs files only for reflectivity, differential reflectivity, differential phase, and cross-correlation ratio. Future upgrades to this script should output files for all six moments.

\subsubsection{Creation of Fuzzy Logic Member Functions}

More testing should be done with the genetic algorithm, which finds the trapezoidal envelop function to ensure that the optimal trapezoid is found, and found consistently. The algorithm is currently not deterministic. It is also not clear that a full trapezoid is needed for the membership function. Krause utilizes single-sided trapezoids in Krause (2016).

\subsubsection{Testing and Optimization of Fuzzy Logic Member Functions with Modified HCA Algorithm}

Successful compilation and execution of the HCA algorithm was completed on netCDF files, which were converted to netCDF format from the native Level II radar data using the ldm2netcdf script. The HCA algorithm outputs a netCDF file with HCA information but does not plot the results. To fill this gap, a Python script was developed to provide a visualization tool to plot the HCA results. The HCA algorithm code has been interrogated, and an understanding of how to modify the code to include additional classes such as smoke plumes has been achieved. The methodology related to optimizing the fuzzy logic definitions of new classes has yet to be completed but can be completed with future funding.

\subsubsection{Estimation of Fallout Rates}

Although work has not been conducted toward estimating the particulate fallout rates of nonmeteorological plumes, we recognize the necessity of conducting this work with future funding. A challenge in this area includes the lack of measured fallout associated with measured plumes. Also, it is unclear if the Level II radar data will allow an estimation of plume particulate densities. Some success in this area has been accomplished by Jones and Christopher (2009) and Melnikov et al. (2013).

\subsection{RADAR ALGORITHM RECOMMENDATIONS}

Though optimized for meteorological applications, current weather radars detect particulate plumes and provide valuable information for decision makers and modeling efforts. Development or modification of algorithms specific to particulate plumes could realize significant improvements with little effort. The sixth recommendation is to improve the HCA algorithm currently used operationally by the National Weather Service to include a "plume" class. One methodology for achieving this new class is through the use of unsupervised machine learning utilizing open-source software. The seventh recommendation is to conduct research into determining what falls out of a plume, such as different sized material or constituents, and potentially determining their fall rates. The eighth recommendation is to assess the ability of radar to track nonparticulate plumes such as aerosols and gases, as this study focused on the 
detection and tracking of particulate plumes. The ninth and final recommendation is to develop optical properties of different chemicals, particles, and gases of interest to be used in post-processing algorithms such as AFIT's Laser Environmental Effects Definition and Reference (LEEDR) software, which can take information from a WSR-88D and characterize the plume at different wavelengths using radar, meteorological, and ambient aerosol data. A capability such as LEEDR could provide additional plume characterization information unattainable with standard Level II radar data. These recommendations all lead toward getting data and information to the decision maker with the intent of decreasing the level of uncertainty during an event.

\section{REFERENCES}

Atlas, D. 1964. Advances in radar meteorology, Adv. Geophys. 10, 317-429.

Atlas, D. 1990. Radar in Meteorology, Battan Memorial and 40 th Anniversary Radar Meteorology Conference, American Meteorological Society, Boston.

Chrisman J. N. and S. D. Smith. 2009. Enhanced velocity azimuth display wind profile (EVWP) function for the WSR-88D, 34 ${ }^{\text {th }}$ Conference on Radar Meteorology, October, Williamsburg, VA.

Harris, D. M., W. I. Rose, Jr., R. Roe, and M. R. Thompson. 1981. Radar observations of ash eruptions, pp. 323-333 in The 1980 Eruptions of Mount St. Hellens, Washington, ed. P. W. Lipman and D. R. Mullineaux, US Geol. Surv. Prof. Pap. 1250.

Helmus, J. J. and S. M. Collins. 2016. The Python ARM Radar Toolkit (Py-ART), a library for working with weather radar data in the Python programming language, J. Open Research Software 4(1), 25, doi: http://doi.org/10.5334/jors.119.

Hertz, H. 1893. Electric waves, paper VIII in Electromagnetic Waves in the Air and Their Reflection, translated by D. E. Jones, MacMillan, London.

Johnson, K. 2002. The electromagnetic field, http://www-history.mcs.stand.ac.uk/Projects/Johnson/Chapters/Ch4_4.html, accessed 10 November 2016.

Jones, T. A. and S. A. Christopher. 2009. Injection height of biomass burning debris estimated from WSR-88D radar observations, IEEE Trans. Geosci. Remote Sensing 47, 2599-2605.

Jones, T. A, S. A. Christopher, and W. Petersen. 2009. Dual-polarization radar characteristics of an apartment fire, J. Atmos. Ocean Tech. 26(10), 2257-2269.

Jones, T. A, and S. A. Christopher. 2010. Satellite and radar remote sensing of Southern Plains grass fires: a case study, J. Appl. Meteorol. Climatol. 49, 2133-2146.

Kabela, E. D., J. A. Rackley, V. J. Jodoin, S. T. Fiorino, J. E. Schmidt, and B. J. Elmore. 2016. Status Report: Use of Radar for Characterizing and Tracking Plumes, Technical Report ORNL/TM2016/711, Oak Ridge National Laboratory.

Kabela, E.D., V. J. Jodoin, D. B. Koch, B. K. Daniel, S. T. Fiorino, J. E. Schmidt, B. J. Elmore, V. Melnikov, D. Zrnic, and R. J. Doviak. 2017. Status Report II: Use of Radar for Characterizing and Tracking Plumes, Sponsor Report ORNL/SPR-2017/500, Oak Ridge National Laboratory.

Krause, J. M. 2016. A simple algorithm to discriminate between meteorological and non-meteorological radar echoes, J. Atmos. Oceanic Technol. 33(9), 1875-1885.

Kurdzo, J. M., B. J. Bennett, M. S. Veillette, D. J. Smalley, E. R. Williams, and M. F. Donovan. 2017. WSR-88D chaff detection and characterization using an optimized hydrometeor classification algorithm, $18^{\text {th }}$ Conference on Aviation, Range, and Aerospace Meteorology, January, Seattle, WA. 
Leelossy, A., I. Lagzi, A. Kovacs, and R. Meszaros. 2018. A review of numerical models to predict the atmospheric dispersion of radionuclides, J. Environ. Radioact. 182, 20-33, doi: 10.1016/j.jenvrad.2017.11.009.

Lindley, T. T. and L. R. Lemon. 2007. Preliminary observations of weak three-body scatter spikes associated with low-end severe hail, E-Journal of Severe Storms Meteorology 2(3).

Marzano, F. S., S. Marchiotto, C. Textor, and D. J. Scheider. 2010. Model-based weather radar remote sensing of explosive volcanic ash eruption, IEEE Trans. Geosci. Remote Sensing 48, 3591-3607.

Mead, J. B., A. L. Pazmany, S. M. Sekelsky, and R. E. McIntosh. 1994. Millimeter-wave radars for remotely sensing clouds and precipitation, Proc. IEEE. 82(12), 1891-1906.

Melnikov, V. M., D. S. Zrnic, R. M. Rabin, and P. Zhang. 2008. Radar polarimetric signatures of fire plumes in Oklahoma, Geophys. Res. Lett. 35.

Melnikov, V. M., D. Zrnic, R. Rabin, B. Pierce, and P. Zhang. 2009a. Radar polarimetric signatures of fire plumes, Proc. $25^{\text {th }}$ Conf. on International Interactive Information and Processing Systems.

Melnikov, V. M., D. S. Zrnic, and R. M. Rabin. 2009b. Polarimetric radar properties of smoke plumes: a model, J. Geophys. Res.-Atmos. 114.

Melnikov, V. M., R. J. Doviak. D. S. Zrnic, and D. J. Stensrud. 2013. Structures of Bragg scatter observed with polarimetric WSR-88D, J. Atmos. Oceanic Technol. 30(7), 1253-1258.

Montopoli, M. 2016. Velocity profiles inside volcanic cloud from three-dimensional scanning microwave dual-polarization Doppler radars, J. Geophys. Res. Atmos. 121, 7881-7900, doi: 10.1002/2015JD023464.

NCEI (National Centers for Environmental Information). 2018. NEXRAD Products, https://www.ncdc.noaa.gov/data-access/radar-data/nexrad-products.

NOAA (National Oceanic and Atmospheric Administration). 2017. NOAA NEXt-Generation RADar (NEXRAD) Products, https://catalog.data.gov/dataset/noaa-next-generation-radar-nexrad-products.

Norment, H. 1979a. DELFIC: Department of Defense Fallout Prediction System: I-Fundamentals, Atmospheric Science Associates, Bedford, MA.

Norment, H. 1979b. DELFIC: Department of Defense Fallout Prediction System: II - User's Manual, Atmospheric Science Associates, Bedford, MA.

Oddsson, B., M. T. Gudmundsson, G. Larsen, and S. Karlsdottir. 2012. Monitoring of the plume from the basaltic phreatomagmatic 2004 Grimsvotn eruption - application of weather radar and comparison with plume models, Bull. Volcanol. 74, 1395-1407, doi: 10.1007/s00445-012-0598-9.

Page, R. M. 1962. The Origin of Radar, Doubleday Anchor, New York.

Propert-Jones, J. R. 1962. The radar equation in meteorology, Q. J. R. Meteorol. Soc. 88, 488-495.

Richards, M. A., J. A. Scheer, and W. A. Holm 2010. Principles of Modern Radar, Scitech Publishing, Raleigh, NC.

Rolph, G. D., F. Ngan, and R. R. Draxler. 2014. Modeling the fallout from stabilized nuclear clouds using HYSPLIT atmospheric dispersion model, J. Environ. Radioact. 136, 41-55, doi: 10.1016/j.jenvrad.2014.05.006.

Skolnik, M. I. 1970. Radar Handbook. McGraw-Hill, New York.

Snyder, J. C. and A. V. Ryzhkov. 2015. Automated detection of polarimetric tornadic debris signatures using a hydrometeor classification algorithm, J. Appl. Meteorol. Climatol. 54(9), 1861-1870. 
Swingle, D. M. 1958. A new use for weather radar, Trans. N.Y.Acad. Sci., II(20), 348-352.

Van den Broeke, M. S. and S. T. Jauernic. 2014. Spatial and temporal characteristics of polarimetric tornadic debris signatures, J. Appl. Meteorol. Climatol. 53, 2217-2231.

Zrnic, D., V. Melnikov, and P. Zhang. 2017b. Capabilities of Existing USA Civilian Radars to Detect Plumes - Part II, report delivered in September 2017 to ORNL in fulfillment of subcontract. 